\title{
Development, Analysis and Case Studies of Impact Resistant Steel Sets for Underground Roof Fall Rehabilitation
}

\author{
Dakota D. Faulkner \\ West Virginia University, dfaulkne@mix.wvu.edu
}

Follow this and additional works at: https://researchrepository.wvu.edu/etd

Part of the Mining Engineering Commons

\footnotetext{
Recommended Citation

Faulkner, Dakota D., "Development, Analysis and Case Studies of Impact Resistant Steel Sets for Underground Roof Fall Rehabilitation" (2020). Graduate Theses, Dissertations, and Problem Reports. 7863.

https://researchrepository.wvu.edu/etd/7863

This Thesis is protected by copyright and/or related rights. It has been brought to you by the The Research Repository @ WVU with permission from the rights-holder(s). You are free to use this Thesis in any way that is permitted by the copyright and related rights legislation that applies to your use. For other uses you must obtain permission from the rights-holder(s) directly, unless additional rights are indicated by a Creative Commons license in the record and/ or on the work itself. This Thesis has been accepted for inclusion in WVU Graduate Theses, Dissertations, and Problem Reports collection by an authorized administrator of The Research Repository @ WVU. For more information, please contact researchrepository@mail.wvu.edu.
} 

REHABILITATION

Dakota D. Faulkner

Follow this and additional works at: https://researchrepository.wvu.edu/etd

Part of the Mining Engineering Commons 


\title{
DEVELOPMENT, ANALYSIS, AND CASE STUDIES OF IMPACT RESISTANT STEEL SETS FOR UNDERGROUND ROOF FALL REHABILITATIONS
}

\author{
Dakota D. Faulkner \\ Thesis submitted to the Benjamin Statler College of \\ Engineering and Mineral Resources at West Virginia University \\ in partial fulfillment of the requirements \\ for the degree of \\ Master of Science \\ in \\ Mining Engineering
}

Brijes Mishra, Ph.D., Committee Chairperson Yi Luo, Ph.D.

Vladislav Kecojevic, Ph.D.

Department of Mining Engineering

Morgantown, West Virginia 2020

Keywords: Mining, Ground Control, Roof Fall Rehabilitation, Steel Set Copyright 2020 Dakota D. Faulkner 


\title{
Abstract \\ DEVELOPMENT, ANALYSIS AND CASE STUDIES OF IMPACT RESISTANT STEEL SETS FOR UNDERGROUND ROOF FALL REHABILITATIONS
}

\begin{abstract}
Dakota D. Faulkner
Underground mines often experience roof falls in entries, crosscuts, and intersections of active mining sections, main travel ways, and belt entries. Roof fall heights greater than $20 \mathrm{ft}(6 \mathrm{~m})$ make re-bolting of the newly exposed roof dangerous and impractical. To protect mine personnel, belts, moving vehicles, and other equipment, mine operators typically install steel structures such as square or arch sets in the roof fall areas. Wood lagging is usually installed between the steel-sets to enclose the area and protect the entry from recurring falls. Usually the void space above the steel-sets and wood lagging is backfilled. However, backfilling high roof fall voids is costly, which causes some operators to leave the voids open. In this case, the durability of wood over time and the capability of the steel-set and wood lagging to resist falling rocks are unknown.
\end{abstract}

During the last few years, an impact-resistant (IR) lagging system was designed, tested, and developed to protect the steel-sets. Various IR steel-sets were approved by Mine Safety and Health Administration (MSHA) and installed in different underground roof fall rehabilitation projects. As of May 2020 more than 200 roof falls in 50 different coal mines were successfully rehabilitated by installing the IR steel sets in the US.

This study focuses on (1) design, development, and laboratory testing of the IR lagging panel, (2) steel-set design methodology according to the American Institute of Steel Construction (AISC) specifications, (3) capacity evaluation of the IR steel set using elastoplastic structural analysis approach (4) two case studies of the performance of IR arch sets installed at various roof fall rehabilitation sites, and (5) an applicability evaluation guideline of the IR steel set for a given roof fall conditions. 


\section{Acknowledgments}

I would like to extend my sincere thanks to my thesis advisor and mentor Dr. Brijes Mishra for his continued support, guidance, patience and encouragement throughout my thesis research. His advice and guidance was influential in developing me as a professional and has been critical to my success. I would also like to thank the members of my thesis committee, Dr. Yi Luo and Dr. Vladislav Kecojevic for their valuable comments and suggestions. Additionally, I would like to extend my gratitude to the rest of the Mining Engineering Department, my employer Jennmar Corporation, and my co-workers as their influence on me has been key to my success. Lastly, I would like to thank my wife Nicole and my family for their continued encouragement during my studies. Their love, understanding, and support helped motivate me to keep pushing forward. 


\section{Table of Contents}

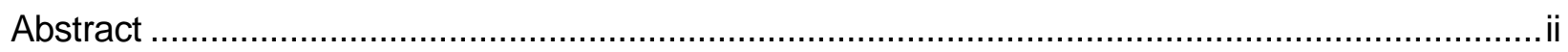

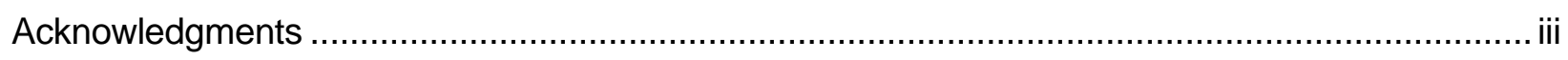

Table of Contents ..............................................................................................................

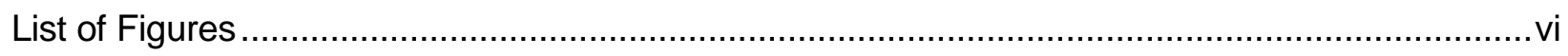

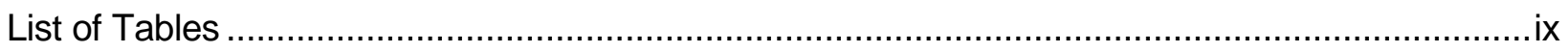

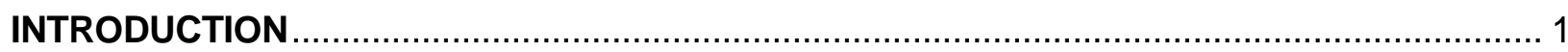

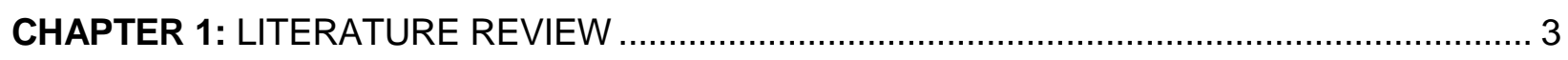

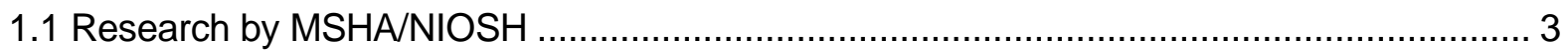

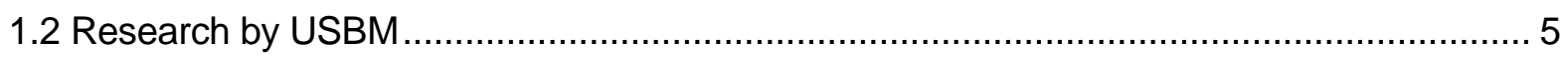

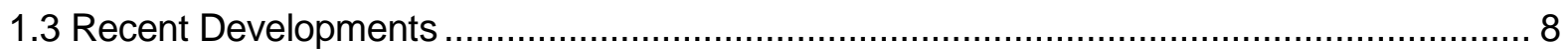

CHAPTER 2: IMPACT RESISTANT LAGGING PANEL................................................. 9

2.1 Main Components: ............................................................................................ 9

2.2 Dynamic Load Support Capacity - Numerical Modeling: ............................................ 10

2.3 Dynamic Load Support Capacity - Laboratory Impact Testing: ..................................... 12

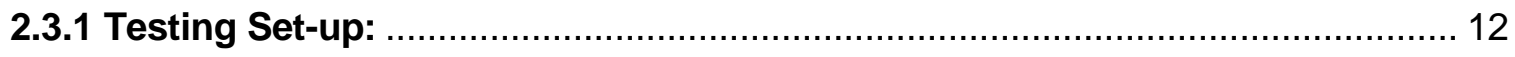

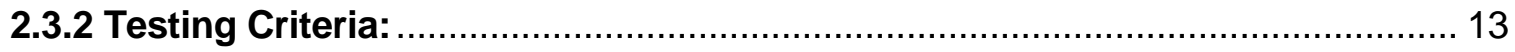

2.3.3 Testing Results:

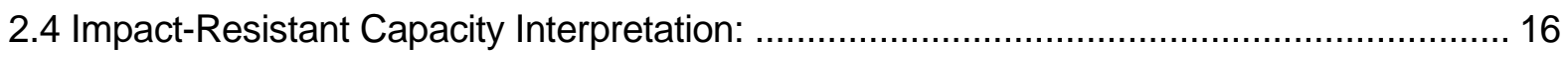

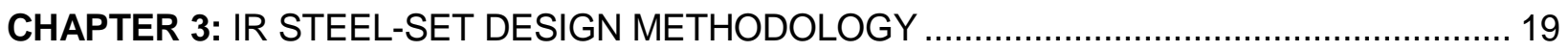

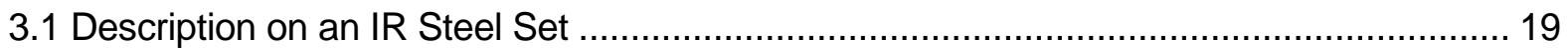

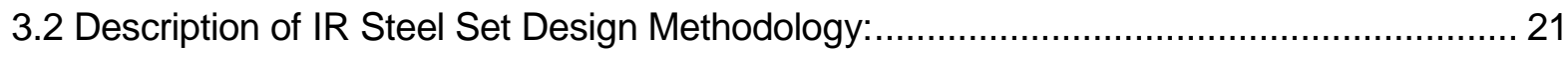

3.2.1 Step 1: Geological Evaluation and Site Visit: ................................................ 21

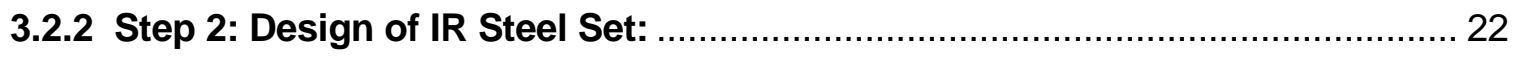

3.2.3 Step 3: Validation of IR Steel Set Design: ................................................ 23

CHAPTER 4: DEMONSTRATION OF THE IR STEEL SET DESIGN METHODOLOGY ............. 24

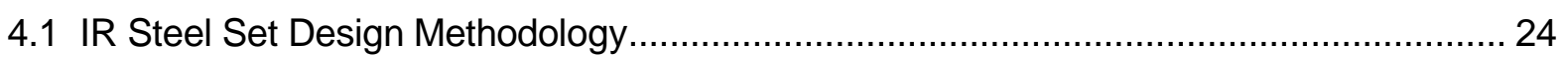

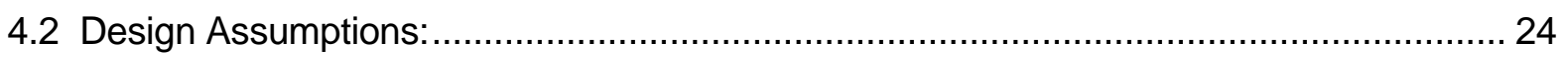

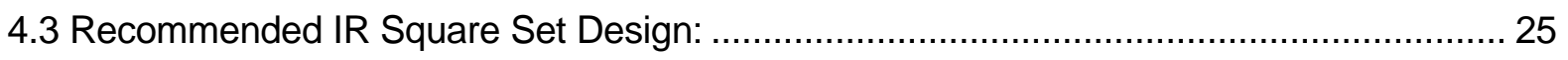

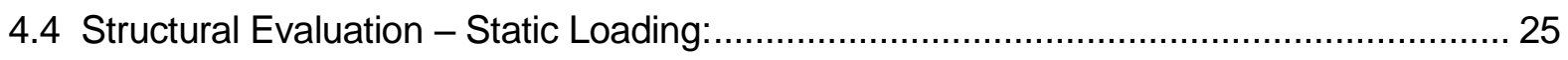

4.5 Elasto-plastic Design Concept:.............................................................................. 26 


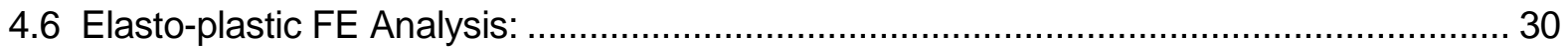

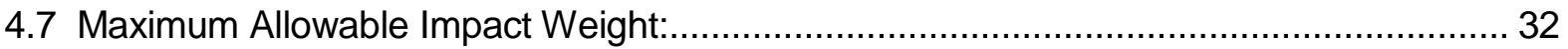

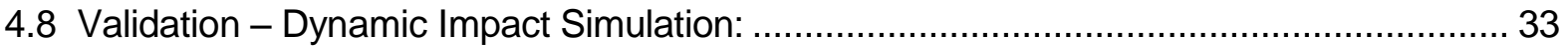

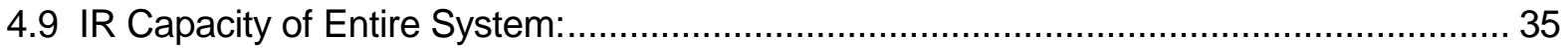

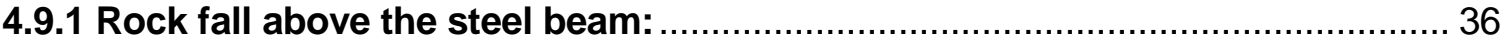

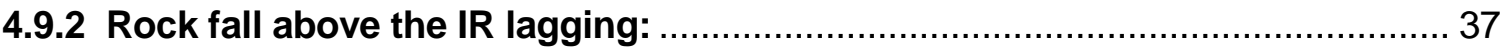

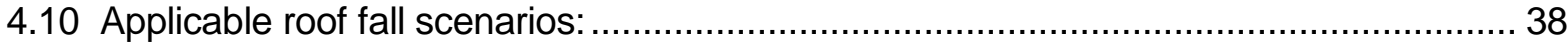

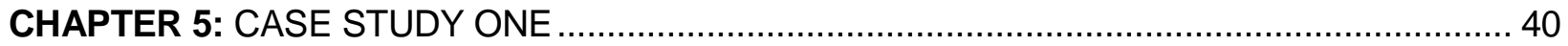

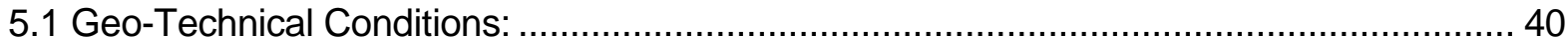

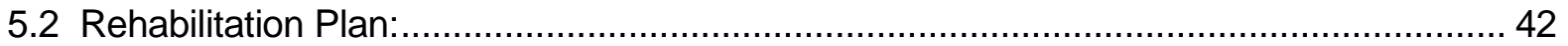

5.3 Structural Analysis of the W8 x 31 IR Arch Set: ........................................................ 43

5.3.1 Structural Analyses - Static Uniform Load: ................................................ 44

5.3.2 Structural Analyses - Dynamic Impact Load: ............................................ 44

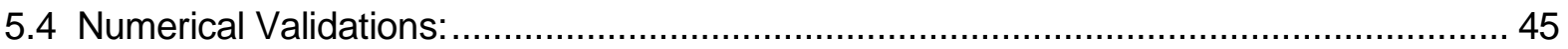

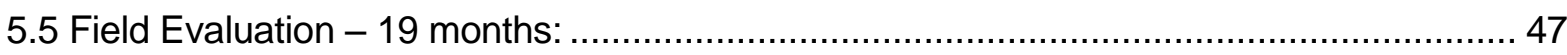

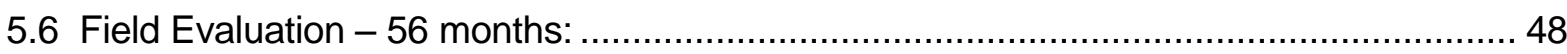

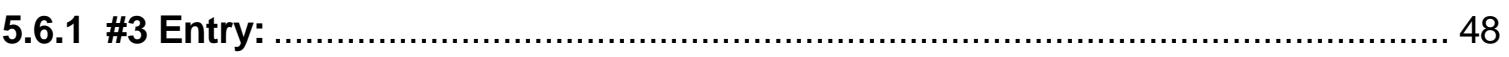

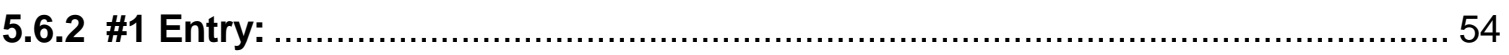

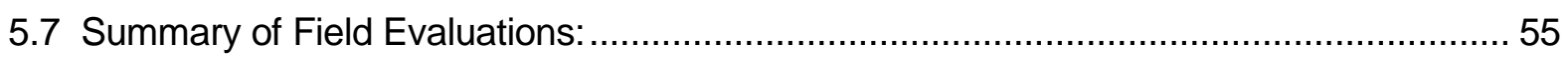

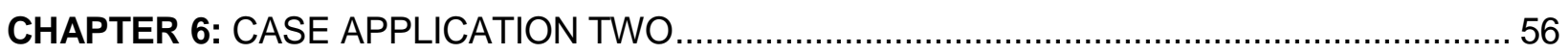

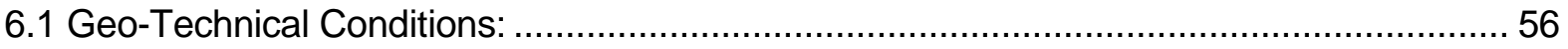

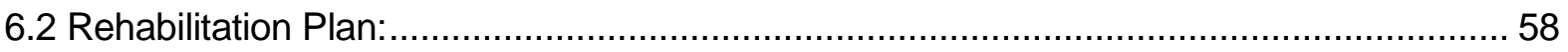

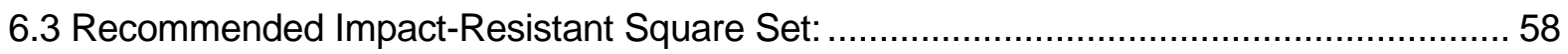

6.4 Structural Analyses - Static Uniform Load:.......................................................... 59

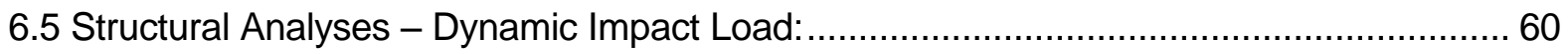

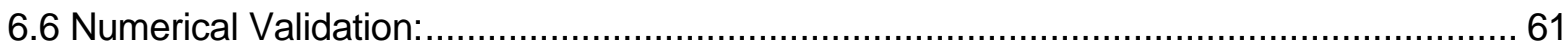

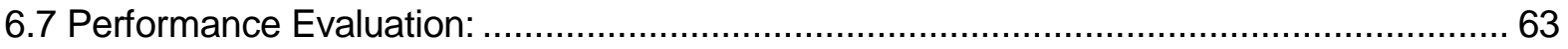

CHAPTER 7: APPLICABILITY EVALUATION GUIDELINE OF AN IR STEEL SET .................... 64

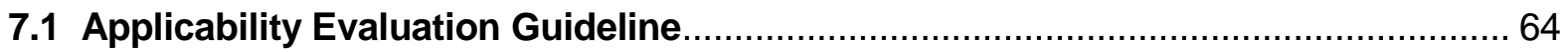

CONCLUSION

REFERENCES

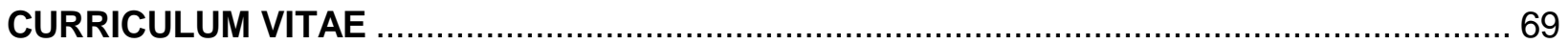




\section{List of Figures}

Figure 1.1 - Historical overview of roof fall fatality rates for underground bituminous coal mines (BOM,MSHA 1900-2009).

Figure 1.2 - Classification of ground fatalities from 1995-2009 (MSHA, NIOSH 1995-2009).

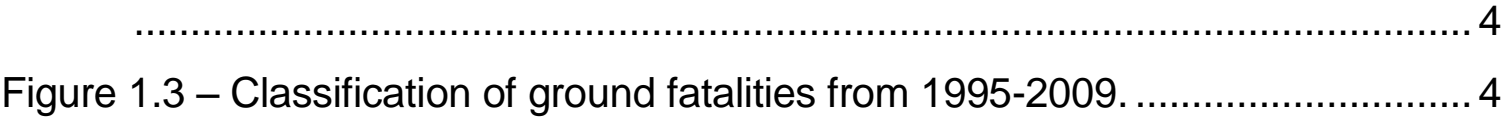

Figure 1.4 - Roof fall cavity height above roof level........................................ 5

Figure 1.5 - Conventional re-support of a roof fall (Allwes, 1987)........................ 6

Figure 1.6 - Re-support of a roof fall using multi-tiered cribbing (Allwes, 1987),..... 6

Figure 1.7 - Linear plate style arch support (Allwes, 1987) . .............................. 7

Figure 1.8 - Comparison of experimental and theoretical resistance and .............. 8

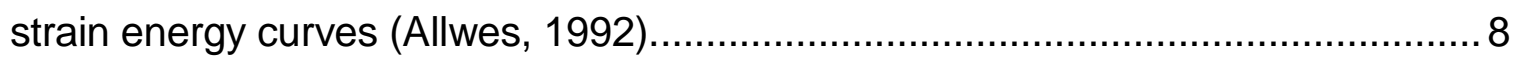

Figure 2.1 - Impact Resistant Lagging Panel ..................................................

Figure 2.2 - Vertical deformation of the lagging panel...................................... 11

Figure 2.3 - Safety factor distribution........................................................... 11

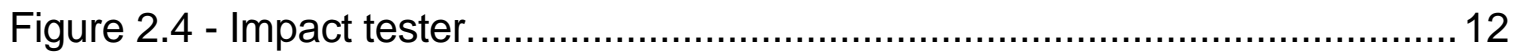

Figure 2.5 - Maximum deflection of the IR lagging panel at mid-span .................. 13

Figure 2.6 - Intact specimen after impact. …………....................................... 14

Figure 2.7 - Deformed specimen after impact. ……..................................... 15

Figure 2.8 - Acceleration vs. time curve of impact testing - Test \#1.................... 16

Figure 2.9 - Acceleration vs. time curve of impact testing - Test \#15................... 16

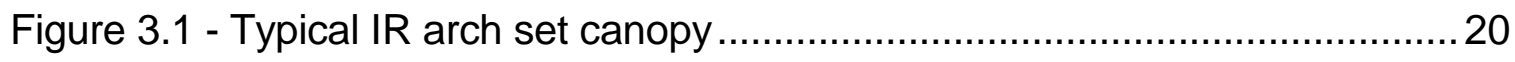

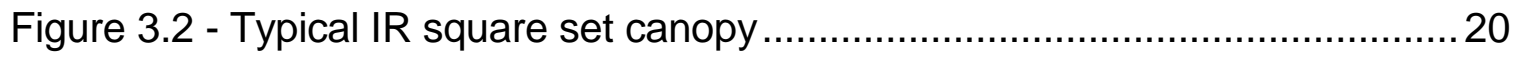

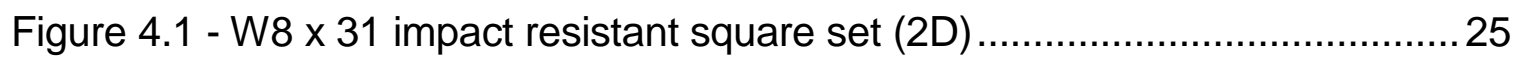

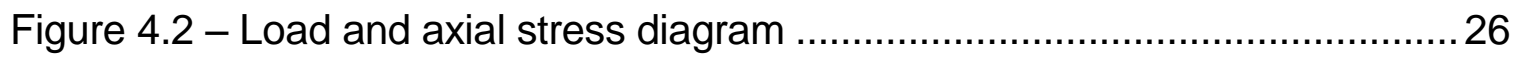

Figure 4.3 - Load and shear stress diagram .................................................26

Figure 4.4 - Load and moment diagram ...................................................... 26

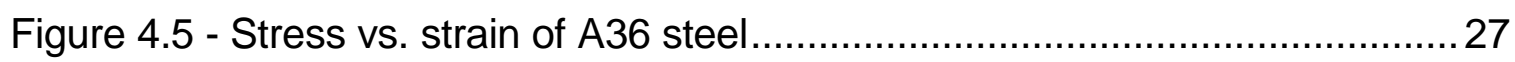

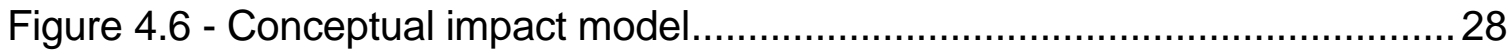


Figure 4.7 - Conceptual load vs. deflection curve ...........................................29

Figure 4.8 - Numerical model of W8 x 31 square set ........................................ 30

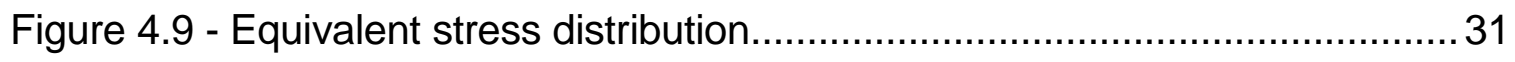

Figure 4.10 - Load vs. deflection of W8 $\times 31$ square set ..................................... 32

Figure 4.11 - Von-Mises stress distribution upon impact..................................... 34

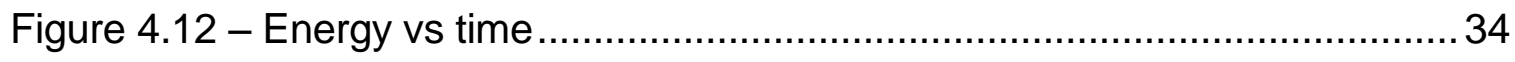

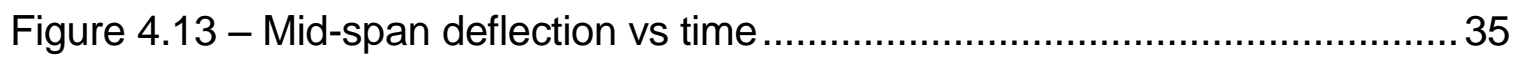

Figure 4.14 - Worst impact loading condition on steel set.................................... 36

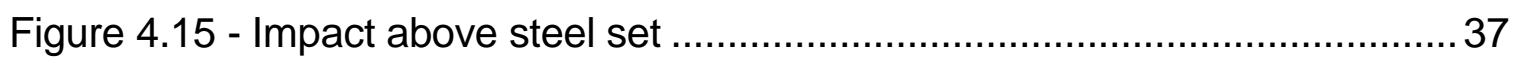

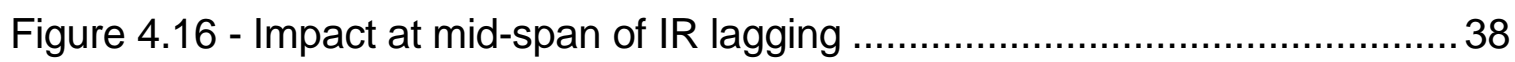

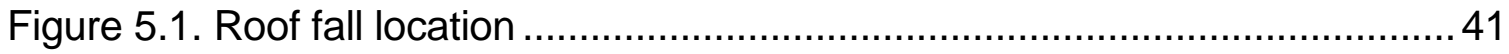

Figure 5.2. Exposed roof cross section ....................................................... 41

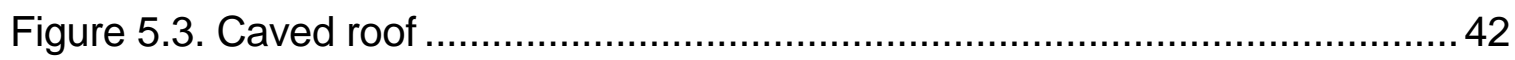

Figure 5.4 - W8x 31 IR arch set................................................................... 43

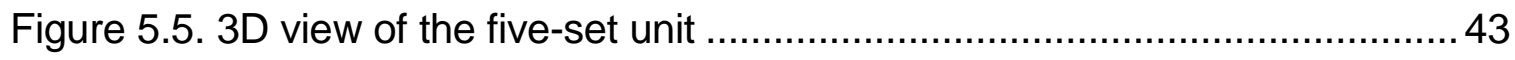

Figure 5.6 - Load and axial diagram .......................................................... 44

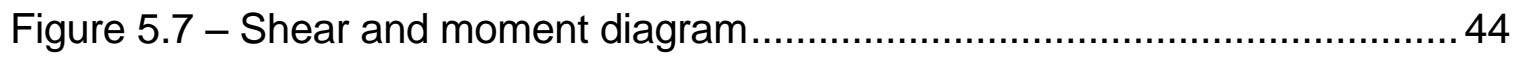

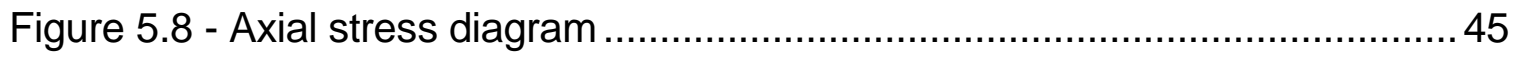

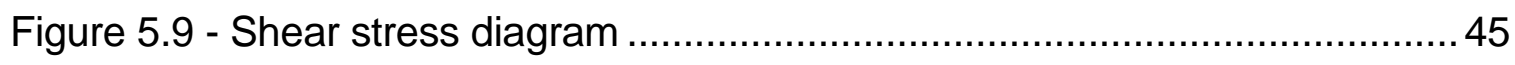

Figure 5.10 - Bending moment diagram ......................................................... 45

Figure 5.11 - Safety factor distribution (static uniform load) ................................. 46

Figure 5.12 - Safety factor (localized impact load) ............................................ 46

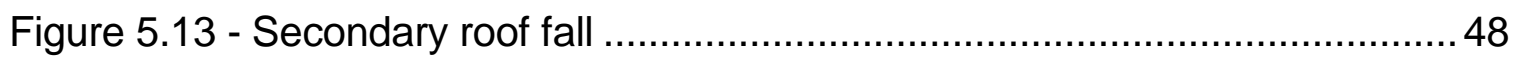

Figure 5.14 - Arch set and lagging impacted by roof fall .................................... 48

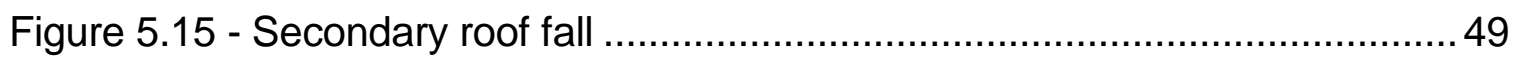

Figure 5.16 - Secondary roof fall ................................................................. 50

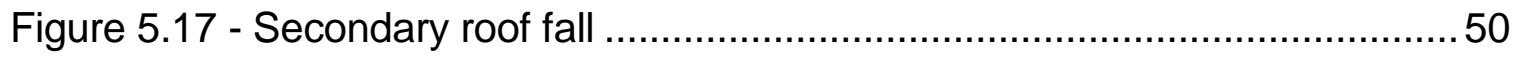

Figure 5.18 - Steel sets under the secondary roof fall area ...................................51

Figure 5.19 - Steel sets under the secondary roof fall area .................................. 51

Figure 5.20 - Minor lagging deflection (0.25”) due to rock impact.........................52 
Figure 5.21 - Medium lagging deflection (3.5") due to rock impact ......................53

Figure 5.22 - Large lagging deflection (8”) due to a pointed impact........................53

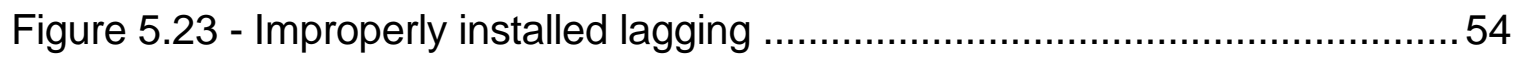

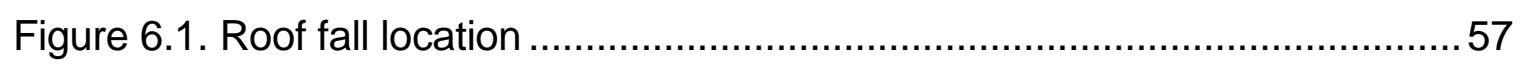

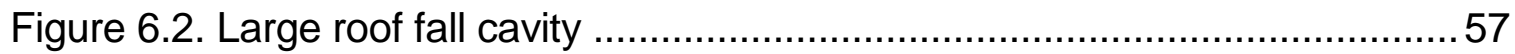

Figure 6.3. 2D engineering drawing - front view ............................................59

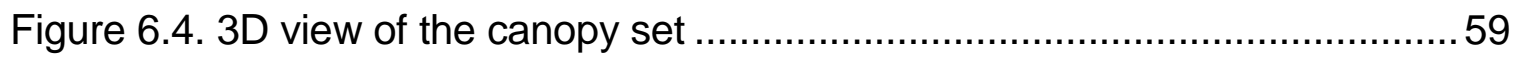

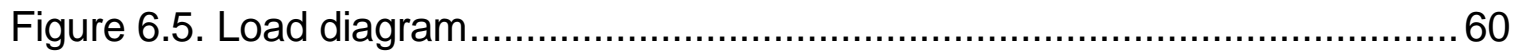

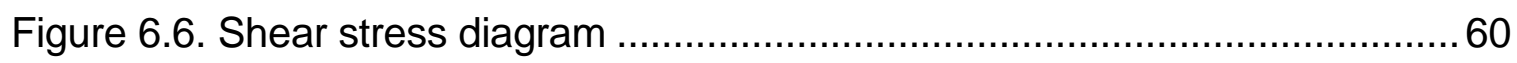

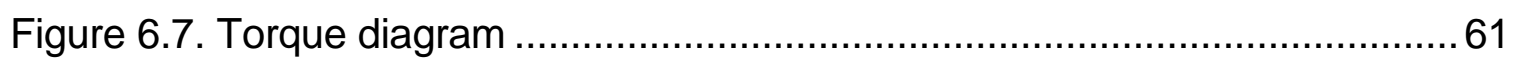

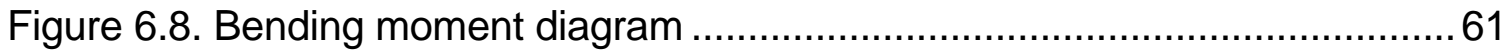

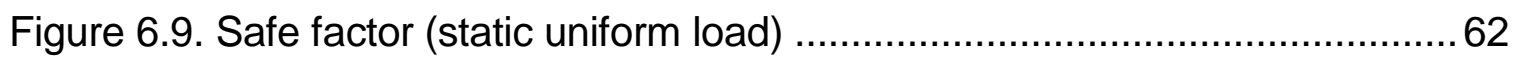

Figure 6.10. Safety factor (dynamic impact load) …......................................... 62

Figure 6.11. Rehabilitated slope bottom ........................................................63 


\section{List of Tables}

Table 2.1 Drop test results - mid span deflections......................................... 14

Table 2.2 - Size and height of falling rock - IR lagging.................................... 18

Table 4.1 Material properties of steel members ….......................................... 31

Table 4.2 - Allowable falling rock weight of the W8 x 31 steel set.......................... 33

Table 4.3 - Maximum allowable thickness of falling rock slab...............................39 


\section{INTRODUCTION}

Underground mines often experience roof falls in entries, crosscuts, and intersections of active mining sections, main travel ways, and belt entries. Roof falls greater than $20 \mathrm{ft}(6 \mathrm{~m})$ make re-bolting a mine's newly-exposed roof strata dangerous and impractical. Rehabilitating the roof fall area in a safe manner becomes a challenge to the ground control engineer and mine operator. To protect mine personnel, belts, moving vehicles, and other equipment, mine operators typically install steel structures such as square or arch sets in the roof fall areas. The operator generally connects the steel-sets with tie rods, inserts wood crib blocks between the flanges of the beams of steel-sets as lagging, and then backfills the voids between the steel-set and roof. However, for large roof falls, which typically occur in intersections, complete void backfilling becomes impractical and expensive.

As a naturally-occurring anisotropic material, wood products are subjected to a wide variations in terms of engineering properties. Such variations are also due to the existence of soft spots, knots, and fractures. Also, moisture absorption can expedite decay which can reduce the woods strength over time. As a result, the capability and reliability of steelsets that are lagged with wood blocks to resist large rock falls are unknown. This has become a concern of MSHA and ground control engineers. Therefore, to improve safety and provide reliable rehabilitation of roof fall areas, developing an impact-resistant steelset system became necessary.

Since 2009, the author and researchers from Jennmar Corporation and Keystone Mining Services, LLC (KMS) designed, tested, and developed an IR resistant lagging system that can be utilized to protect the steel sets from dynamic impact by falling rock. As of May 2020, various types of IR steel sets (IR lagging + steel sets) were fabricated and successfully installed at more than 200 roof fall rehabilitation projects in over 50 different coal mines. 
After a brief literature review (Chapter 1), this thesis presents an IR lagging panel design (Chapter 2), briefs laboratory impact testing results, and evaluates the dynamic load support capacity of the IR lagging panel based on the Law of Conservation of Energy. Chapter 3 outlies a three-step IR steel set design methodology. The methodology is demonstrated via an IR square set design project, which includes design assumptions, structural analysis, elasto-plastic evaluation, dynamic impact simulation, and IR capacity evaluation. To demonstrate effectiveness of the IR steel set design methodology, two case studies (Chapters 5 and 6 ) are presented. In addition, to help engineers to evaluate applicability of an IR steel set to a given roof fall condition, a preliminary applicability evaluation guideline is outlined in Chapter 7 . 


\section{CHAPTER 1: LITERATURE REVIEW}

\subsection{Research by MSHA/NIOSH}

Underground ground falls have plagued the mining industry since the beginning of the industry. It is estimated that nearly 45,000 coal miners have perished in ground falls in the U.S. (Mark it al., 2010). Through advancements in ground support and engineering design practices in recent decades the industry has witnessed a substantial decrease in ground fall fatalities as detailed in Figure 1.1 (BOM, MSHA 1900-2009). Even with these technological advancements, fatalities and ground falls still occur although at a much lower rate. In 2010, MSHA and NIOSH compiled a summary of ground fall fatalities from 1995 to 2009 and classified them by fall type, Figure 1.2. It was reported that 120 fatalities occurred from ground falls during that time period with $10 \%$ occurring from massive roof falls and an additional $12 \%$ from other rock falls such as falls between supports.

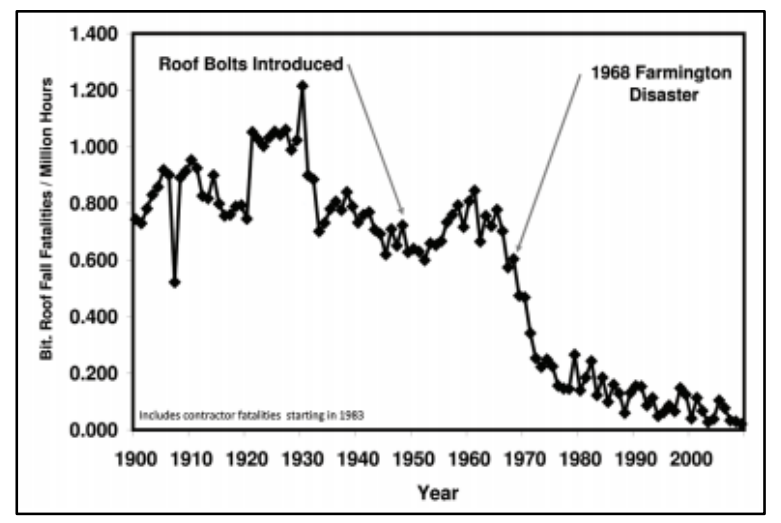

Figure 1.1 - Historical overview of roof fall fatality rates for underground bituminous coal mines (BOM,MSHA 1900-2009). 


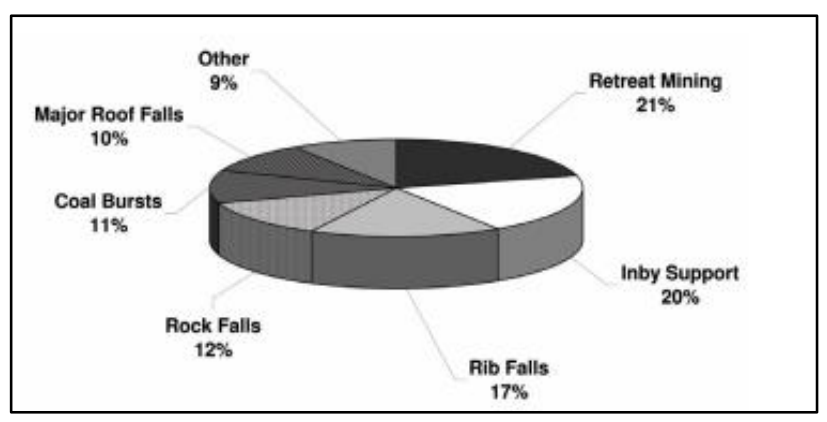

Figure 1.2 - Classification of ground fatalities from 1995-2009 (MSHA, NIOSH 19952009).

With a substantial number of fatalities occurring from ground falls MSHA requires coal mine operators to report two types of roof falls: 1) falls causing injury to workers; and 2) non-injury falls in active areas that impair ventilation, impede passage of miners or extend at least to the anchorage zone of roof bolts (MSHA CFR 50, 2007). From 1999 to 200811,648 non-injury roof falls were reported to MSHA by coal mine operators, Figure 1.3, (Bajpayee it al., 2014). On average over 1,100 reportable non-injury roof falls were recorded each year. MSHA further separated out the 11,648 reported non-injury roof falls into fall height above the roofline, Figure 1.4. The roof fall heights ranged from as little as $2.5 \mathrm{ft}$ to greater than $20 \mathrm{ft}$.

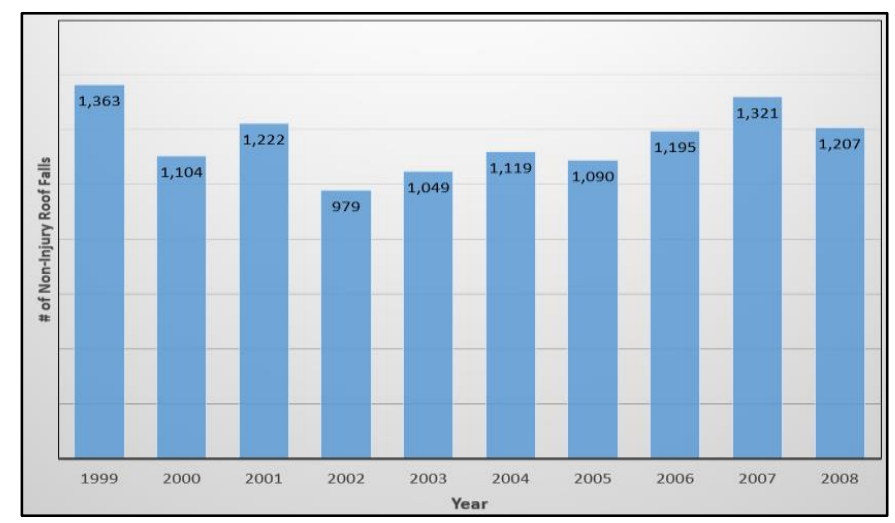

Figure 1.3 - Classification of ground fatalities from 1995-2009. 


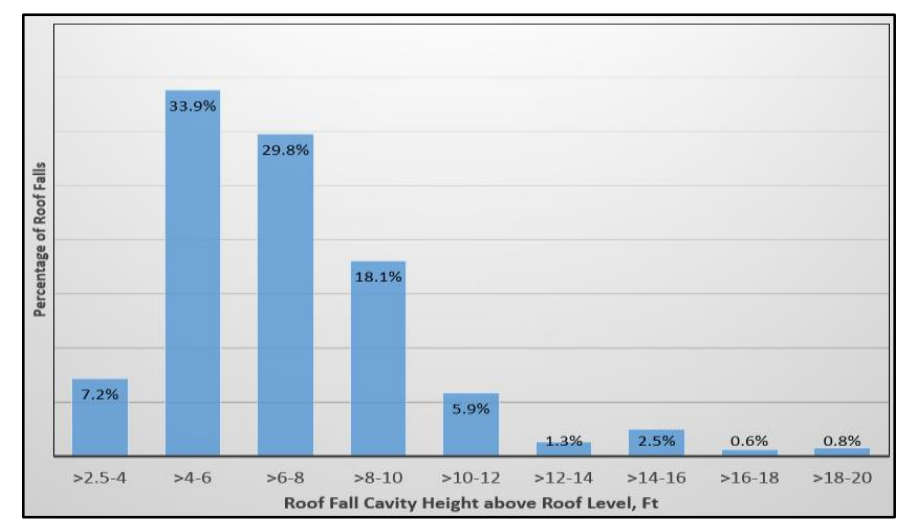

Figure 1.4 - Roof fall cavity height above roof level.

After a roof fall is reported the mine operator is required to rehabilitate the fall area to allow for safe passage of equipment and/or personnel. In limited cases the mine operator may be allowed to barricade off the area to prevent passage entirely. In instances where the cavity height is near to the mining height a mine operator will typically re-support the exposed strata with roof bolts. In cases where the cavity height has reached a height where it is not feasible for the equipment or personnel to safely bolt the exposed strata an operator will generally use alternative methods of support. These methods could consist of installing steel sets or even backfilling the entire fall area with a cementitious grout and re-mining the entry. With over $11 \%$ of the reported roof falls from 1999 to 2008 exceeding a cavity height of greater than 10 feet safe there is a need for safe alternative methods. It should be noted that in some cases with high cavities an operator is able to drive a bolting machine on top of the ground fall debris in order to safety re-bolt the exposed strata.

\subsection{Research by USBM}

In 1987 The U. S. Bureau of Mines (USBM) conducted research to develop a design procedure for an arch canopy for use in rehabilitating high-roof-fall areas (Allwes et al., 1987). At the time, mine operators typically used two rehabilitation practices. The first is to install active and/or passive supports while tunneling through the roof fall debris. The second, is to protect the mine from recurring roof falls with the construction of a structure 
such as a steel arch canopy. The conventional approach to re-support was to install standing support with cribbing, roof bolts and steel straps, Figure 1.5. This process was conducted in incremental steps with installing supports and removing debris. In massive roof fall areas cribbing, Figure 1.6, or multi-tiered steel sets may have been used.

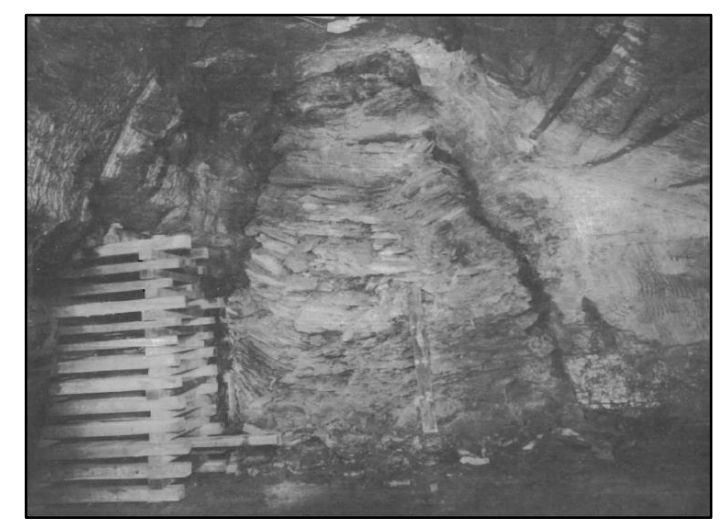

Figure 1.5 - Conventional re-support of a roof fall (Allwes, 1987).

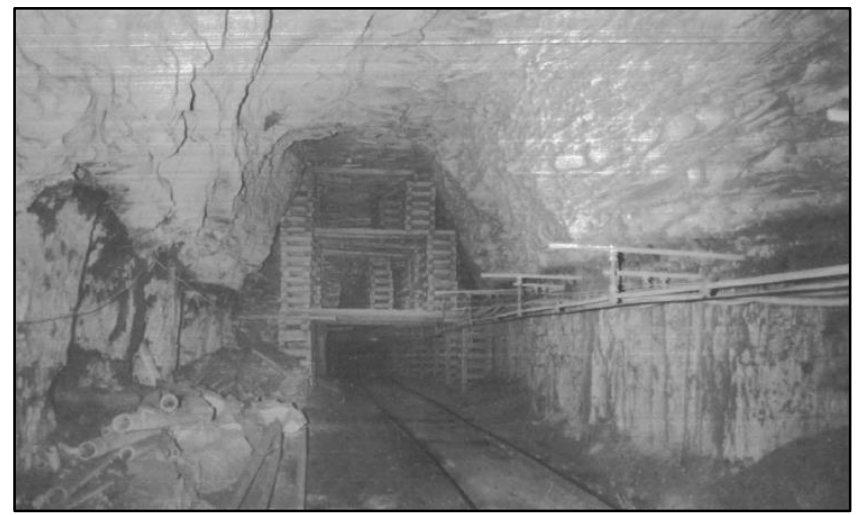

Figure 1.6 - Re-support of a roof fall using multi-tiered cribbing (Allwes, 1987).

The first arch canopy used to rehabilitate a roof fall in the U.S. was installed in 1977. Although arch canopies have been used regularly in Europe and in poor geologic conditions in the U.S. this was the first for a roof fall rehabilitation. At the time the Allwes article was written in 1987 the typical arch support was a liner plate arch or a steel set arch, Figure 1.7. In providing guidelines to operators on arch canopies, the USBM's stated that an arch canopy should not deflect more than a set maximum amount under the action of a subsequent roof fall. The design procedure used was based on the concept that the steel 
structure absorbs strain energy when an arch canopy is subjected to impact loading at its crown and deflects to maximum deflection.

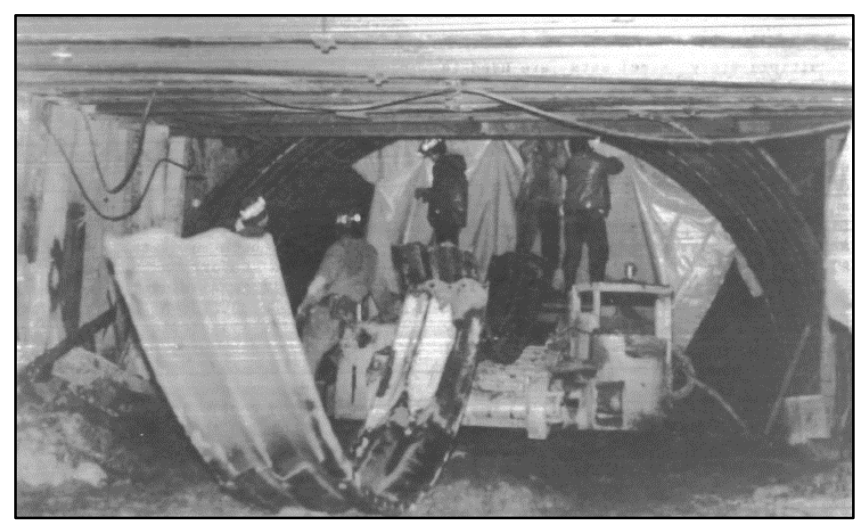

Figure 1.7 - Linear plate style arch support (Allwes, 1987).

Later, to evaluate the suitability of steel-set arches and tri-sets for use in roof-fall areas, the USBM conducted structural analyses and full-scale physical tests on these structures (Allwes and Mangelsdorf, 1992). The dynamic tests demonstrated that the previously developed arch canopy design procedure is appropriate and that it yields conservative designs for both steel-set arches and tri-sets Figure 1.8. However, the design procedure relies on the elastic and plastic strain energy absorbing capability of the steel structure to resist the impact load of the falling rock. Such a design concept is theoretically sound; however, from an engineering design perspective, the design concept tends not to be conservative if the plastic deformation of the steel-set is permitted in actual practice. Also, the design procedure is complicated and hard to implement. It will be difficult to calculate the strain energy from a static load-displacement diagram for every possible steelset design. This is because the strain energy capacity of the structure differs between designs depending on the type and size of the steel member used. Most importantly, the design procedure ignores the adequacy of the wood lagging, which is likely the weak link of the entire impact-resistant steel-set system. Thus, steel-set and impact-resistant lagging panel designs have previously been by trial-and-error based on field experience. 


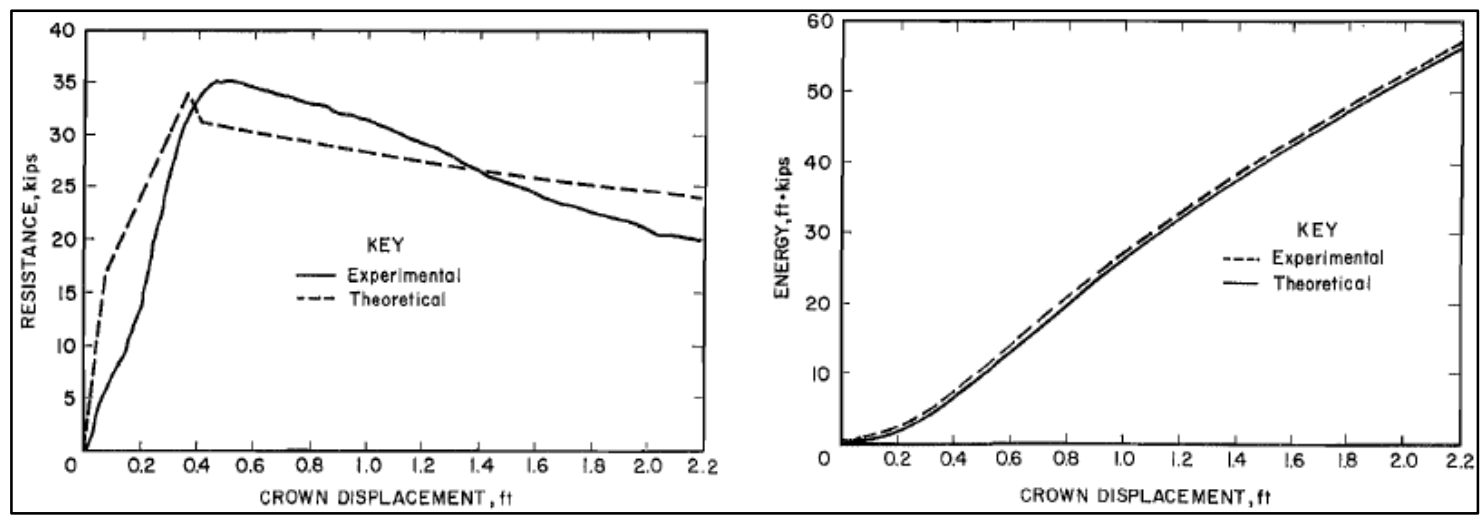

Figure 1.8 - Comparison of experimental and theoretical resistance and strain energy curves (Allwes, 1992).

Therefore, it became necessary to develop a reliable and economic impact-resistant lagging system and easy-to-implement steel structural design methodology for application in underground mining.

\subsection{Recent Developments}

Since 2009, the author and researchers of Jennmar Corporation and Keystone Mining Services, LLC, (KMS) designed and developed a special impact-resistant lagging panel (Ma et al., 2009). Various steel-set designs were developed using the American Institute of Steel Construction (AISC) national standard. With the impact-resistant lagging panels as protection, various IR steel sets were fabricated and successfully installed in roof fall rehabilitation sites across the country. 


\section{CHAPTER 2: IMPACT RESISTANT LAGGING PANEL}

In addition to a sufficient flexural strength and an acceptable cushioning effect, the impact-resistant lagging panel should be cost effective and corrosion-resistant and enable easy material handling and installation in the field. Working with the mining industry for the last few years, author and researchers of Jennmar and KMS designed and developed various special impact-resistant lagging panel designs. Figure 2.1 shows the latest IR lagging panel design that was presented to the mining industry in 2010.

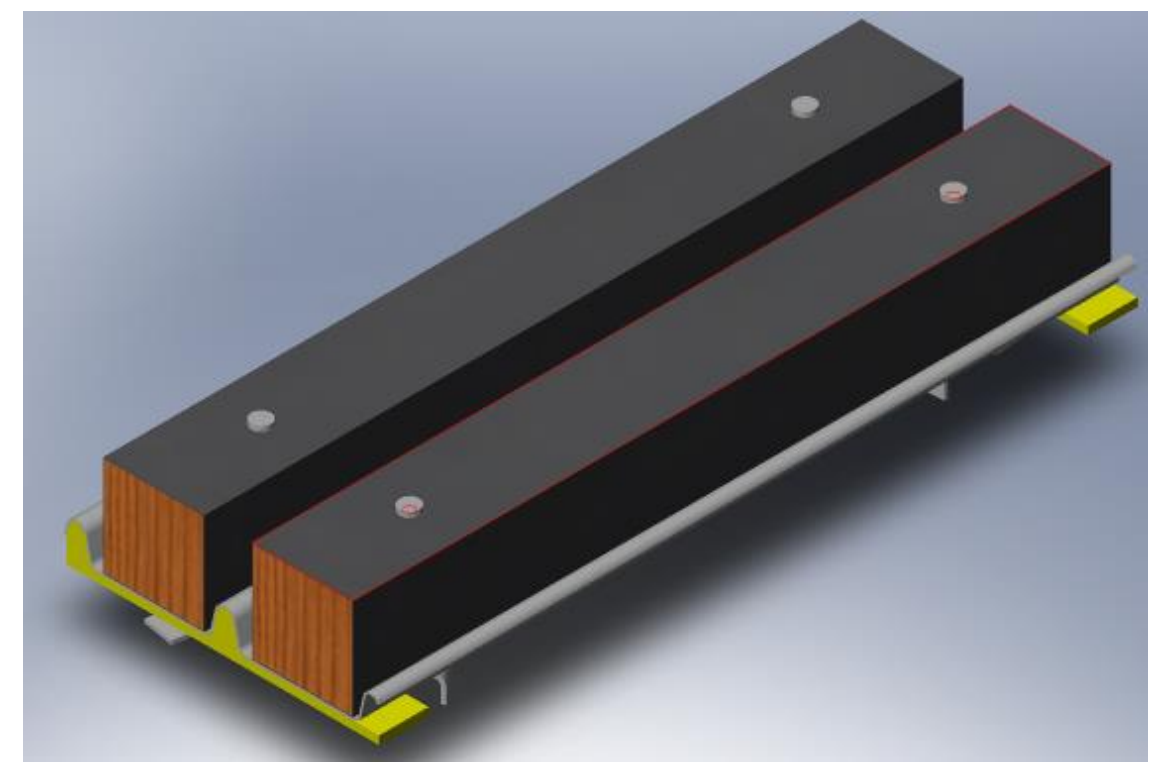

Figure 2.1 - Impact Resistant Lagging Panel

\subsection{Main Components:}

The IR lagging panel consists of the following components:

- V-Deck Panel: A 18 in $(45 \mathrm{~cm}) \times 46$ in $(116 \mathrm{~cm}) \times 12$ gage galvanized V-deck panel is used to provide primary flexural strength. Two clips are attached to facilitate easy installation of the lagging panel to the upper flange of the beam. 
- Special Lagging Blocks (SLB): Two pieces of 6 in $(15 \mathrm{~cm}) \times 6$ in $(15 \mathrm{~cm}) \times 46$ in $(116 \mathrm{~cm})$ medium-soft wood SLBs that are attached to the V-deck panel. The block provides additional flexural strength to the system, absorbs impact energy, distributes the impact load over a larger area of the V-deck panel, and extends the duration of impact.

- Cushion Inserts: Two pieces of half-inch $(1.27 \mathrm{~cm})$ thick hard foam strips are installed between the V-deck panel and the flange of the W-beam. The foam strip acts as a cushion, increasing the impact duration and reducing the magnitude of the instantaneous impact load on the system.

- Surface Coating: A thin layer of waterproof bonding coating is applied to the surface of the SLBs. The tough-textured coating provides necessary protection against water, acid, chemicals, UV exposure, salt water, abrasion, fire, and freeze-thaw. It is expected that the coating will dramatically extend the life span of the SLBs as compared with plain wood blocks.

\subsection{Dynamic Load Support Capacity - Numerical Modeling:}

The dynamic load support capacity of the IR lagging panel was evaluated using computer modeling technique. To determine the impact support capacity of the lagging panel, 3-D dynamic numerical modeling was conducted using the ANSYS program. The panel is supported over a $4 \mathrm{ft}$ span by W8 $\times 31$ beams on both ends. Figures 2.2 and 2.3 show the vertical deformation and safety factor distribution on the impact-resistant lagging panel at a given impact load. 


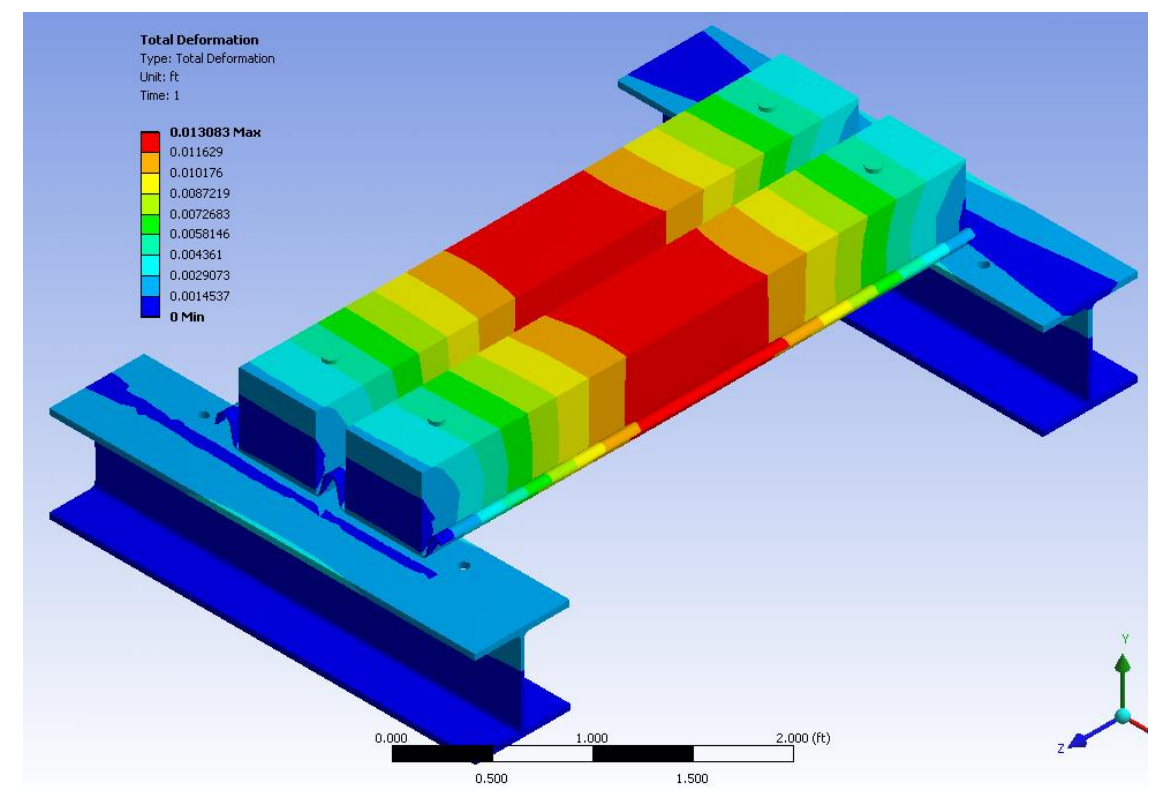

Figure 2.2 - Vertical deformation of the lagging panel.

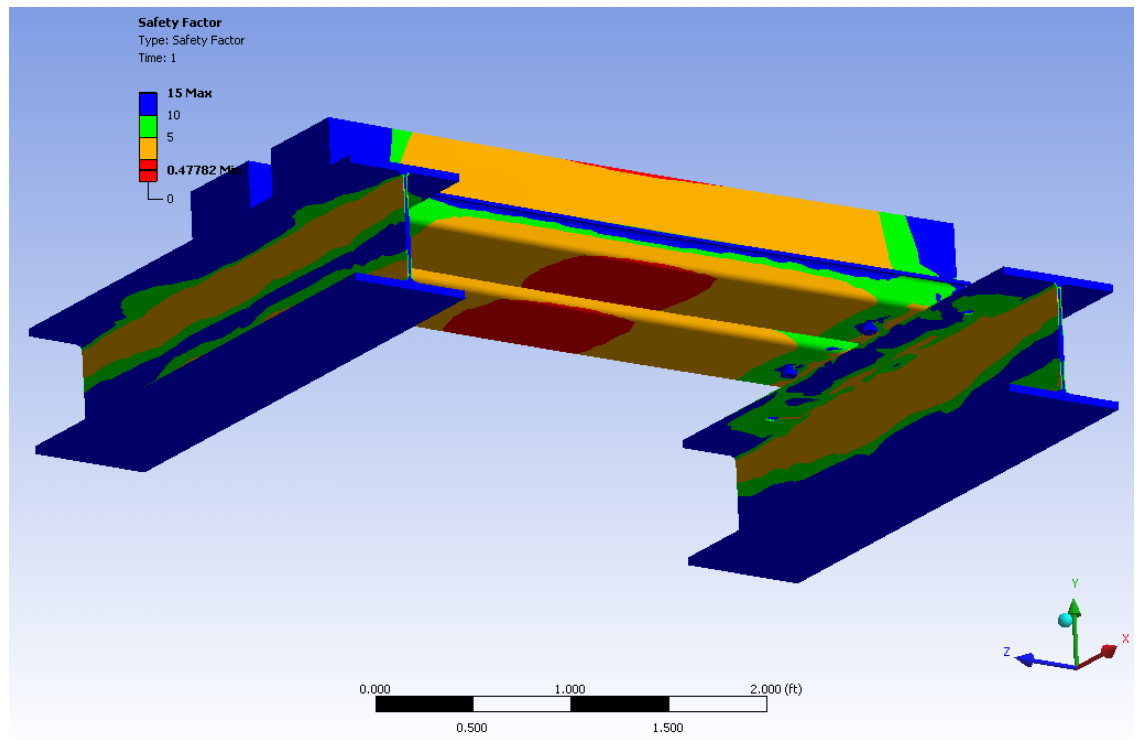

Figure 2.3 - Safety factor distribution.

Analysis indicates that, under 68 kips of a localized dynamic impact loading, the panel develops less than 0.16 in of deflection at mid-span, and material yielding initiates at the bottom outermost fiber of the V-deck panel and SLB top, as shown in Figure 2.3. Since the panel deflects within the serviceability range and the yielding zone does not propagate 
through the SLB, it is concluded that the lagging panel has enough flexural strength to sustain 68 kips of dynamic impact load.

\subsection{Dynamic Load Support Capacity - Laboratory Impact Testing:}

The dynamic load support capacity of the lagging panel was also evaluated through full scale laboratory testing.

\subsubsection{Testing Set-up:}

A full-scale laboratory test of the impact-resistant lagging panels was conducted with the Jennmar Impact Drop Tester shown in Figure 2.4. To simulate the actual loading condition, a steel block (600-1550 lbs) drops freely from a height of approximately 63 inches above the lagging panel assembly. An accelerometer is mounted on the steel block and a computerized data acquisition system records the steel block acceleration and duration of impact.

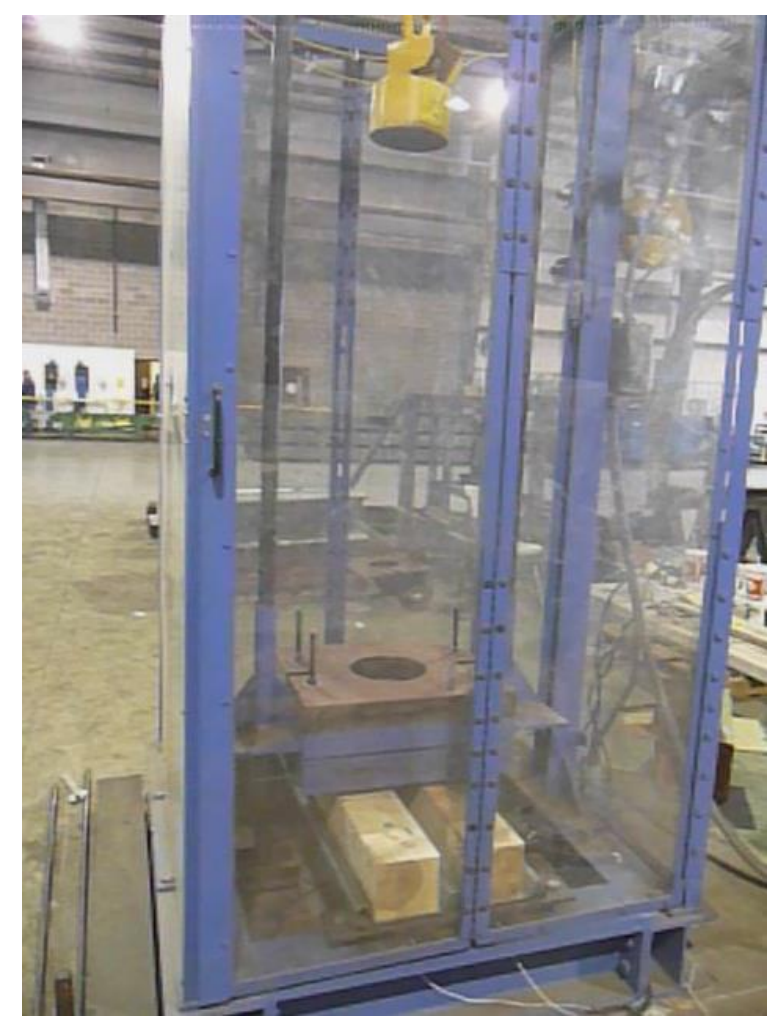

Figure 2.4 - Impact tester. 


\subsubsection{Testing Criteria:}

From a serviceability perspective, it is considered that the IR lagging panel will serve its engineering purpose as long as the lagging assembly still remains on the steel set after being impacted by falling rock. To determine maximum allowable deflection, it is assumed that, upon a localized impact at mid-span, the IR lagging shall yield and deform to the extent that at least 1 inch of the lagging will remain on the W-beam flange on either end. With this assumption, it is determined that the maximum mid-span deflection is 9.187 in (Figure 2.5). However, to be conservative, a safety factor of 1.5 is applied and an allowable mid-span deflection of 6.125 in is considered as the testing criteria during the new laboratory drop tests. This assumption is considered reasonable while still conservative given the acceptable 8 inches of deflection measured in the field.

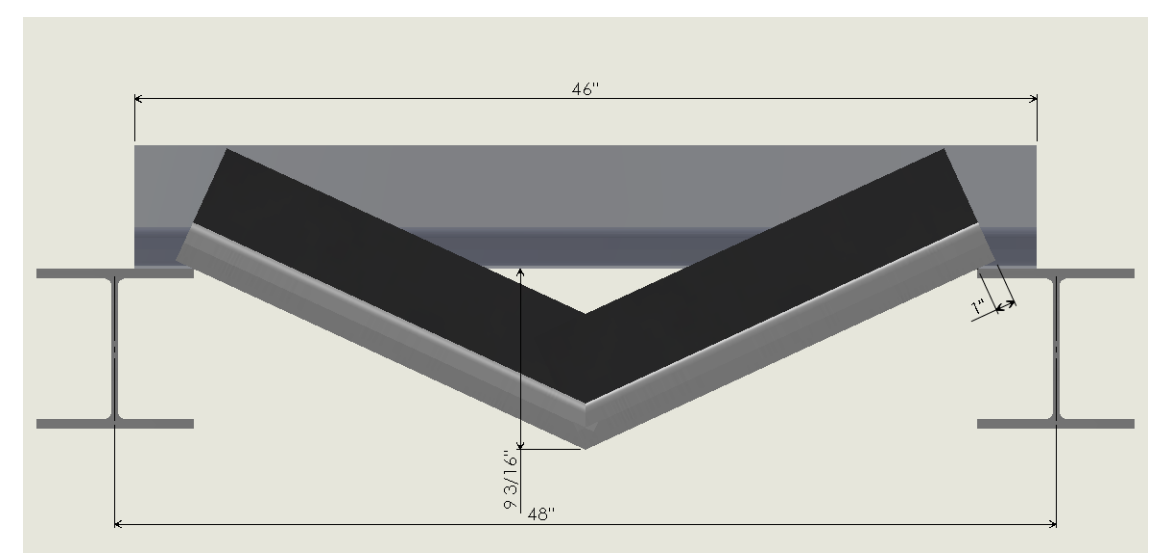

Figure 2.5 - Maximum deflection of the IR lagging panel at mid-span

\subsubsection{Testing Results:}

Figure 2.6 shows a typical drop test specimen that did not reach the 6.125 " midspan deflection failure state. To identify the maximum support capacity of the impactresistant lagging panel, a series of drop tests were conducted by gradually increasing drop weight whereas the drop height was maintained constant. Permanent deflections of the $\mathrm{V}$ deck panel and SLB were manually measured at mid-span with a straight edge. 
Listed in Table 2.1 are results of sixteen (16) samples tested using the impact tester. Test results indicate that, with a $12 \times 12$ in impact area at mid-span, the IR lagging panel is capable of sustaining a dynamic impact load generated by a maximum of a $1,541.5 \mathrm{lb}$ metal block falling from a 63 inches height. The results indicate that, even at 1,541.5 lb of drop weight, the highest deflection (5.5 in, Test \#15) is still lower than the allowable mid-span deflection.

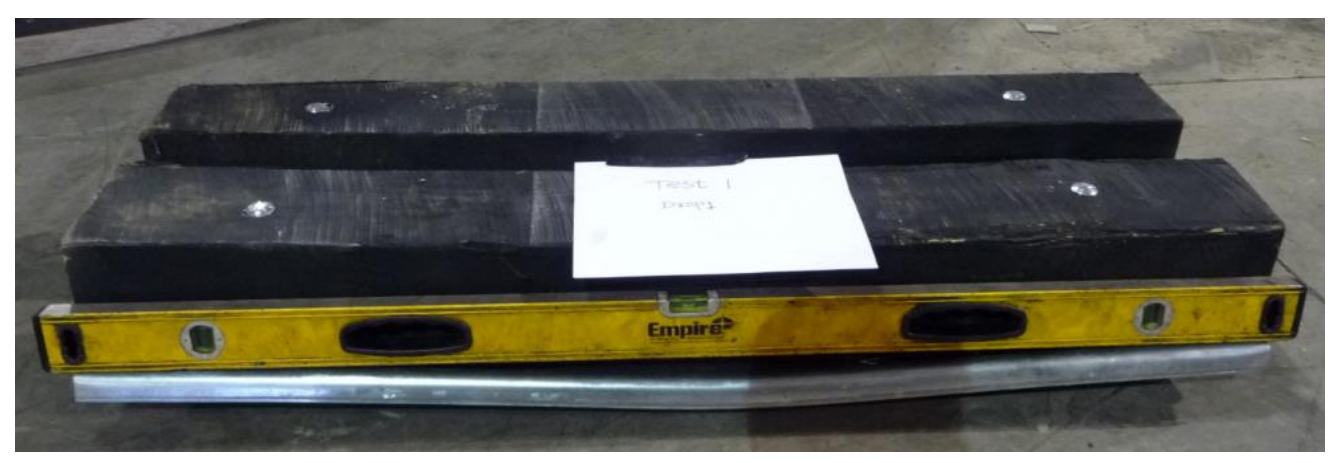

Figure 2.6 - Intact specimen after impact.

Table 2.1 Drop test results - mid span deflections

\begin{tabular}{|c|c|c|c|c|c|c|}
\hline \multirow{2}{*}{$\begin{array}{c}\text { Test } \\
\#\end{array}$} & \multirow{2}{*}{$\begin{array}{c}\text { Drop } \\
\text { height }\end{array}$} & \multirow{2}{*}{$\begin{array}{c}\text { Drop } \\
\text { weight (lb) }\end{array}$} & \multicolumn{2}{|c|}{ V-deck } & \multicolumn{2}{|c|}{ SLB } \\
\hline & & & Side 1 & Side 2 & Piece 1 & Piece 2 \\
\hline 1 & $63^{\prime \prime}$ & 1293.53 & $2.75^{\prime \prime}$ & $2.25 "$ & 1.375" & 1.312" \\
\hline 2 & 63" & 1129.03 & $2.375^{\prime \prime}$ & $1.875^{\prime \prime}$ & $1.625^{\prime \prime}$ & $1.5^{\prime \prime}$ \\
\hline 3 & 63" & 1129.03 & $4.0 "$ & $3.5^{\prime \prime}$ & $2.75^{\prime \prime}$ & $2.5^{\prime \prime}$ \\
\hline 4 & $63^{\prime \prime}$ & 1129.03 & $2.75 "$ & $3.25 "$ & 1.625" & $2.125 "$ \\
\hline 5 & $63^{\prime \prime}$ & 1241.53 & 3.5" & 3.625" & 2.375" & $2.875 "$ \\
\hline 6 & 63" & 1241.53 & $1.25 "$ & $1.5 "$ & $0.375 "$ & $0.375 "$ \\
\hline 7 & 63" & 1241.53 & $2.25 "$ & $2.25 "$ & $1.625 "$ & $1 . \mathrm{s}^{\mathrm{N}}$ \\
\hline 8 & 63" & 1241.53 & $0.625 "$ & $0.375^{\prime \prime}$ & 0.375" & $0.125 "$ \\
\hline 9 & $63^{\prime \prime}$ & 1241.53 & $1.25 "$ & $2.25 "$ & 1.625" & $2.125 "$ \\
\hline 10 & $63^{\prime \prime}$ & 1241.53 & $0.375^{\prime \prime}$ & $2 "$ & $0.125 "$ & $1.875 "$ \\
\hline 11 & $63^{\prime \prime}$ & 1326.03 & 5" & 3.875" & 3.375" & 3" \\
\hline 12 & $63^{\prime \prime}$ & 1410.53 & $1.625^{\prime \prime}$ & 3.375" & $0.875 "$ & $2.25 "$ \\
\hline 13 & $63^{\prime \prime}$ & 1541.53 & 3.375 & 2.375 & 2.125 & 1.75 \\
\hline 14 & $63 "$ & 1541.53 & 5.375" & $4.5^{\prime \prime}$ & 3.5" & 3.125" \\
\hline 15 & $63^{\prime \prime}$ & 1541.53 & $5.5^{\prime \prime}$ & $5.375^{\prime \prime}$ & $4.25 "$ & 3.625" \\
\hline 16 & $63 "$ & 1541.53 & $1.75^{\prime \prime}$ & $2.75^{\prime \prime}$ & $1.25 "$ & $1 . \mathrm{F}^{\mathrm{N}}$ \\
\hline
\end{tabular}


Figure 2.7 shows the sample \#14 after the impact. Upon a free drop impact at midspan by a $1541.5 \mathrm{lb}$ weight falling from 63 in high, the metal V-deck panel at the bottom experienced permanent deformation and the Special Lagging Block (SLB) fractured at the bottom but still maintained acceptable integrity.

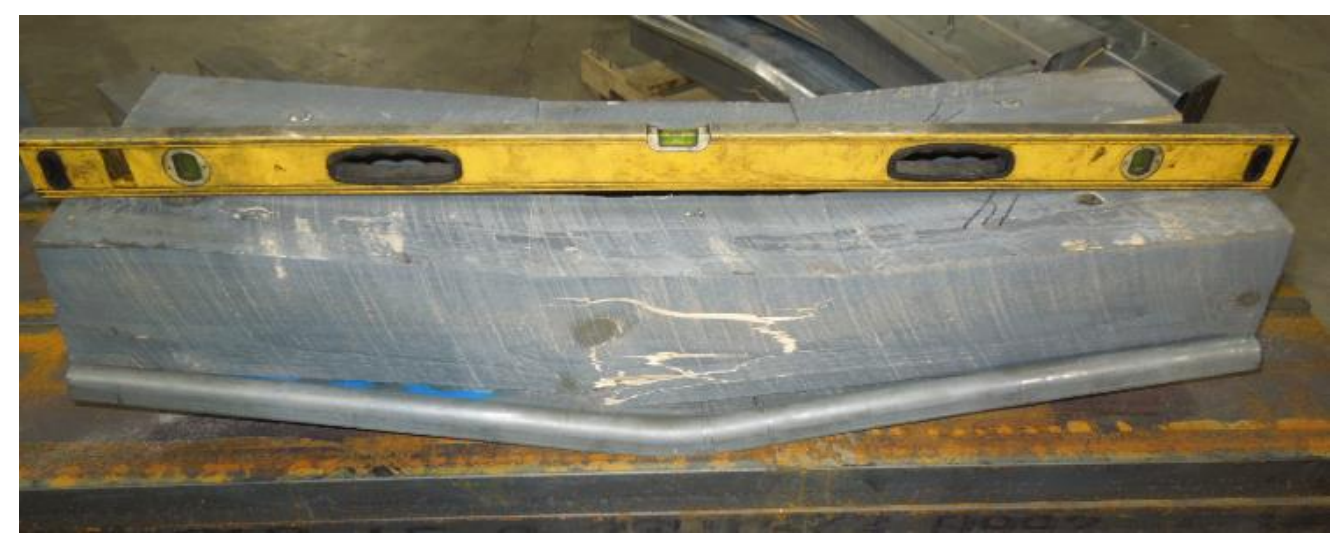

Figure 2.7 - Deformed specimen after impact.

Figures 2.8 and 2.9 show the acceleration vs. time curves recorded for two typical impact tests. The weight block bounces up and down $5-6$ times before the impact energy attenuates. Due to the spring effect of the panel, the steel block bounced up and down several times in each test. As a result, the IR lagging was actually subjected to 4 - 6 miniimpacts. As shown in Figure 2.9, impact duration of the first and second mini-impacts ranged approximately $0.03-0.05$ seconds, and total duration of the impact was approximately 0.702 seconds. The instantaneous impact load peaks at $77 \mathrm{kips}$. In this case, the V-deck panel deflected 1.75 - 3.375 inches at mid-span and some deformation and/or fractures occurred to the SLB's. 


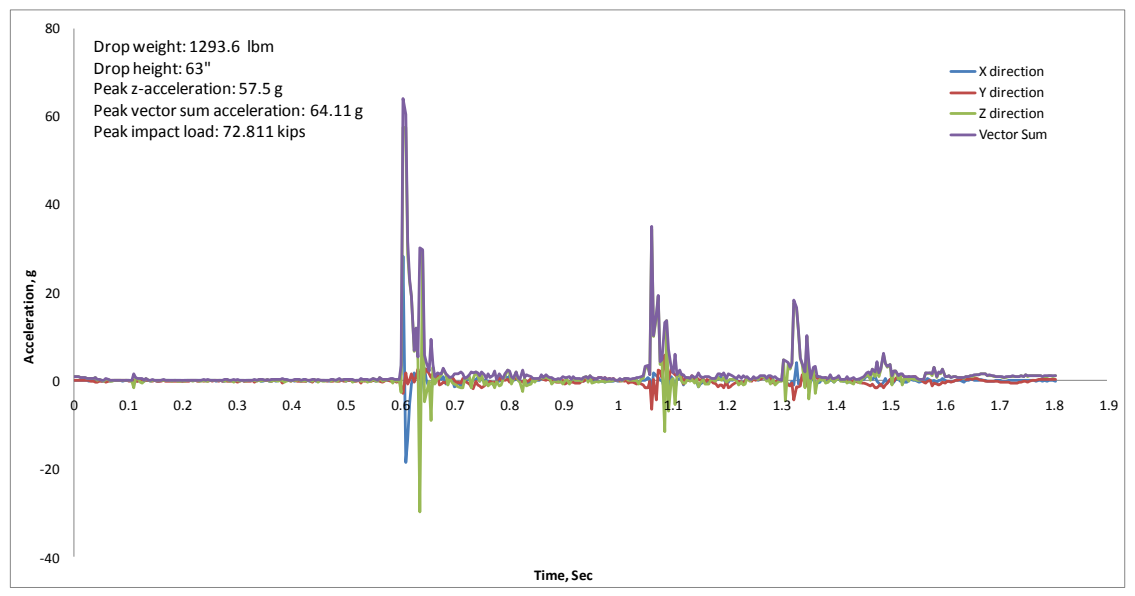

Figure 2.8 - Acceleration vs. time curve of impact testing - Test \#1.

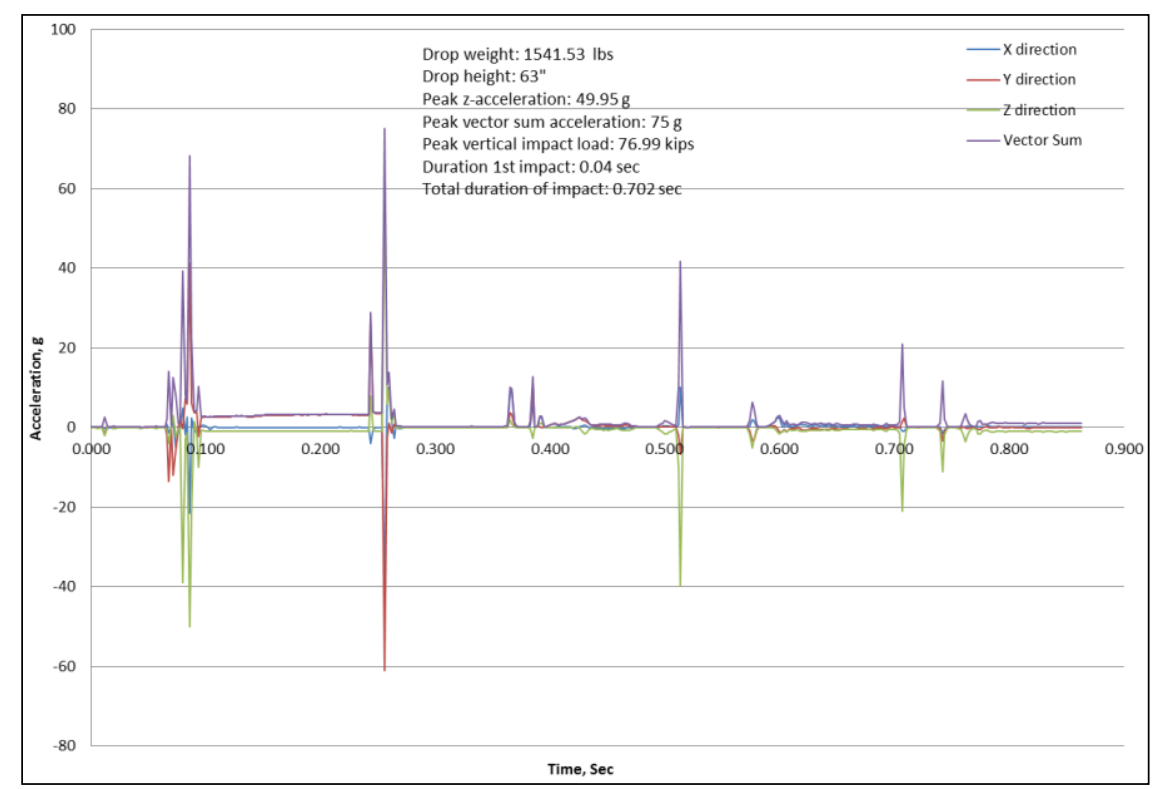

Figure 2.9 - Acceleration vs. time curve of impact testing - Test \#15.

\subsection{Impact-Resistant Capacity Interpretation:}

The dynamic impact load on the IR lagging panel is a function of the weight and height of the falling rock, the contact area, deflection and energy absorption capabilities of the SLBs and foam inserts. The lab tests verify that the IR lagging panel is capable of supporting an instantaneous impact load that was generated by a 1,541.5 lb metal block falling 63 in with an acceptable mid-span deflection ( $<6$ in). 
To estimate the maximum size of falling rock for different roof fall heights that can be supported by the panel, the Law of Conservation of Energy is used. The law states that the total mechanical energy remains constant along the path of a falling object, provided that the net work done by external non-conservative forces is zero. For the impact test, non-conservative forces, such as air resistance and friction between the weight block and guide, are negligible.

Assuming that the falling rock has the same potential energy (PE) as the steel block and will achieve the same amount of kinetic energy (KE) before impacting the SLB, the potential energy of the steel block and falling rock should be equal. Therefore, the following formula can be established:

$$
M_{s} H_{s}=M_{r} H_{r}
$$

where:

$$
\begin{aligned}
& \mathrm{Ms}=\text { Mass of the steel block, } 1,541.5 \mathrm{lbs} \\
& \mathrm{Mr}=\text { Mass of a falling rock, lbs } \\
& \mathrm{Hs}=\text { Falling height of steel block, } 63 \text { in or } 5.25 \mathrm{ft}(1.6 \mathrm{~m}) \\
& \mathrm{Hr}=\text { Falling height of a rock, } \mathrm{ft}
\end{aligned}
$$

Table 2.2 lists various sizes of falling rock for different falling heights calculated based on Equation (1). The rock density is assumed to be $160 \mathrm{lbs} / \mathrm{ft}^{3}\left(2562 \mathrm{~kg} / \mathrm{m}^{3}\right)$.

For example, the impact resistant lagging panel can sustain an instantaneous dynamic impact load generated by a maximum of $578.1 \mathrm{lb}$ of rock falling from a $14 \mathrm{ft}$ height to the top of the impact-resistant lagging panel at mid-span. 
Table 2.2 - Size and height of falling rock - IR lagging.

\begin{tabular}{|c|c|}
\hline $\begin{array}{c}\text { Fall Height, } \\
\mathrm{ft}\end{array}$ & $\begin{array}{c}\text { Falling Weight, } \\
\text { lbs }\end{array}$ \\
\hline 2 & $4,046.5$ \\
\hline 4 & $2,023.3$ \\
\hline 5.25 & $1,541.5$ \\
\hline 6 & $1,348.8$ \\
\hline 8 & $1,011.6$ \\
\hline 10 & 809.3 \\
\hline 12 & 674.4 \\
\hline 14 & 578.1 \\
\hline 16 & 505.8 \\
\hline 18 & 449.6 \\
\hline 20 & 404.7 \\
\hline 22 & 367.9 \\
\hline 24 & 337.2 \\
\hline 26 & 311.3 \\
\hline 28 & 289.0 \\
\hline 30 & 269.8 \\
\hline
\end{tabular}




\section{CHAPTER 3: IR STEEL-SET DESIGN METHODOLOGY}

\subsection{Description on an IR Steel Set}

An IR steel set is a standing support system that, with the IR lagging panel as protection and its own energy absorbing capability, can sustain impact loads generated by falling rock pieces in roof fall areas, and can be used by the underground mine operators to rehabilitate roof fall areas in a safe, quick, and economical manner. From an engineering design perspective, an IR steel set system needs to have:

- Sufficient support capacity to support the static load by rock debris piled above the canopy over time,

- Capability to sustain dynamic loads by falling rock pieces without losing necessary serviceability,

- Certain degree of installation mobility that will allow it to be dragged or pushed to the roof fall site, and

- A special lagging structure between the steel-sets to provide full coverage and adequate flexural strength while effectively absorbing the impact energy generated by falling rock.

An IR steel set canopy usually consists of multiple courses of single steel set (square or arch) that are spaced a few feet (typical $4 \mathrm{ft}$ center to center), interconnected with each other with tie rods and spacer tube, assembled with runner channels with sled tips at the front, and totally covered with IR lagging panels on the top and v-deck panels on the sides. Shown in Figures 3.1 and 3.2 are typical $20 \mathrm{ft}$ long IR arch set canopies. Note that coverage of IR lagging on the canopy shown in the figure is partial for demonstrational purpose only. 


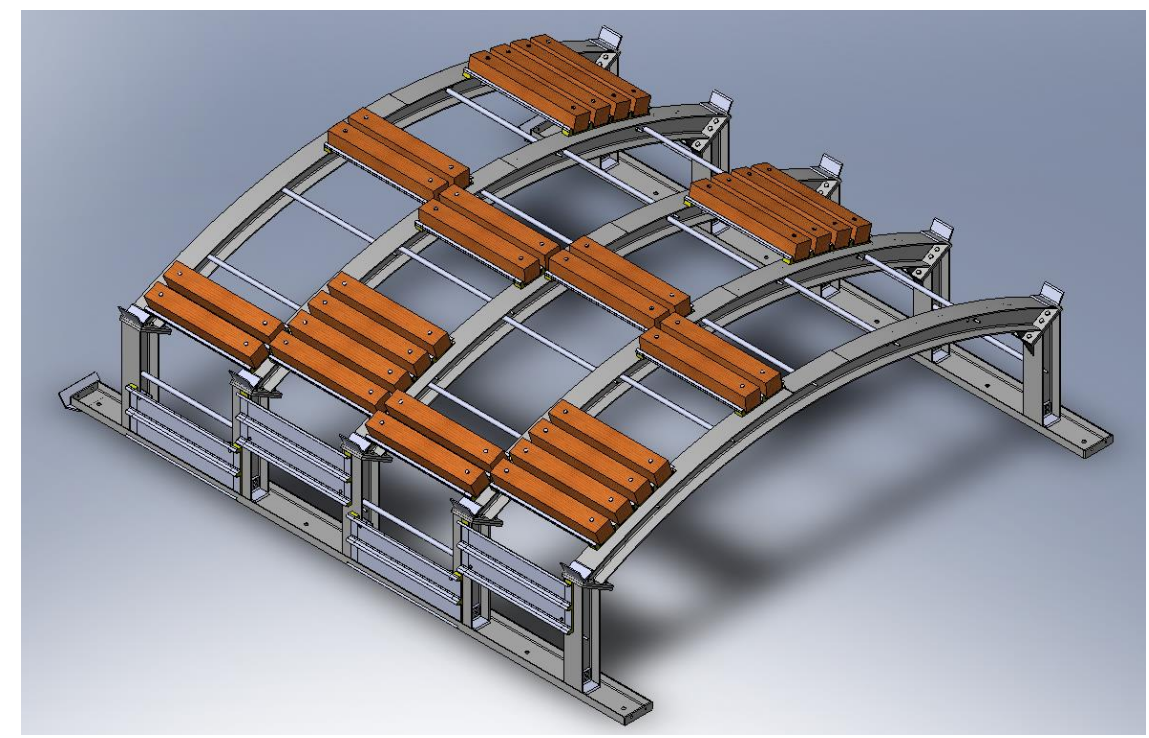

Figure 3.1 - Typical IR arch set canopy

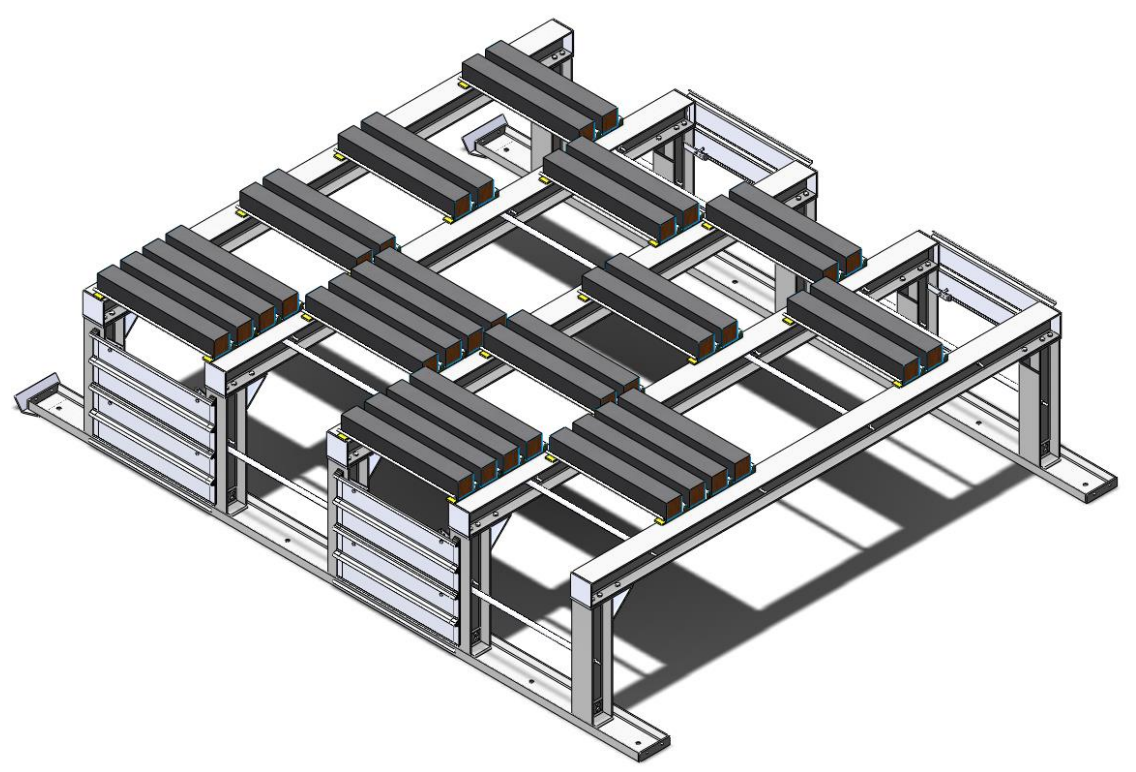

Figure 3.2 - Typical IR square set canopy

Once the IR steel set canopy is assembled in an adjacent safe area, a continuous miner can be driven underneath the canopy. By chaining to the continuous miner, the IR steel canopy can be slightly lifted up and dragged/pushed forward. Doing so enables the operator to safely and gradually move IR steel canopies into the roof fall area while the rock debris is removed by the continuous miner. After the continuous miner cleans through the 
roof fall area, the IR steel set system is unchained and positioned at the designated roof fall area. By fixing the runner channel to the floor strata with rock bolts, the IR steel set system is installed and becomes a permanent standing support structure. With the specially design IR lagging panel, it is technically feasible not to backfill the voids above the structure as long as accumulation of hazardous gas in the voids can be managed properly.

\subsection{Description of IR Steel Set Design Methodology:}

From an engineering design perspective, a steel-set system for roof fall rehabilitation should have sufficient support capacity to sustain static and dynamic loads generated by falling rock pieces. Also the system should have certain degree of installation mobility that will allow it to be dragged or pushed to the fall site. Most importantly, it should protect personnel and equipment from falling rock. To minimize backfilling costs, a special lagging structure should be installed between the steel-sets to provide full coverage and adequate flexural strength while effectively absorbing the impact energy generated by falling rock.

The impact-resistant steel-set design methodology is summarized in the following four steps, although actual practice may assume alternative sequences:

- Step 1: Geological evaluation and site visit of roof fall area

- Step 2: Design of IR steel set per field geotechnical condition and engineering requirements. This includes determination of proper beam size per maximum allowable beam deflection using elasto-plastic analysis techniques, and evaluation of its applicability using the Law of Conservation of Energy.

- Step 3: Validation of the IR steel set using full scale nonlinear dynamic impact computer modeling technique.

\subsubsection{Step 1: Geological Evaluation and Site Visit:}

During the site visit, relevant geotechnical information and data will be collected and carefully evaluated, including opening size and orientation of the mine entry, pillar size, geological features of the overburden, installed primary and supplemental roof support, 
location and dimensions of the roof fall, and maximum and average size of rock fall. Additional information may include surface topography of the area, borehole data, strata fracture log, rock mechanics test data, geological structural maps of the area, historical roof fall data, opening dimension at an adjacent safe area, and the type and overall dimensions of equipment used to clean out the rock fall debris. Other information collected may include the preliminary rehabilitation plan and steel-set design parameters, such as minimum width and height of the rehabilitated entry opening, and type of preferred steel-set (square set, long-radius arch, double radius arch, or semi-circular arch).

\subsubsection{Step 2: Design of IR Steel Set:}

Using the geo-technical data, the stability of the newly exposed roof fall cavity will be evaluated. Based on strata lithology, average rock size from the primary roof fall, possible size of secondary roof fall, falling height, expected entry width and height after rehabilitation, preferred type of steel-set, expected static load support capacity, and maximum allowable beam deflection upon a dynamic impact at mid span, a steel set design will be developed following AISC national specification and using an elasto-plastic structural analysis approach. The following design criteria are usually considered:

- Steel set dimension to meet field engineering requirements.

- Maximum static load support capacity to support expected height of collapsed rock debris and/or backfill material.

- Maximum dynamic load support capacity no less than that of the IR lagging panel.

- Cross member deflection at mid span upon a rock impact shall not exceed the maximum deflection specified by mine engineer per serviceability requirement in the field. 
- The IR steel set canopy shall be able to sustain the impact by a secondary rock fall that drops from the highest position onto the mid span of the cross member. Thickness of the falling rock slab shall be determined based on either historic roof fall data or fracture log of the overburden strata.

The design procedure usually starts with a smaller beam size. Accordingly, a static nonlinear elasto-plastic structural model shall be run to establish a load-deflection curve of the design. With the curve, the Law of Conservation of Energy can be used to determine the maximum weight of a rock piece falling a given height. If the elasto-plastic analysis indicates that the design does not meet the aforementioned criteria, then a larger beam size shall be used and the design procedure reiterates. The procedure may be repeated several times until a proper beam size is identified to satisfy all design criteria.

\subsubsection{Step 3: Validation of IR Steel Set Design:}

After developing the optimal IR steel set design, a nonlinear full-scale dynamic impact simulation model can be used to validate the adequacy of the design under the extreme localized impact loading conditions. Typically, a localized impact by a block, with certain amount of weight and initial impact speed that is equivalent to the maximum fall height, will be applied at the mid-span of the cross member. The validations include the determination of the permanent deflection of the cross member at mid-span, Von-Mises stress of each component, variation of kinetic energy, absorbed strain energy, and total energy over time, etc. Under an extreme loading condition, if the full-scale dynamic model demonstrates acceptable deflection, the IR steel set design is considered reasonable. Otherwise, the design procedure is repeated to identify an alternative design. 


\section{CHAPTER 4: DEMONSTRATION OF THE IR STEEL SET DESIGN METHODOLOGY}

\subsection{IR Steel Set Design Methodology}

With an actual roof fall rehabilitation project as an example, this chapter demonstrates how to evaluate static capacity and dynamic impact capacity of an IR square set system.

\subsection{Design Assumptions:}

Based on field visits, field measurements, and the information provided by the mine, the following design assumptions are derived and adopted in the design and evaluation:

- Minimum inside clearance of the steel set is $14 \mathrm{ft} \times 3.5 \mathrm{ft}$;

- The steel set will be spaced on $4 \mathrm{ft}$ centers, and five sets will be assembled together as a $20 \mathrm{ft}$ long unit;

- Steel sets will be assembled outby at a safe area and then pushed into the fall area;

- Dynamic resistant lagging panels will be installed on the top of the structure, and regular V-deck panels will be installed on the sides;

- Overburden strata reaches an equilibrium state after the roof fall, and disturbance due to future mining activities is negligible;

- After the steel set unit is positioned at the desired location, the runner channel will be bolted to the floor to provide adequate lateral constraint for the entire structure;

- The structure should support a maximum of $14 \mathrm{ft}$ piled dead rock; 
- The IR steel set should sustain an impact load generated by a maximum of 24 in thick rock slab falling $14 \mathrm{ft}$ from the canopy; and

- Maximum allowable mid-span deflection of the square set and/or lagging panel is 8 in.

\subsection{Recommended IR Square Set Design:}

After a few design iterations, a W8 $\times 31$ IR square set is considered appropriate. Shown in Figure 4.1 is a $2 \mathrm{D}$ drawing of the design.

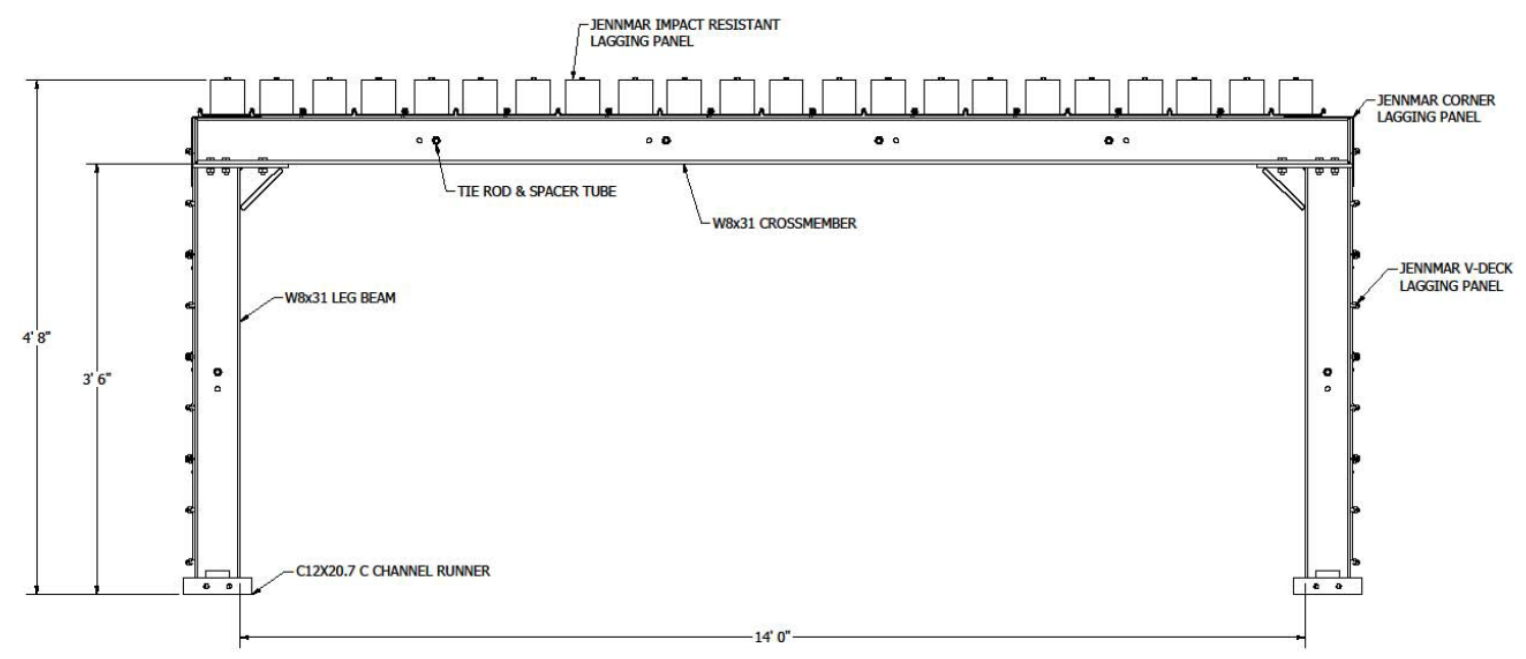

Figure 4.1 - W8 x 31 impact resistant square set (2D)

\subsection{Structural Evaluation - Static Loading:}

When overburden strata consists of thinly laminated weak rock, secondary roof falls may occur in a gradual manner and the impact load of each single rock piece is not significant. Eventually, the IR steel set may be buried underneath the fractured rock over time. In this case, it is reasonable to assume that the steel set may be subjected to static loading. Steel structure analysis following the AISC standard indicates that, the proposed square set is capable of sustaining a maximum of 52.42 tons of uniformly distributed static load, or equivalently $14.89 \mathrm{ft}$ of dead rock assuming 4' spacing and $120 \mathrm{lb} / \mathrm{ft} 3$ average 
density of fractured rock. Shown in Figures 4.2, 4.3, and 4.4 are the load, axial stress, shear stress, and moment diagrams.

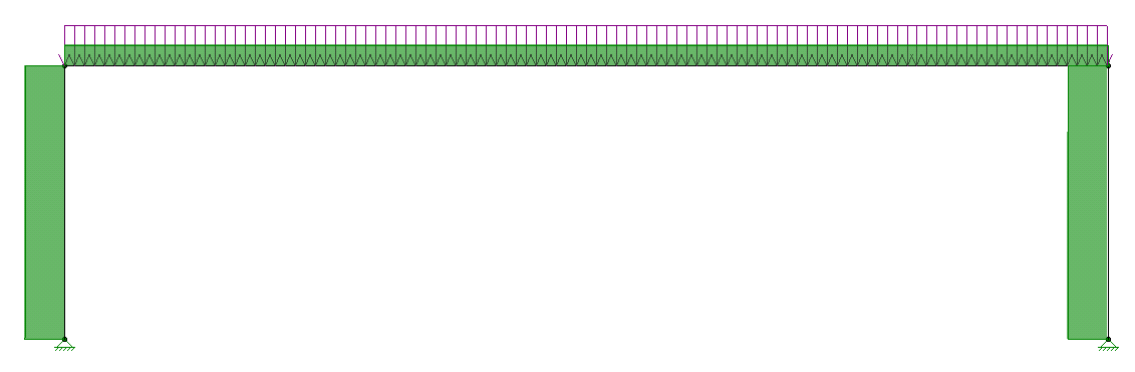

Figure 4.2 - Load and axial stress diagram

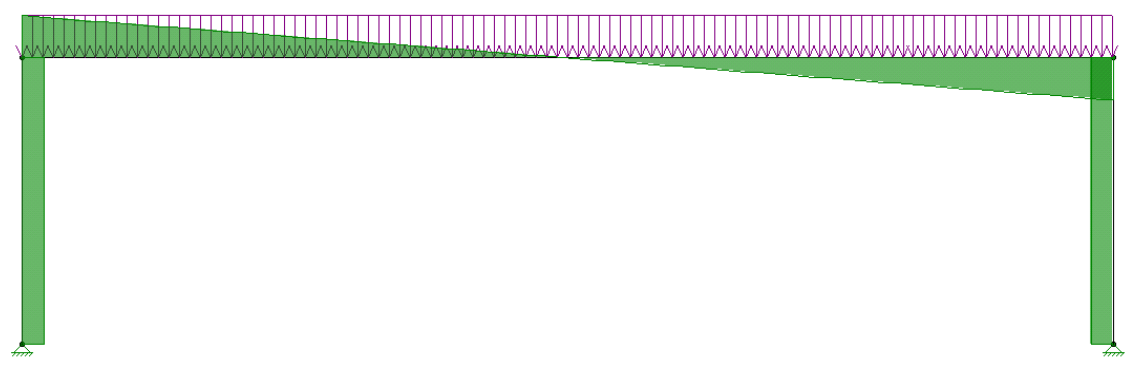

Figure 4.3 - Load and shear stress diagram

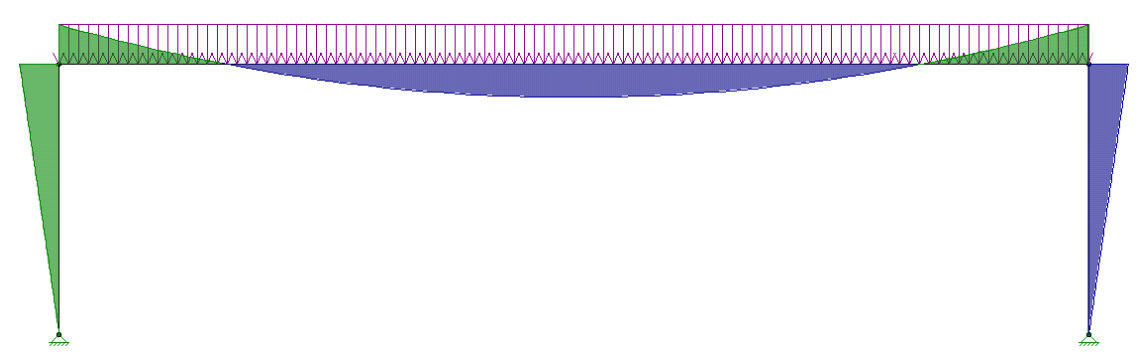

Figure 4.4 - Load and moment diagram

\subsection{Elasto-plastic Design Concept:}

In idealized elastic design, the deformation behavior of steel material is linear. This means that the force needed to deform the steel set is proportional to the beam deflection. The force increase is linear only up to the onset of yielding, which represents the limiting 
load in elastic design. However, in reality, most structural steel (A36, A992, A325, etc) exhibit a strain hardening characteristic, as shown in Figure 4.5.

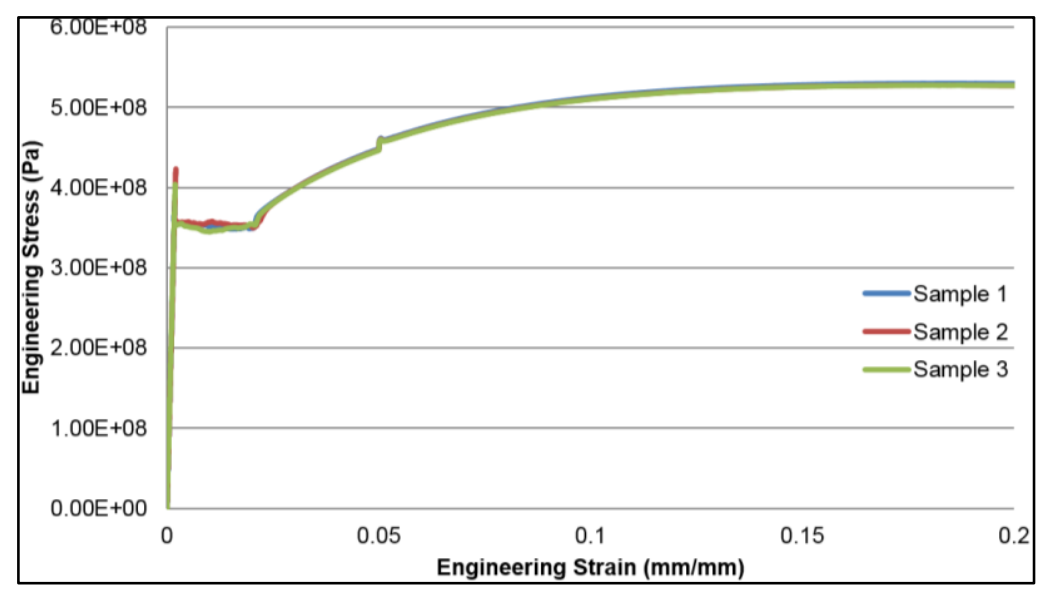

Figure 4.5 - Stress vs. strain of A36 steel

In practice, steel structural designs that are rugged enough to withstand a large impact load elastically without any material yield are costly and impracticably heavy. Plastic deformation of a steel set, due to the strain hardening property of steel and structural nonlinearity, are excellent and economical means to cushion against impact by allowing for a certain amount of material yielding and structural deformation.

To evaluate impact resistant capacity, an elasto-plastic steel analysis was conducted for the W8 $\times 31$ square set under an impact by a block with a weight (W) (mass $\mathrm{x}$ gravity) and a falling height $(\mathrm{H})$ as shown in Figure 4.6. 


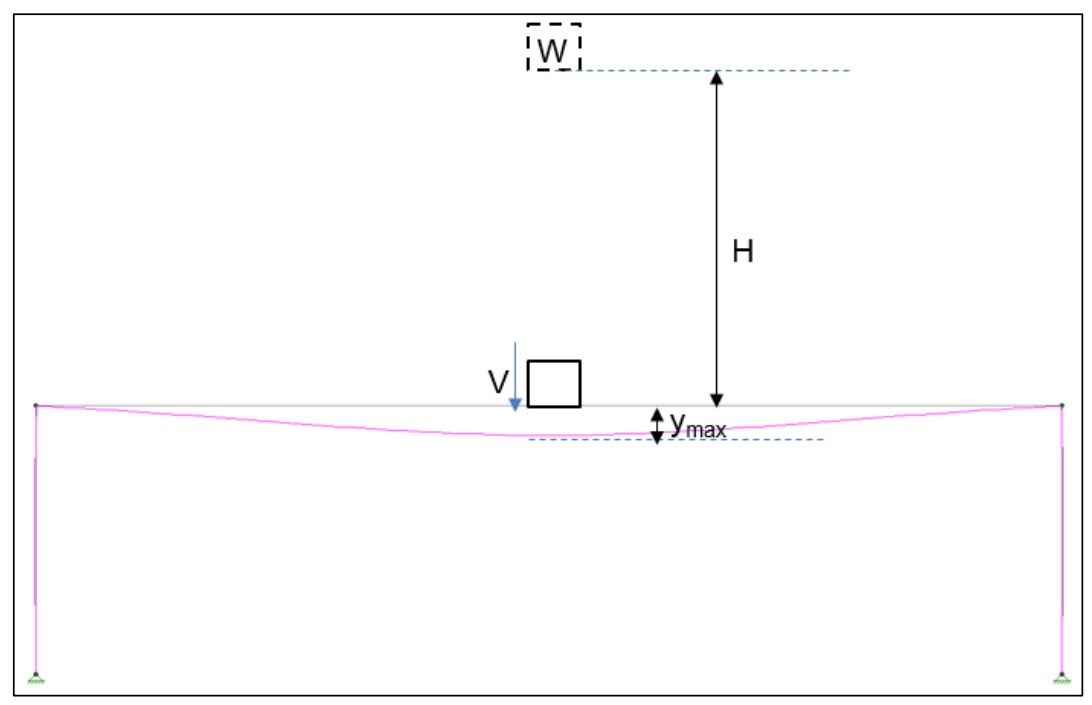

Figure 4.6 - Conceptual impact model

Prior to impacting, the block attains an initial impact speed of $\mathrm{V}$ given by Equation (4.1) and carries a kinetic energy of Ek by Equation (4.2):

$$
\begin{aligned}
& V=\sqrt{2 g H} \\
& E_{k}=W H=\frac{W V^{2}}{2 g}
\end{aligned}
$$

Shown in Figure 4.7 is an idealized elastic plastic load vs deflection behavior of the steel set under impact load. The shaded area represents the energy absorbed by a steel set structure undergoing yielding upon impact load. The deflection increases linearly up to the yield load $\mathrm{Fu}$, after which the structure deforms nonlinearly with a slight increase of additional capacity with the increase of deflection. The energy absorbed Ep is simply the area under the curve in Figure 4.7 and can be determined by Equation (4.3):

$$
E_{p}=\int_{0}^{y} F d y=F_{u} y_{\max }-\frac{F_{u} y_{u}}{2}+\frac{\left(y_{\max }-y_{u}\right)\left(F_{\max }-F_{u}\right)}{2}
$$




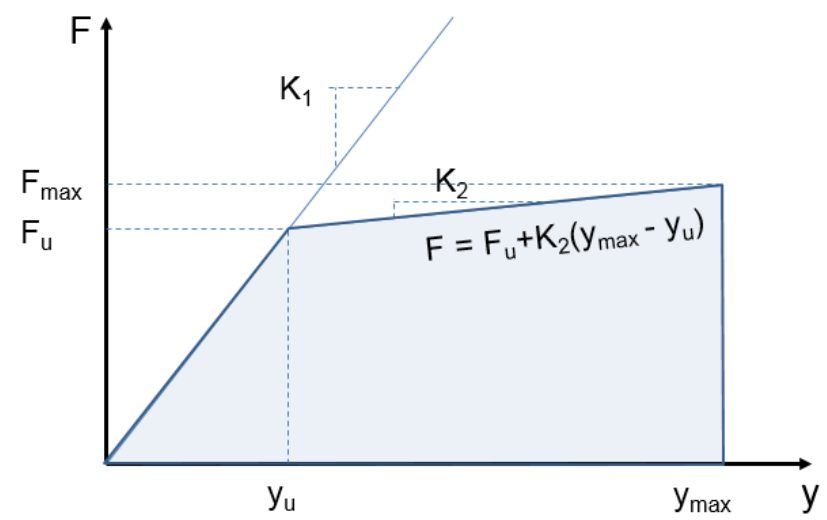

Figure 4.7 - Conceptual load vs. deflection curve

Based on the Law of Conservation of Energy, the energy to be absorbed, including the incoming kinetic energy and additional work done by the weight $W$, equates the work of elastic and plastic deflection, as described by Equation (4.4):

$W H+W y_{\max }=F_{u} y_{\max }-\frac{F_{u} y_{u}}{2}+\frac{\left(y_{\max }-y_{u}\right)^{2} K_{2}}{2}$

Solving for weight $\mathrm{W}$ from Equation (4.4) gives Equation (4.5):

$$
W=\frac{F_{u} y_{\max }-\frac{F_{u} y_{u}}{2}+\frac{\left(y_{\max }-y_{u}\right)^{2} K_{2}}{2}}{12 H+y_{\max }} \times 1000
$$

Where: W - weight of falling rock, $\mathrm{lb}$,

$\mathrm{H} \quad$ - falling height, $\mathrm{ft}$,

$F_{u} \quad$ - yield load, kips,

yu - deflection upon yield load, in,

$y_{\max } \quad$ - maximum allowable deflection, in, and

$\mathrm{K}_{2}$ - equivalent post-yield stiffness of steel set, kips/in.

From a design perspective, the weight of a falling block $\mathrm{W}$, falling at height $\mathrm{H}$, with a maximum allowable mid-span deflection $y \max$, can be estimated using equation (4.5) if 
the yield load $F_{u}$, yield deflection $\mathrm{yu}$, and equivalent post-yield stiffness $\mathrm{K}_{2}$ can be determined through either laboratory testing or numerical modeling.

\subsection{Elasto-plastic FE Analysis:}

In this evaluation, a 3D elasto-plastic finite element analysis was conducted to determine the parameters $F_{u}$, yu, and $\mathrm{K}_{2}$. The W8 $\times 31$ square set (Figure 4.8) was virtually tested and numerically analyzed to assess the yielding and deformation and to determine the relationship between mid-span deflection and the load applied. Listed in Table 4.1 are the material properties of the steel members used in the model. The stress-strain relationship for steel members was modeled using a multi-linear strain hardening constitutive model similar to the curve shown in Figure 4.5.

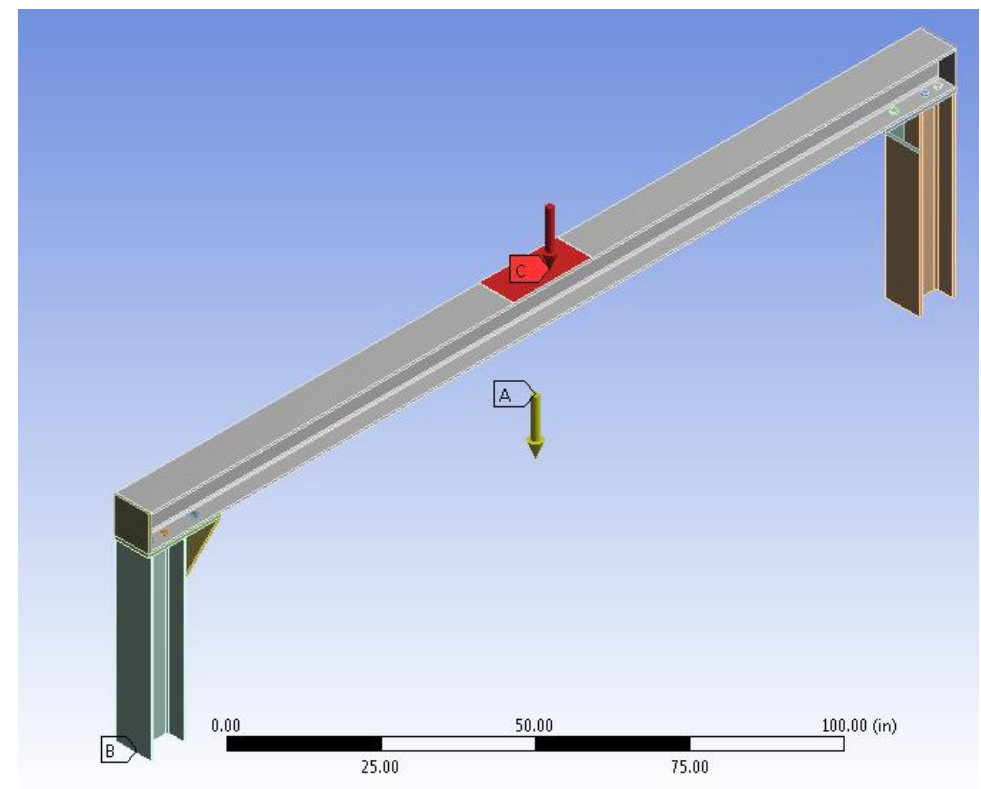

Figure 4.8 - Numerical model of W8 x 31 square set 
Table 4.1 Material properties of steel members

\begin{tabular}{|c|c|c|c|c|}
\hline $\begin{array}{c}\text { Steel } \\
\text { Type }\end{array}$ & $\begin{array}{c}\text { Young's } \\
\text { Modulus, } \\
\text { psi }\end{array}$ & $\begin{array}{c}\text { Poisson's } \\
\text { Ratio }\end{array}$ & $\begin{array}{c}\text { Yield } \\
\text { Strength, } \\
\text { psi }\end{array}$ & $\begin{array}{c}\text { Ultimate } \\
\text { Strength, } \\
\text { psi }\end{array}$ \\
\hline A36 & $2.90 \mathrm{E}+07$ & 0.3 & 36259 & 66717 \\
\hline A992 & $2.90 \mathrm{E}+07$ & 0.3 & 50000 & 75000 \\
\hline A325 & $2.90 \mathrm{E}+07$ & 0.3 & 92000 & 120000 \\
\hline
\end{tabular}

An isotropic strain hardening rule with Von Mises yield criteria was applied for simulating non-linear behavior of the steel member after yielding. Shown in Figure 4.9 is the equivalent stress (Von-Mises) distribution of the deflected W8 $\times 31$ square set due to localized impact load at mid-span.

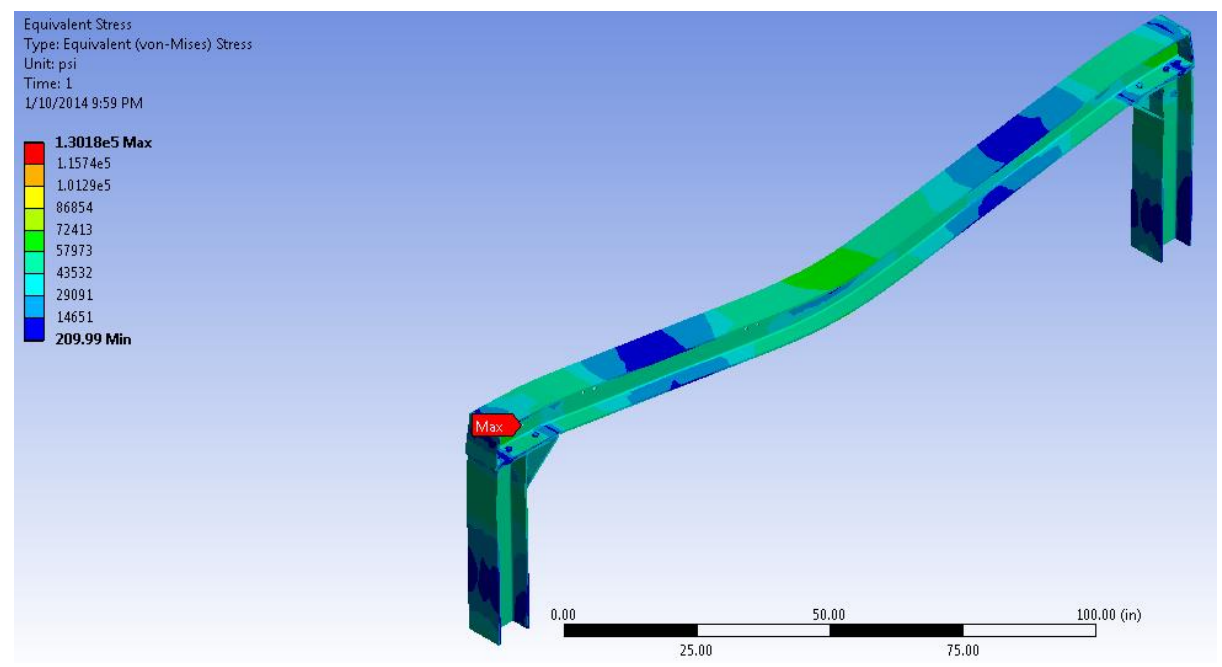

Figure 4.9 - Equivalent stress distribution

By increasing load F gradually, a load vs. mid-span deflection curve (Figure 4.10) was established based on the results derived from the elasto-plastic nonlinear FE model. From the curve, the equivalent stiffness of the square set prior to and after yielding were calculated as $K_{1}=93.87 \mathrm{kips} / \mathrm{in}$ and $\mathrm{K}_{2}=2.14 \mathrm{kips} / \mathrm{in}$. The square set starts to exhibit 
plastic yielding and deformation when the load exceeds $F_{u}=87.82$ kips and the mid-span deflection is greater than $\mathrm{y}_{\mathrm{u}}=0.968$ ".

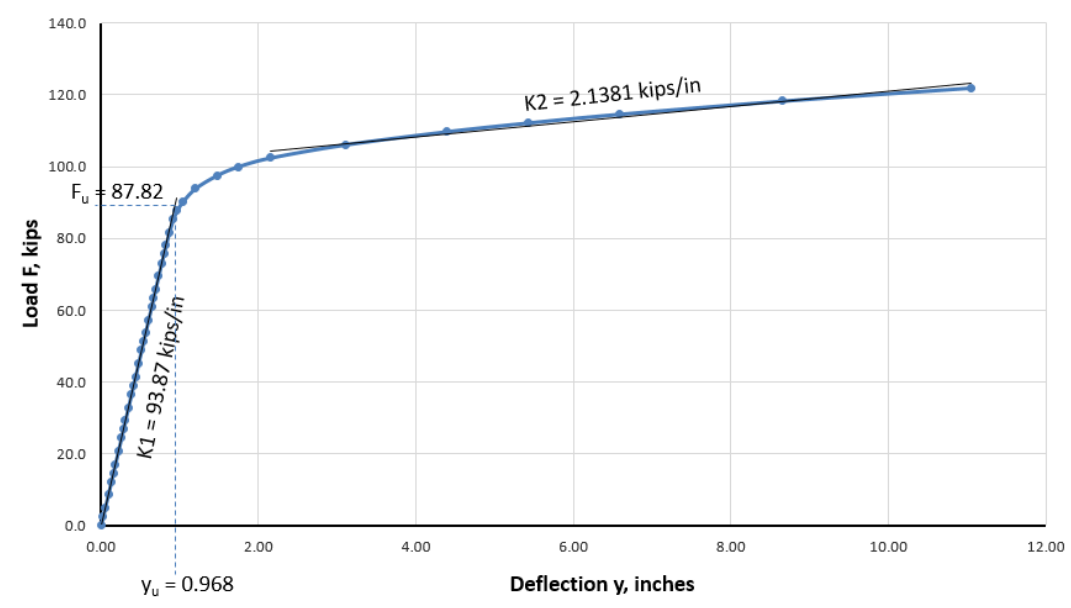

Figure 4.10 - Load vs. deflection of W8 $\times 31$ square set

\subsection{Maximum Allowable Impact Weight:}

With the aforementioned value of the variables $F_{u}, \mathrm{yu}_{\mathrm{u}}$, and $\mathrm{K}_{2}$, and the 8 inches of maximum allowable mid-span deflection per the field data, the maximum allowable weight of the falling rock for a given falling height is determined using Equation (4.5). Listed in Table 4.2 are maximum weights of falling rock for various possible falling heights that the W8 $\times 31$ square set can sustain with a maximum of 8 inches plastic deflection at mid-span. 
Table 4.2 - Allowable falling rock weight of the W8 $\times 31$ steel set

\begin{tabular}{|c|c|}
\hline $\begin{array}{c}\text { Fall } \\
\text { height, } \mathrm{H}, \\
\mathrm{ft}\end{array}$ & $\begin{array}{c}\text { Fall } \\
\text { weight, lb }\end{array}$ \\
\hline 2 & $22,278.9$ \\
\hline 4 & $12,730.8$ \\
\hline 5.25 & $10,041.2$ \\
\hline 6 & $8,911.5$ \\
\hline 8 & $6,855.0$ \\
\hline 10 & $5,569.7$ \\
\hline 12 & $4,690.3$ \\
\hline 14 & $4,050.7$ \\
\hline 16 & $3,564.6$ \\
\hline 18 & $3,182.7$ \\
\hline 20 & $2,874.7$ \\
\hline 22 & $2,621.0$ \\
\hline 24 & $2,408.5$ \\
\hline 26 & $2,227.9$ \\
\hline 28 & $2,072.5$ \\
\hline 30 & $1,937.3$ \\
\hline & \\
\hline
\end{tabular}

\subsection{Validation - Dynamic Impact Simulation:}

To validate the elasto-plastic analysis results of the design, a full-scale 3D nonlinear dynamic impact model was developed to evaluate the performance of the structure under a worst case impact loading condition.

A weight block (1,937.3 lb) impacts the cross beam at mid-span with an initial speed of $43.93 \mathrm{ft} / \mathrm{s}$ which is equivalent to a $30 \mathrm{ft}$ falling height. Figure 4.11 shows the Von-Mises stress distribution of the steel set at $t=0.0099$ second after initial impact contact. Figure 
4.12 shows energy variation vs time. Analysis indicates that the kinetic energy carried by the weight block was absorbed as internal energy through cross beam deflection and deformation of the structure. The mid-span deflection of the cross member is approximately 8.25 inches (Figure 4.13) after the weight block becomes stationary. The results match well with the elasto-plastic analysis results, and it is concluded that the W8 $\times 31$ square set meets design requirements.

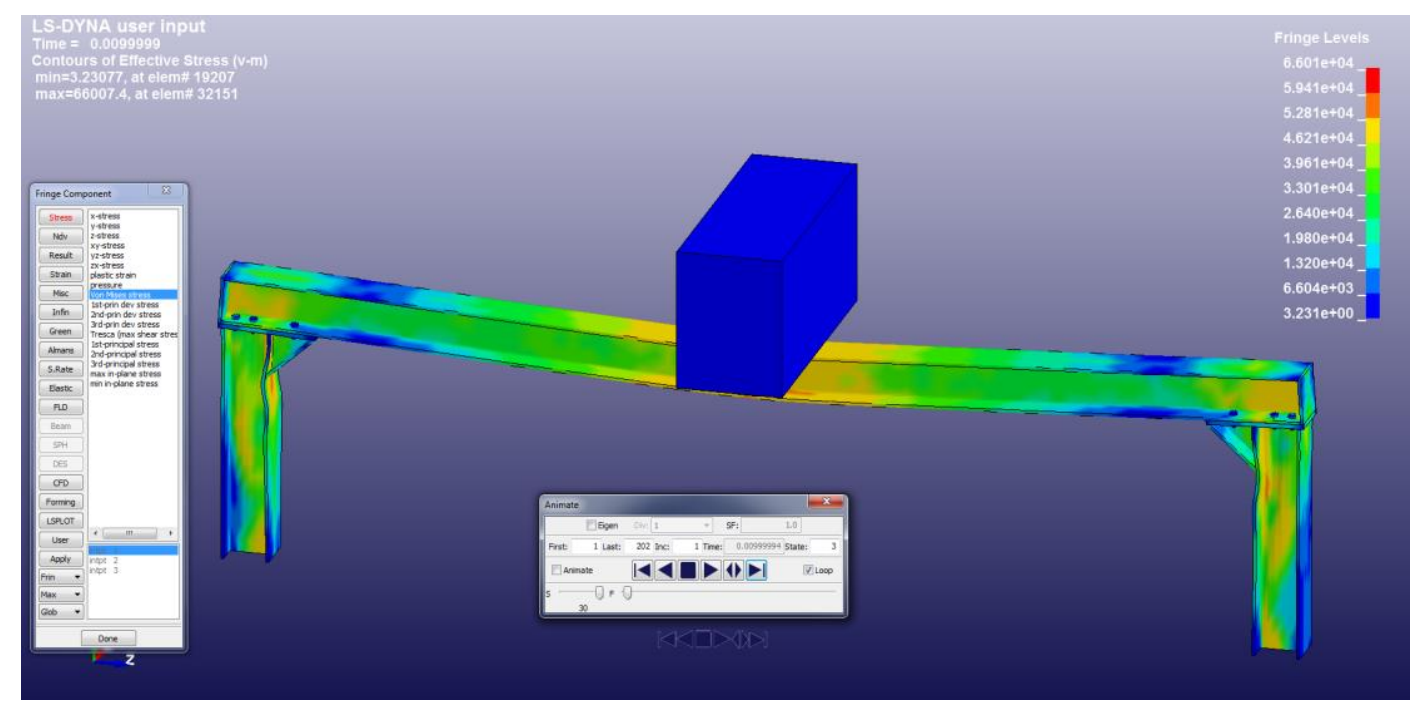

Figure 4.11 - Von-Mises stress distribution upon impact

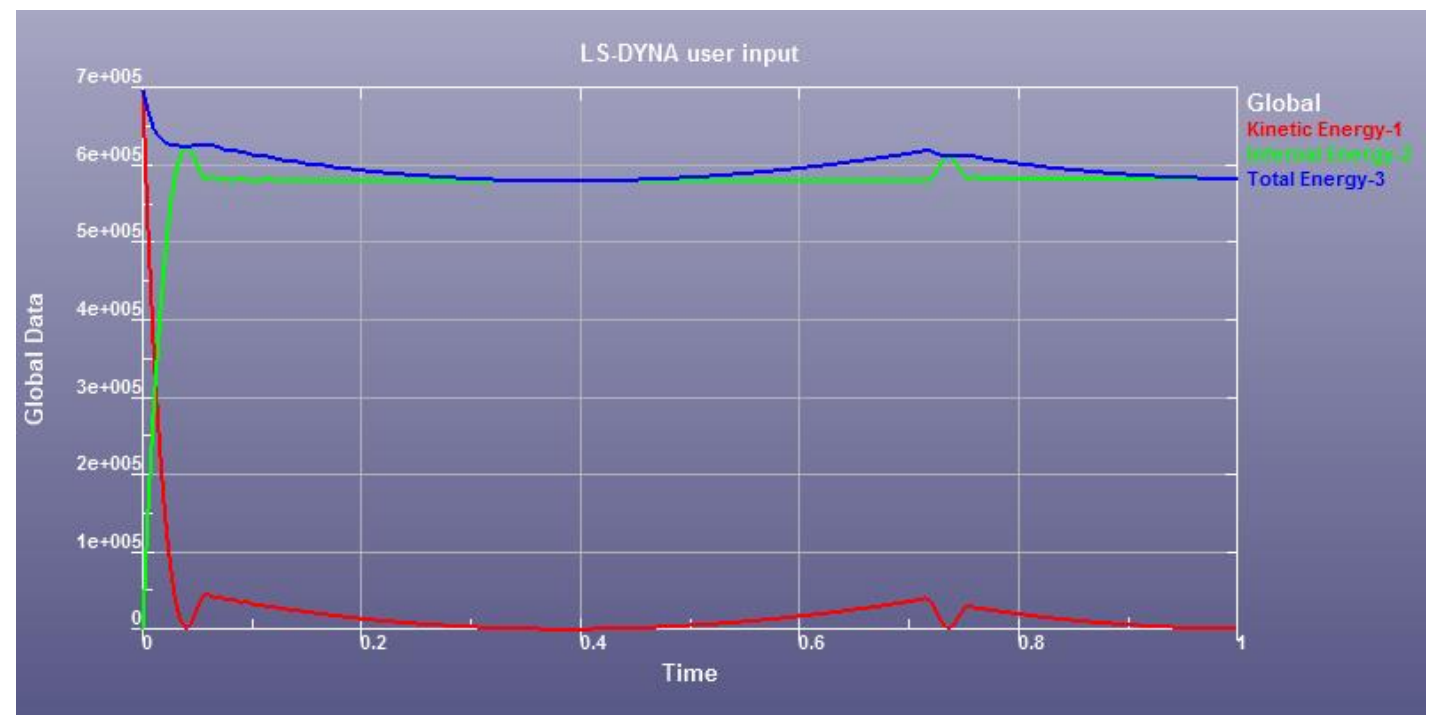

Figure 4.12 - Energy vs time 


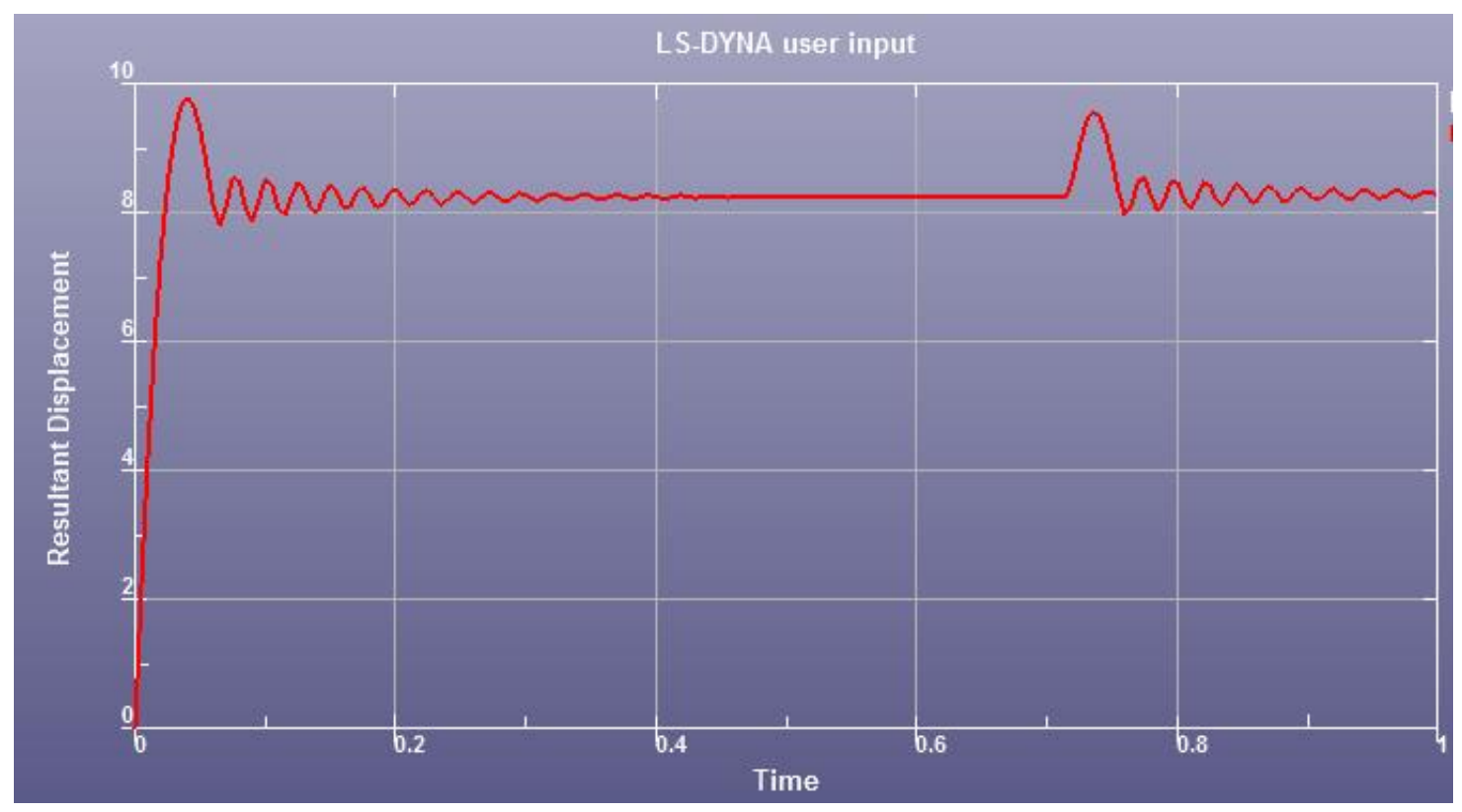

Figure 4.13 - Mid-span deflection vs time

\subsection{IR Capacity of Entire System:}

As an entire system, the IR steel set consists of two major components: steel set and IR lagging. The capacity of the system to sustain an impact load is contingent upon the location where the rock impacts.

For a steel set, a localized impact loading at mid-span (Figure 4.14) represents the worst case loading condition. Considering the fact that the impact load will be distributed to the steel beam through the 18 inches wide IR lagging panel, the rock slab thickness is evaluated on a unit basis (18 inches wide). Impact load by a rock slab that is greater than 18 inches wide is assumed to be shared by adjacent lagging panels. 


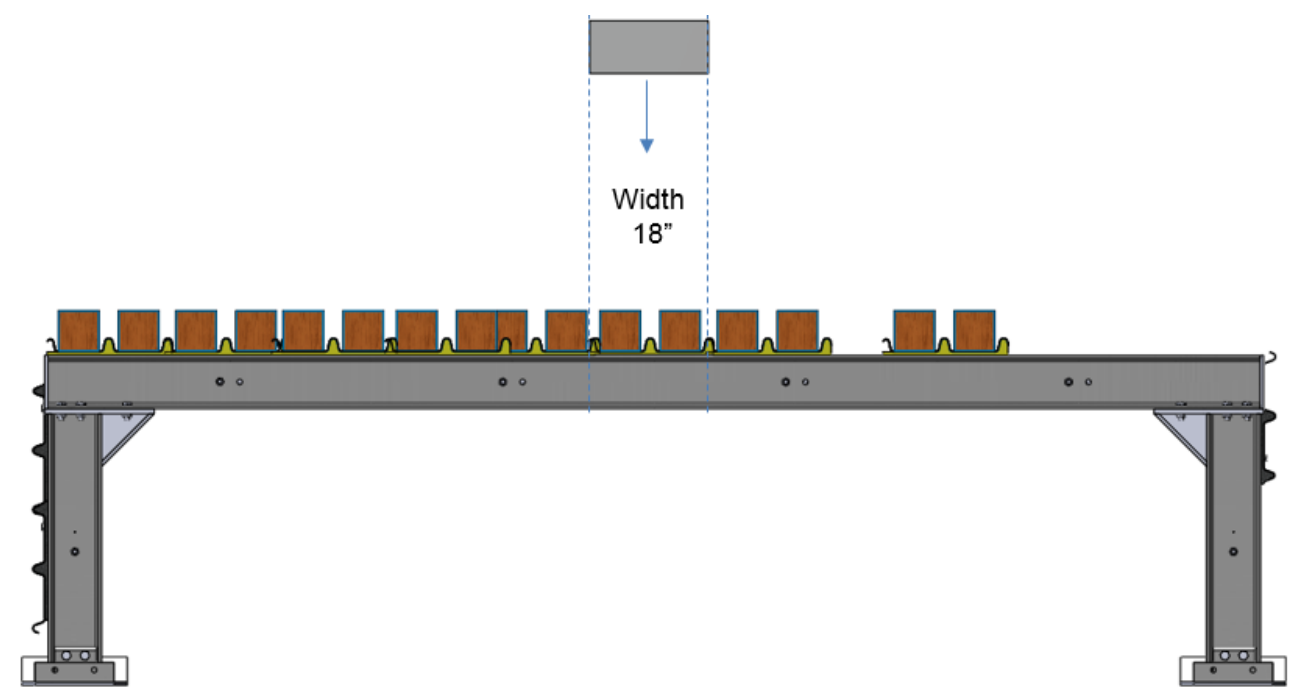

Figure 4.14 - Worst impact loading condition on steel set

Along the entry axial direction, there are two possible impact cases depending on the location of the falling rock with respect to the steel beam and lagging panel.

\subsubsection{Rock fall above the steel beam:}

The majority of the impact load will be undertaken and absorbed by the steel set if the impact contact point and center of gravity of a falling rock slab are above and through the cross beam of the steel set (Figure 4.15). If the rock slab is long, it may span over multiple steel cross beams. It is reasonable to assume that impact load by a rock slab longer than the steel set spacing will be shared by adjacent steel cross beams. With this assumption, the maximum allowable thickness of the falling rock slab that each steel set can sustain is estimated on a unit basis ( $4 \mathrm{ft}$ long or set spacing $\times 18$ in wide) using the maximum weight values in Table 4.2. Listed in third column of Table 4.3 are maximum rock slab thicknesses that each W8 $\times 31$ square set can sustain for different falling heights. 


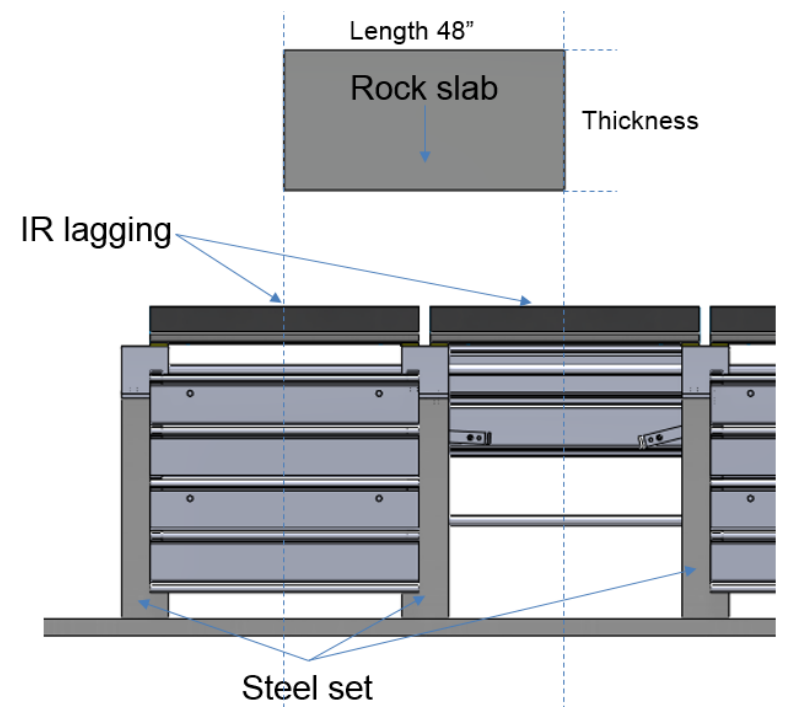

Figure 4.15 - Impact above steel set

\subsubsection{Rock fall above the IR lagging:}

If the contact point and center of gravity of a falling rock slab are above and through the mid-span of the IR lagging (Figure 4.16), part of the rock fall kinetic energy will be absorbed by the IR lagging by means of SLB yielding, deformation of the cushion pad, and plastic deflection of the V-deck. Similarly, the maximum allowable thickness as listed in column 2 of the Table 4.3 of the falling rock slab that each IR lagging can sustain is estimated on a unit basis (12 inches long $x 18$ inches wide) using the maximum values in Table 2.2. 


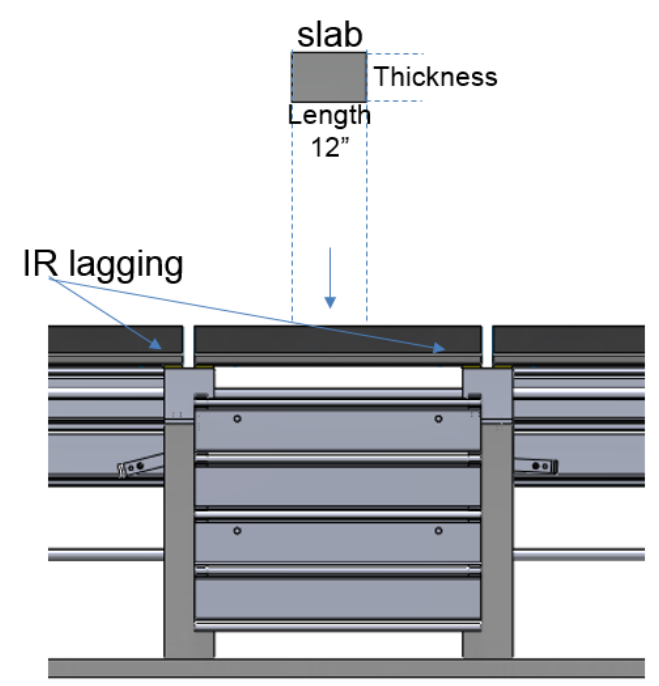

Figure 4.16 - Impact at mid-span of IR lagging

\subsection{Applicable roof fall scenarios:}

Listed in Table 4.3 are maximum allowable thicknesses of falling rock slab for different falling heights. Each combination represents a roof fall scenario that the IR steel set can sustain and absorb the impact kinetic energy by means of a possible 6 inches midspan deflection on the IR lagging and/or an 8 inches mid-span deflection on the W8 $\times 31$ square set cross member. 
Table 4.3 - Maximum allowable thickness of falling rock slab

\begin{tabular}{|c|c|c|}
\hline \multirow{2}{*}{ Fall Height, $\mathrm{ft}$} & \multicolumn{2}{|c|}{ Maximum allowable rock slab thickness, $\mathrm{ft}$} \\
\hline & If fall on IR lagging ${ }^{1}$ & If fall on cross beam ${ }^{2}$ \\
\hline 2 & 16.9 & 23.2 \\
\hline 4 & 8.4 & 13.3 \\
\hline 5.25 & 6.4 & 10.5 \\
\hline 6 & 5.6 & 9.3 \\
\hline 8 & 4.2 & 7.1 \\
\hline 10 & 3.4 & 5.8 \\
\hline 12 & 2.8 & 4.9 \\
\hline 14 & 2.4 & 4.2 \\
\hline 16 & 2.1 & 3.7 \\
\hline 18 & 1.9 & 3.3 \\
\hline 20 & 1.7 & 3.0 \\
\hline 22 & 1.5 & 2.7 \\
\hline 24 & 1.4 & 2.5 \\
\hline 26 & 1.3 & 2.3 \\
\hline 28 & 1.2 & 2.2 \\
\hline 30 & 1.1 & 2.0 \\
\hline \multicolumn{3}{|c|}{$\begin{array}{l}\text { Note: } \\
\text { 1. Estimated on a unit basis ( } 12 \text { " long x } 18 \text { " wide) based on actual } \\
\text { drop test results. } \\
\text { 2. Determined on a unit basis ( } 48 \text { " long x } 18 \text { " wide) based on elasto- } \\
\text { plastic structural analysis results of a W } 8 \text { x } 31 \text { square set. }\end{array}$} \\
\hline
\end{tabular}




\section{CHAPTER 5: CASE STUDY ONE}

A mining company in the Appalachian region experienced a large roof fall in the mains in early April, 2009. MSHA shut down the mining section and requested that the operator rehabilitate the fall area before any coal production could be resumed. To quickly and safely rehabilitate the entry and to protect moving vehicles and personnel from falling rock, the mine decided to install the IR steel-sets in the fall area.

\subsection{Geo-Technical Conditions:}

Coal is extracted from the Upper Freeport seam by room-and-pillar mining method. The mining height is 55 in (1.4 m) and entry width is $20 \mathrm{ft}(6 \mathrm{~m})$. Overburden at the roof fall area is approximately $700 \mathrm{ft}(213 \mathrm{~m})$. Figure 5.1 shows the location of the roof fall area, which is approximately $120 \mathrm{ft}(36.6 \mathrm{~m})$ long in the \# 3 main entry and $60 \mathrm{ft}(18.3 \mathrm{~m})$ across at the angled crosscut. Based on the underground examination, it was found that the immediate roof consists of $4.5 \mathrm{ft}(1.4 \mathrm{~m})$ thick, thinly laminated black shale that is interbedded with thin pyrite coal streaks at an intervals ranging from 3 to 8 in $(7.6-20 \mathrm{~cm})$. Above the immediate roof is 5-6 ft (1.5-1.8 $\mathrm{m})$ thick layered dark gray shale/sandy shale and massive competent sandstone. Figures 5.2 and 5.3 show the overburden exposed at the adjacent roof fall area and caved entry. The mine was using a $48 "(1.2 \mathrm{~m}) \times \# 5$, grade 60 , fully-grouted, non-tensioned rebar as primary support and 10-12 ft (3-3.65 m) x 0.6 in (15 mm), grade 270 , non-tensioned cable bolts as supplemental support. From the field examination, it appears that the roof fall is due to a localized problem caused by a change in geology and inadequate roof support. 


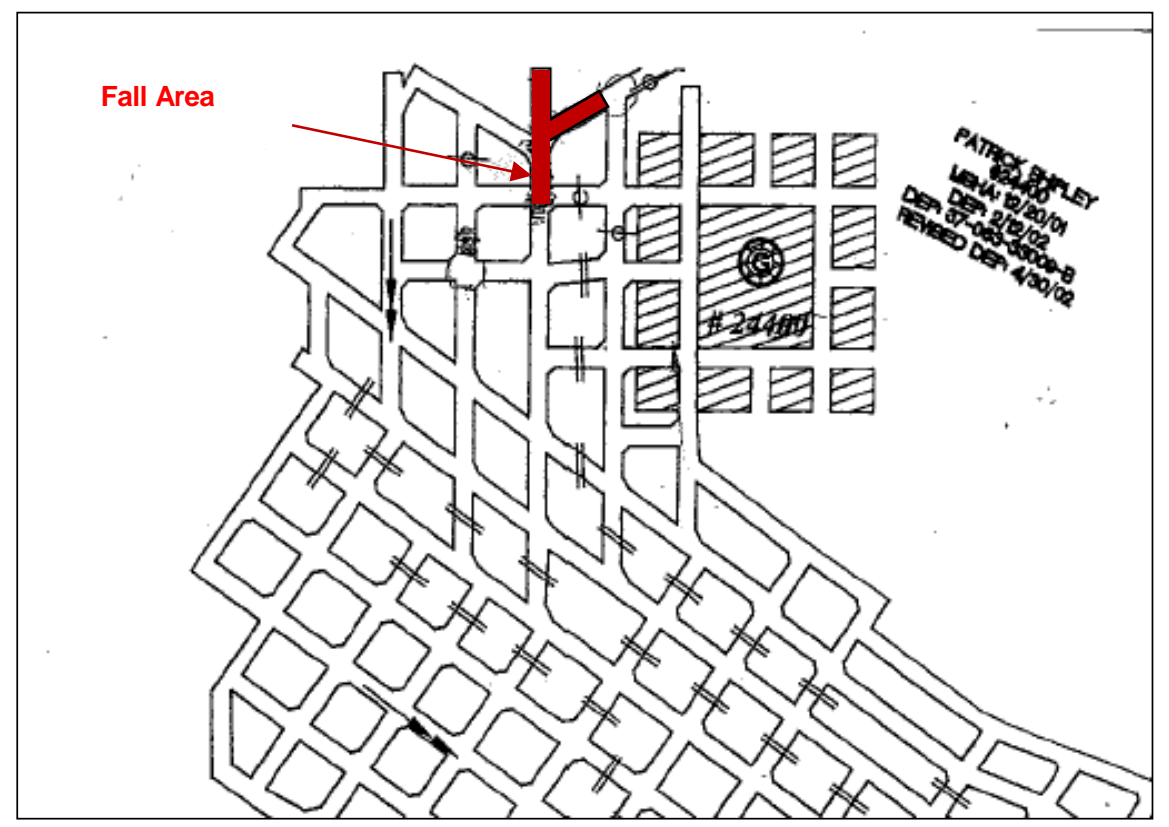

Figure 5.1. Roof fall location

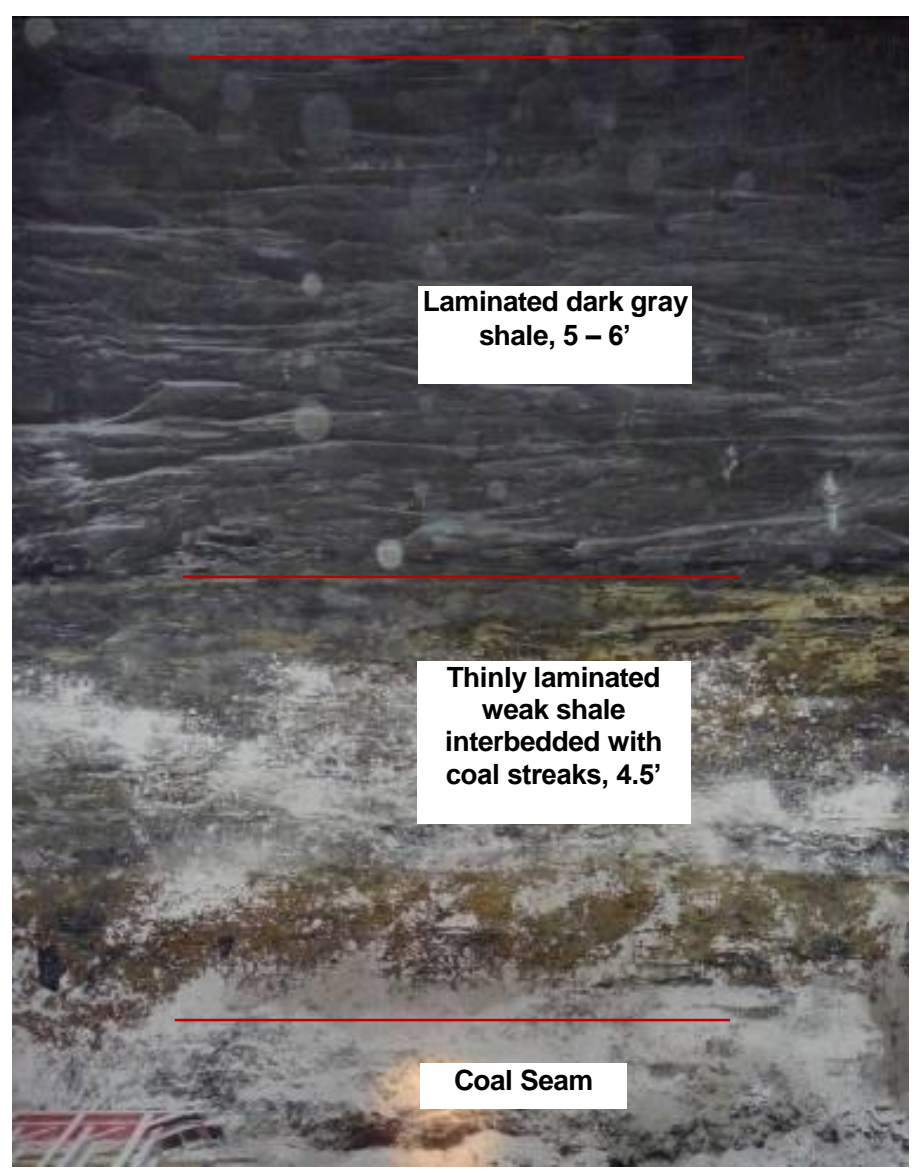

Figure 5.2. Exposed roof cross section 


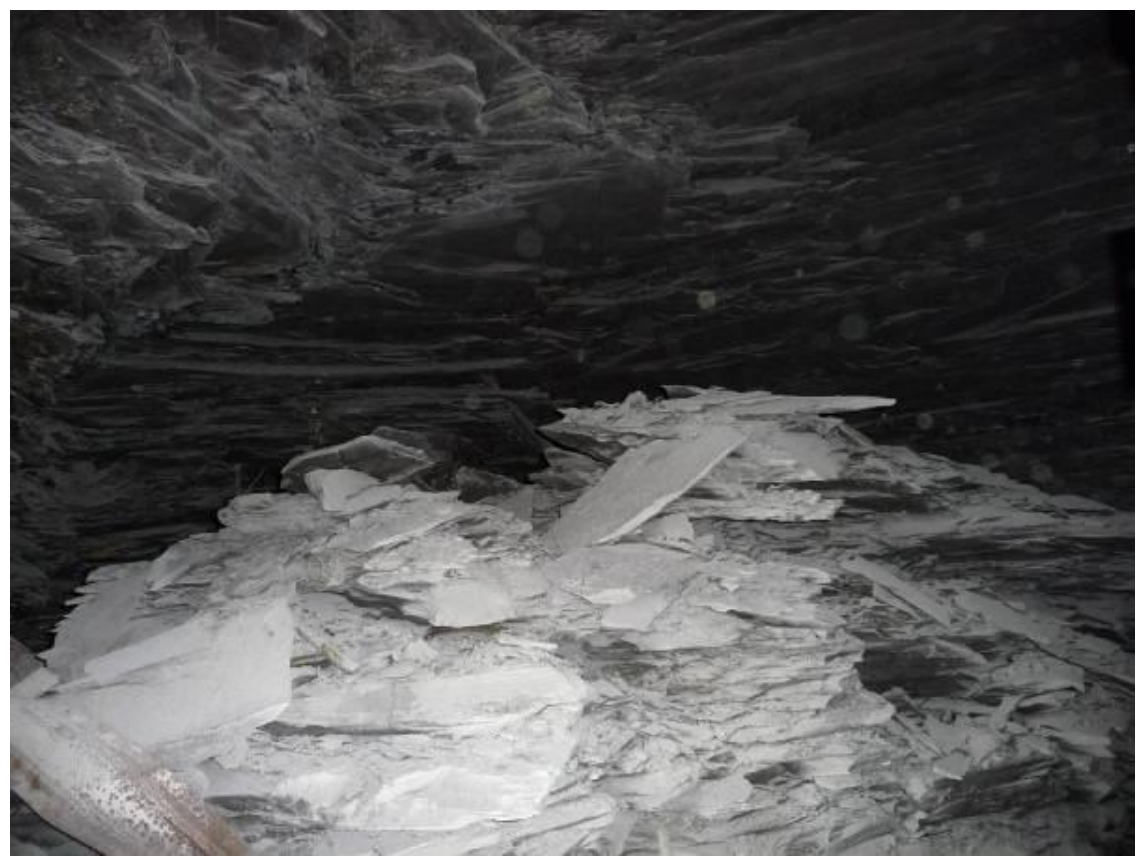

Figure 5.3. Caved roof

\subsection{Rehabilitation Plan:}

Field evaluation indicated that the strata in the caved area already reached a stable condition, and the exposed strata was mostly thinly laminated weak shale or dark gray shale, and falling rock pieces were fairly small $\left(<2 \mathrm{ft}^{3}\right)$. After the site visit and field evaluation, a rehabilitation plan was developed and proposed using a W8 $\times 31$ IR arch set (Figure 5.4). Upon MSHA's approval, the mine installed the IR arch set at both roof fall areas. To accommodate the continuous miner, the steel set had a minimum inside clearance of $16 \mathrm{ft} \times 5 \mathrm{ft}$. In addition, the structure was designed to sustain possible impact loads generated by rock pieces falling from $16 \mathrm{ft}$ high. During the rehabilitation process, the $20 \mathrm{ft}$ long IR arch canopy set was first assembled outby in an adjacent safe area. The set was then gradually moved to the roof fall areas using the continuous miner while the rock debris was removed by the $\mathrm{CM}$ and shuttle cars.

The sets were successfully installed in the two roof fall areas in April, 2009 without any accidents or injuries. According to a follow up visit with the mine, the impact-resistant steel-sets performed very well, and no problems have been reported to date. 


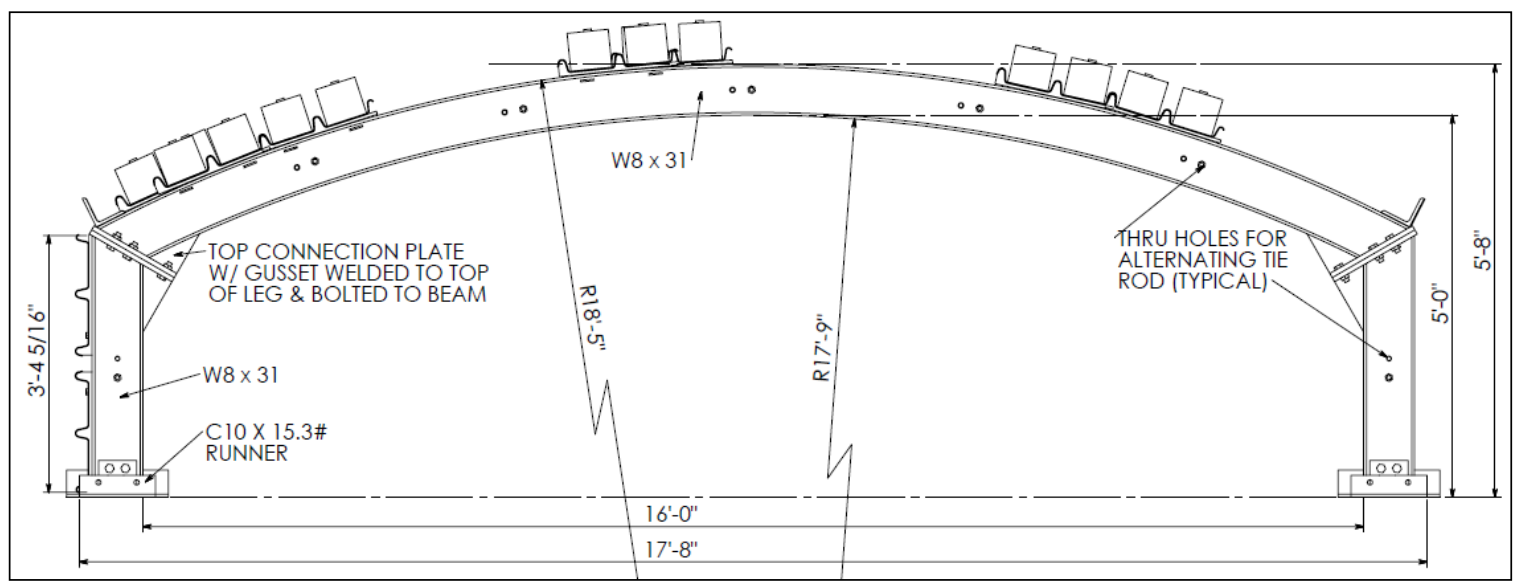

Figure $5.4-\mathrm{W} 8 \times 31 \mathrm{IR}$ arch set

\subsection{Structural Analysis of the W8 $\times 31$ IR Arch Set:}

To reduce the weight of the structure while maintaining a higher support capacity, mine management decided to use a long radius impact-resistant arch set in lieu of a square set. Structural analysis following the AISC national standard indicated that a three-piece, W8 $\times 31$ (W200 x 46) long radius arch set will meet the design requirements. Figure 5.5 shows a three-dimensional view of the same design as a five-set unit.

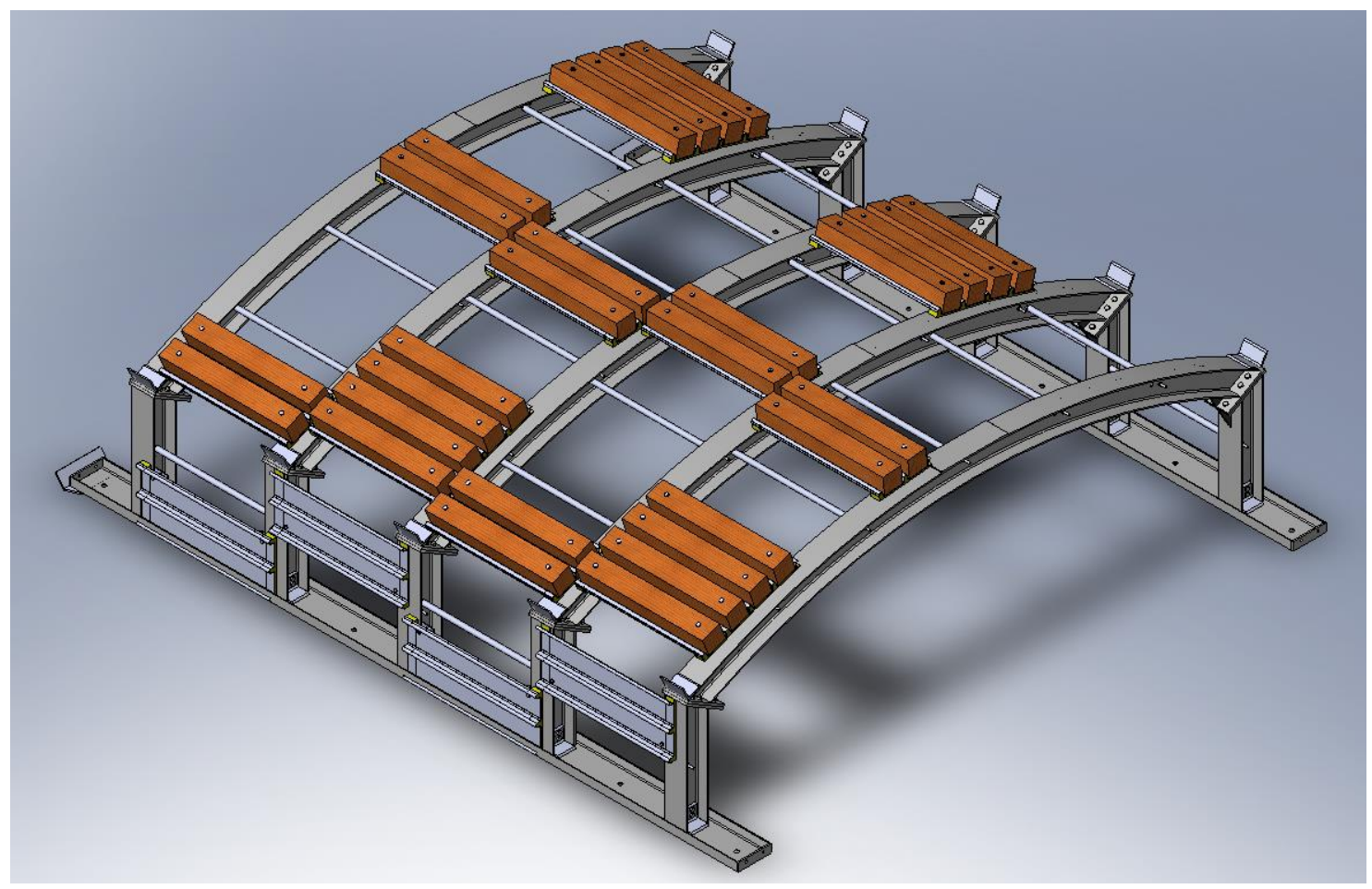

Figure 5.5. 3D view of the five-set unit 


\subsubsection{Structural Analyses - Static Uniform Load:}

Structural analysis following the AISC standard indicates that the proposed long radius arch set can support a maximum of 58.7 tons of static load, or equivalently $11.1 \mathrm{ft}$ of dead rock load (assuming a rock density of $160 \mathrm{lb} / \mathrm{ft}^{3}$ and $4 \mathrm{ft} \mathrm{set} \mathrm{spacing).}$

Figure 5.6 shows the loading and axial stress diagrams. Figure 5.7 shows the shear stress and bending moment diagram.

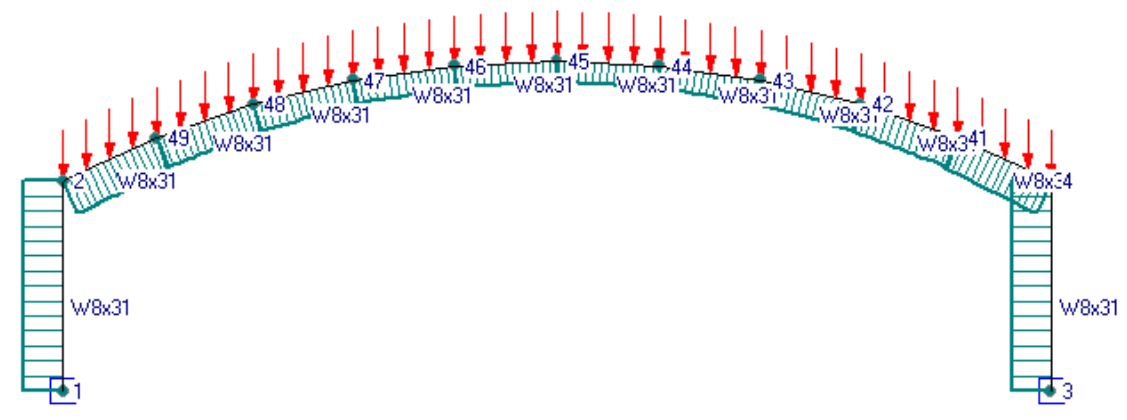

Figure 5.6 - Load and axial diagram

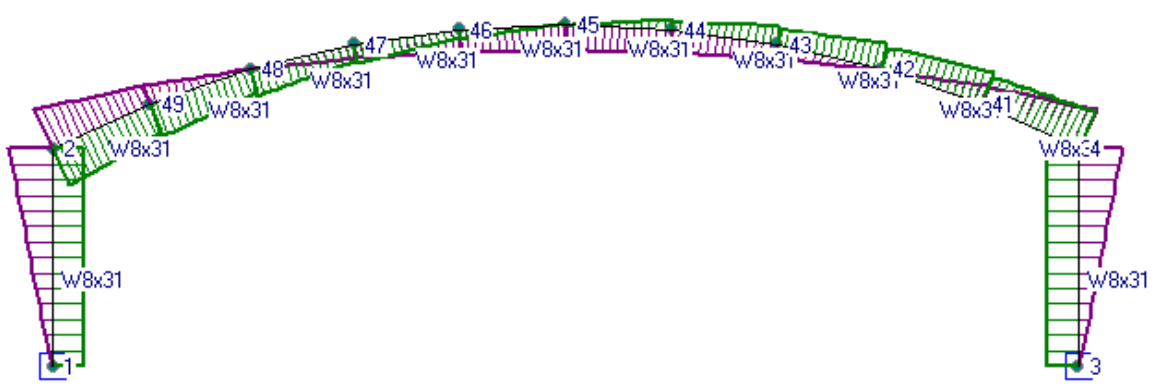

Figure 5.7 - Shear and moment diagram

\subsubsection{Structural Analyses - Dynamic Impact Load:}

The proposed long radius arch can sustain a maximum of 31.9 tons (28.9 tonnes) localized dynamic load at mid-span. Figures $5.8-5.10$ present the axial, shear, and moment diagrams. 


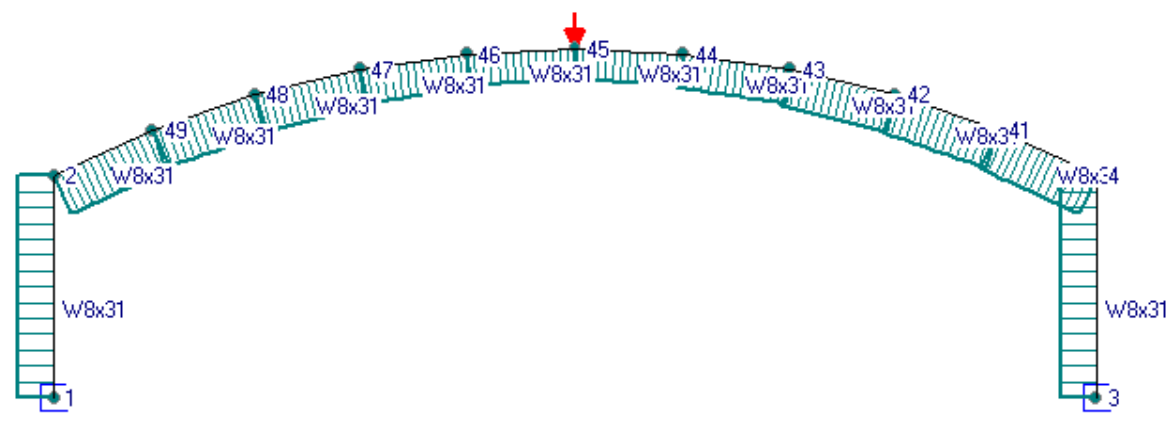

Figure 5.8 - Axial stress diagram

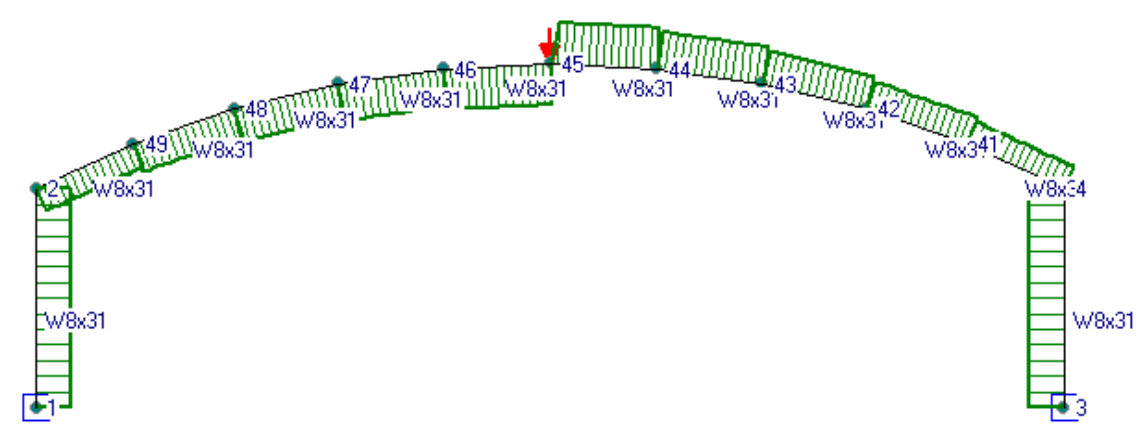

Figure 5.9 - Shear stress diagram

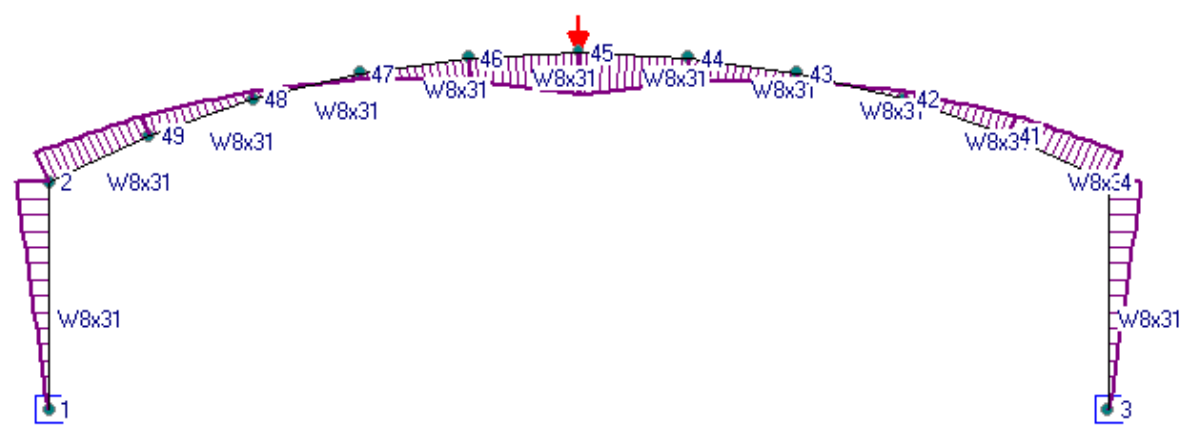

Figure 5.10 - Bending moment diagram

\subsection{Numerical Validations:}

A three-dimensional finite element computer model was developed to evaluate the long radius arch set under 58.7 tons (53.25 tonnes) of uniform rock load. The safety factor distribution shown in Figure 5.11 indicates that the designed structure has the expected static support capacity. With 31.9 tons (28.9 tonnes) of localized dynamic impact load, the model (Figure 5.12) shows slight material yielding (red color code) at the immediate impact 
surface on the cross-member. Since the yielding only occurs on the beam surface, it can be concluded that the structure has the expected impact load support capacity.

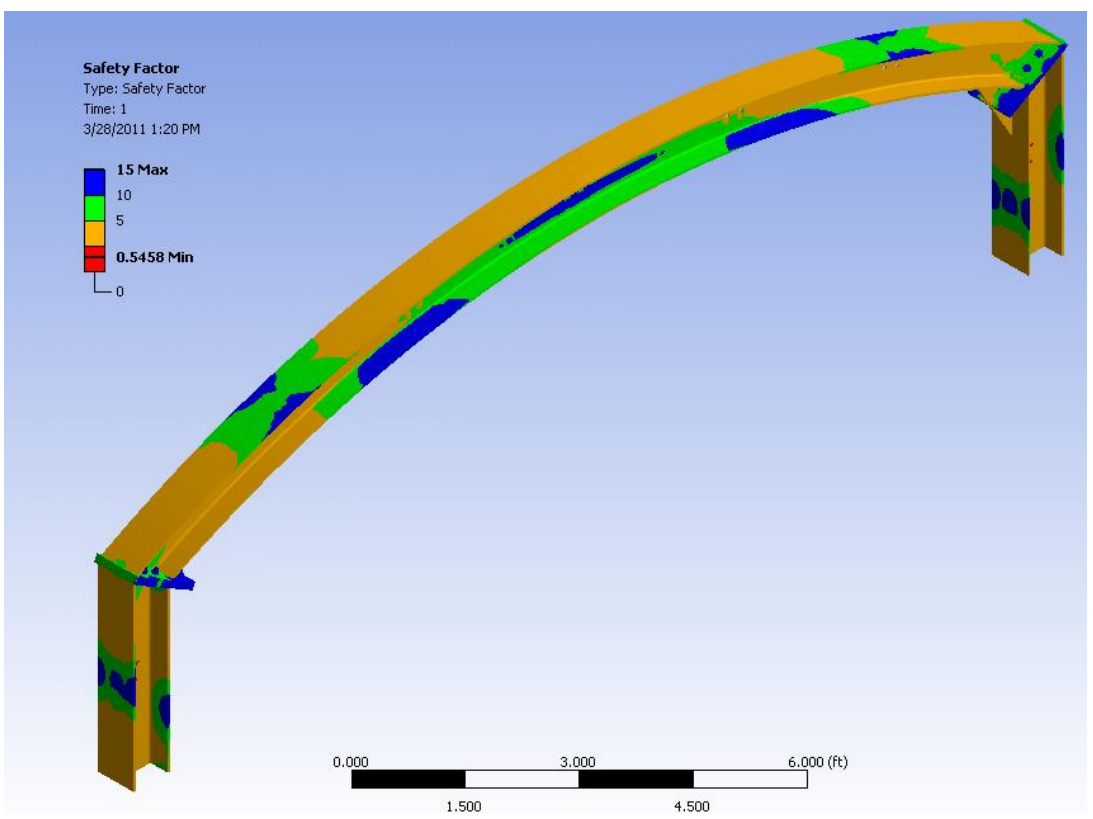

Figure 5.11 - Safety factor distribution (static uniform load)

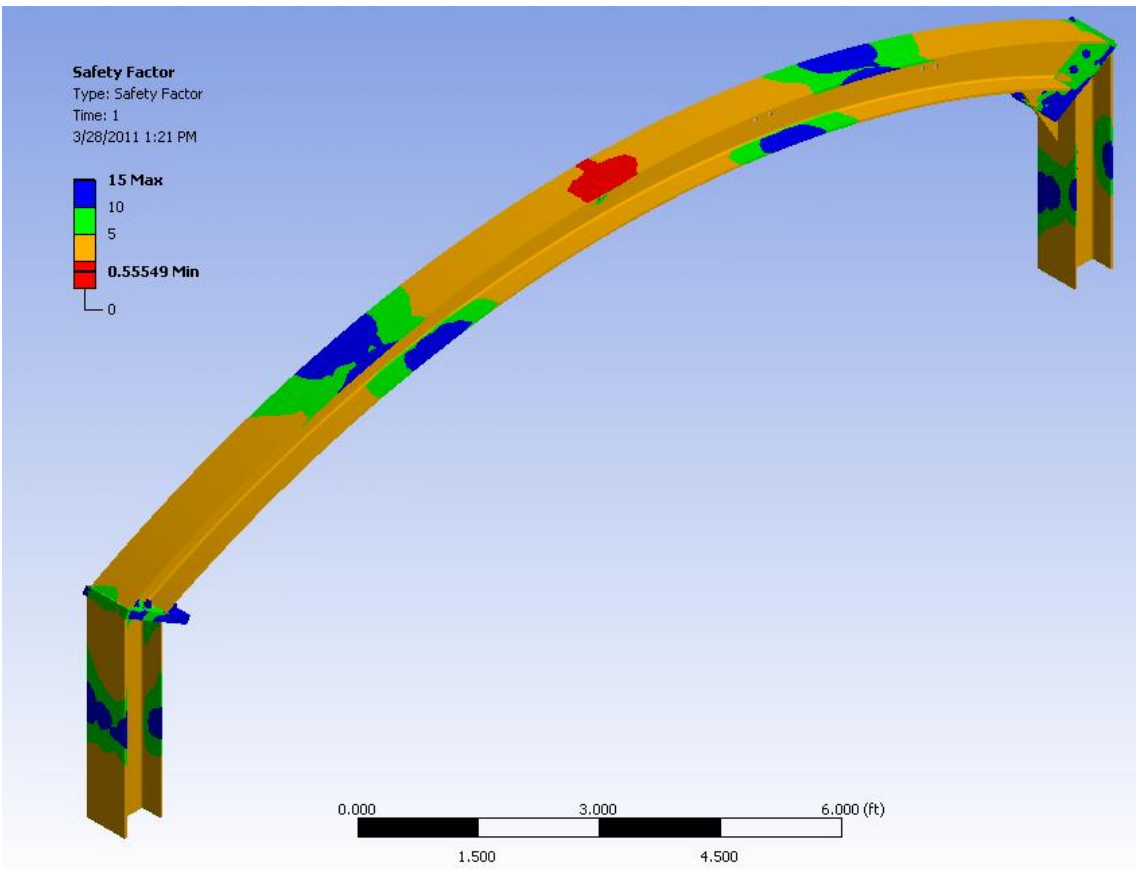

Figure 5.12 - Safety factor (localized impact load) 


\subsection{Field Evaluation - 19 months:}

The analysis of the proposed impact-resistant arch set was evaluated by the MSHA technical support group and subsequently approved for installation at two roof fall sites (belt entry and \#3 main entry) in April, 2009. The roof falls were successfully rehabilitated without any accidents or injuries. According to the follow-up field evaluations over the 1.5-year period since the installation as well as feedback from the mine operator, the impactresistant steel-sets performed very well, and no problems have been reported to date.

At the belt entry roof fall site, the overburden strata stabilized; only a few small rock pieces $\left(<1 \mathrm{ft}^{3}\right)$ fell on the canopy over the last 19 months, and the impact-resistant arch sets remained intact. At another roof fall site, a small scale, secondary roof fall (Figure $5.13)$, composed of approximately $7-9$ tons (6.4-8.2 tonnes) of rock fell off the $6 \mathrm{ft}(1.8 \mathrm{~m})$ high rib sometime in early 2010 . Field investigation indicates that the impact-resistant arch sets performed very well and there was no apparent structural deformation or lagging panel failure. Figure 5.14 shows the inside of the arch set and lagging where the rocks fell. Only one of the impact-resistant lagging panels was deflected by less than $3 / 4 \mathrm{in}(19 \mathrm{~mm})$ at mid-span.

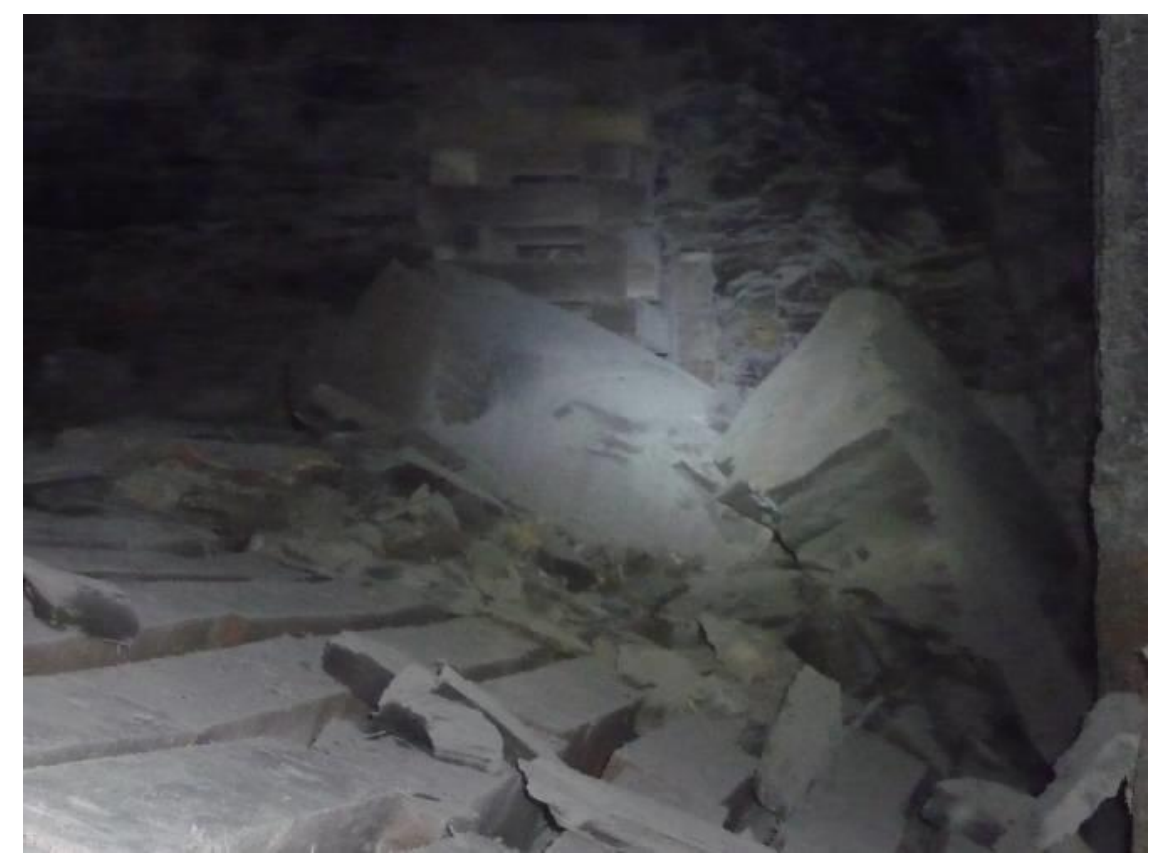


Figure 5.13 - Secondary roof fall

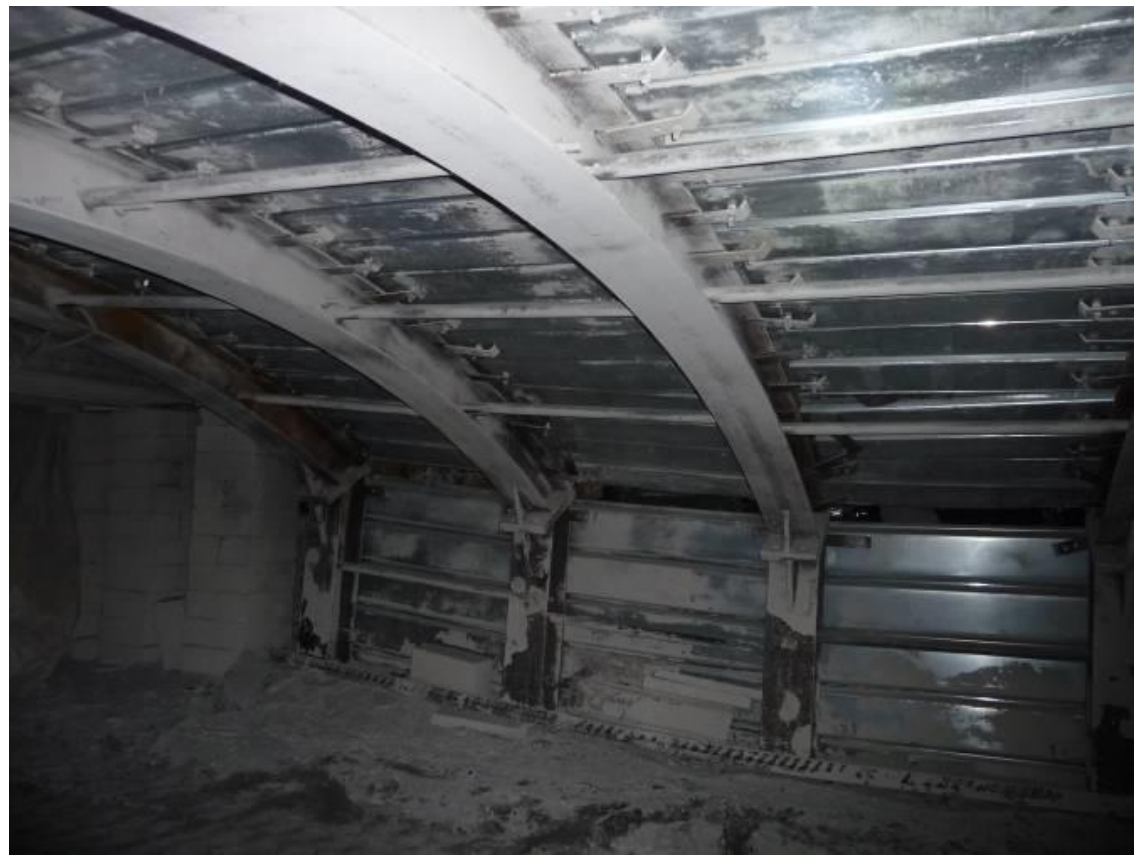

Figure 5.14 - Arch set and lagging impacted by roof fall

\subsection{Field Evaluation - 56 months:}

In evaluation on 11/21/13 (56 months after installation), personnel from MSHA, $\mathrm{KMS}$, and the coal company visited the two roof fall areas that were rehabilitated using the IR arch sets, and estimated maximum falling height, size of the secondary rock fall size, and checked the deformation of the impact lagging and steel set where the falling rock made impact.

\subsection{1 \#3 Entry:}

At the \#3 entry fall area, i appears that various small scale secondary roof falls have occurred during the 56 months period. Shown in Figures 5.15, 5.16, and 5.17 is the rock debris inby, nearby, and outby the cross cut.

With a laser distance meter, it was determined that the maximum roof fall height was approximately $14.5 \mathrm{ft}$ from the top of the canopy. Rock pieces ranged from several $\mathrm{in}^{3}$ to $18.75 \mathrm{ft}^{3}$ in size, are mostly irregular slab shaped, and are piled one on another. The 
relatively large piece landed across several lagging panels and individual steel sets. Since the fall area is not accessible, the rock size could not be exactly measured. By visual estimation, the piece as shown in Figure 5.17 is the largest and estimated as $3 \mathrm{ft} \times 7.5 \mathrm{ft} x$ 10 in (or $\left.18.75 \mathrm{ft}^{3}\right)$.

Underground examination of the steel set, lagging panel, and SLBs indicate that the installed W8 $\times 31 \mathrm{IR}$ arch set performed very well during the last 56 month period. No lagging panels or SLBs were knocked off from the W-beam, and the steel set did not exhibit any measurable deflection (Figure 5.18 and 5.19 ) at the area where impacted by secondary roof falls.

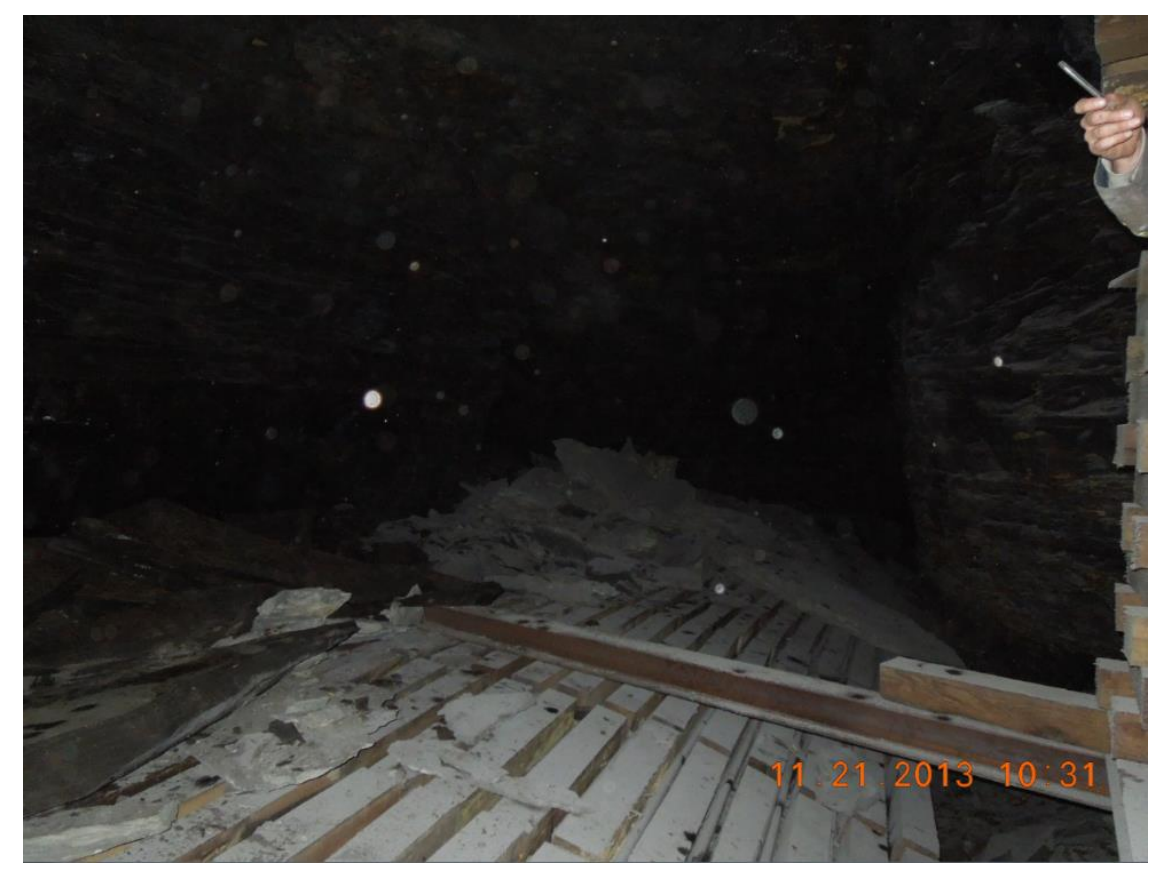

Figure 5.15 - Secondary roof fall 


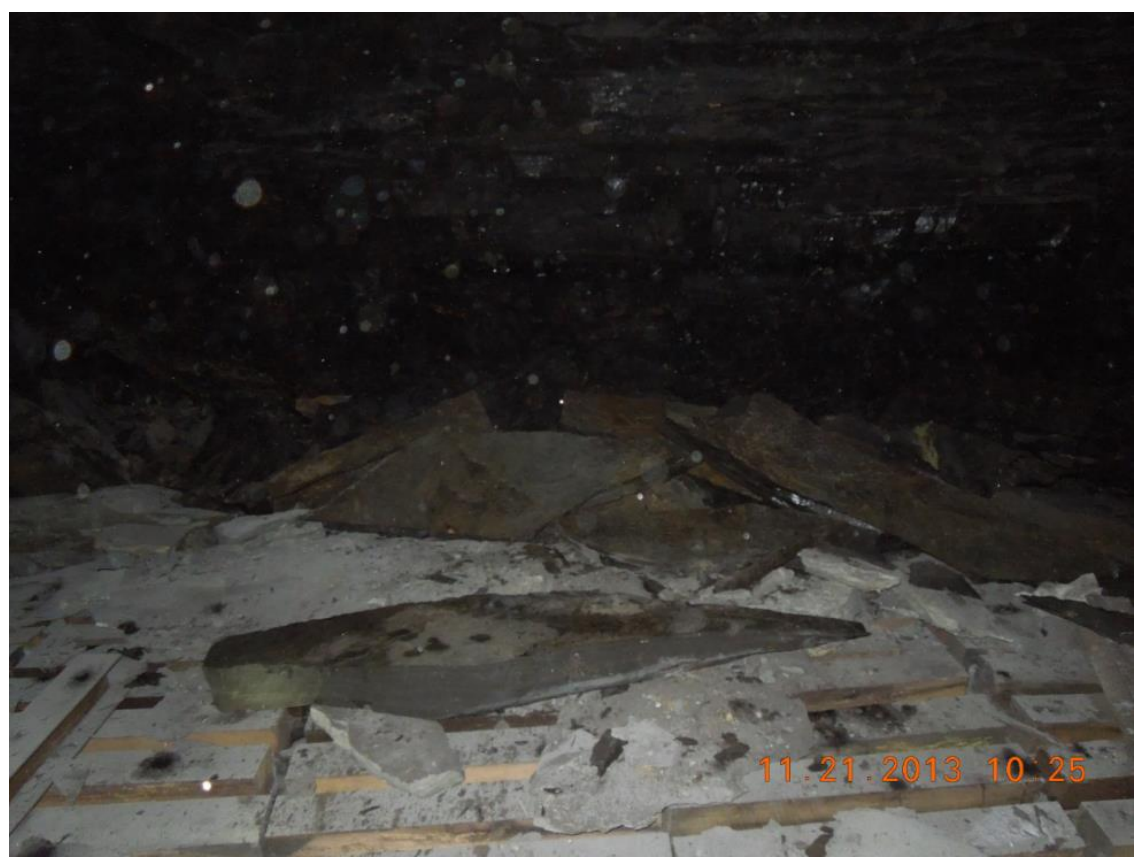

Figure 5.16 - Secondary roof fall

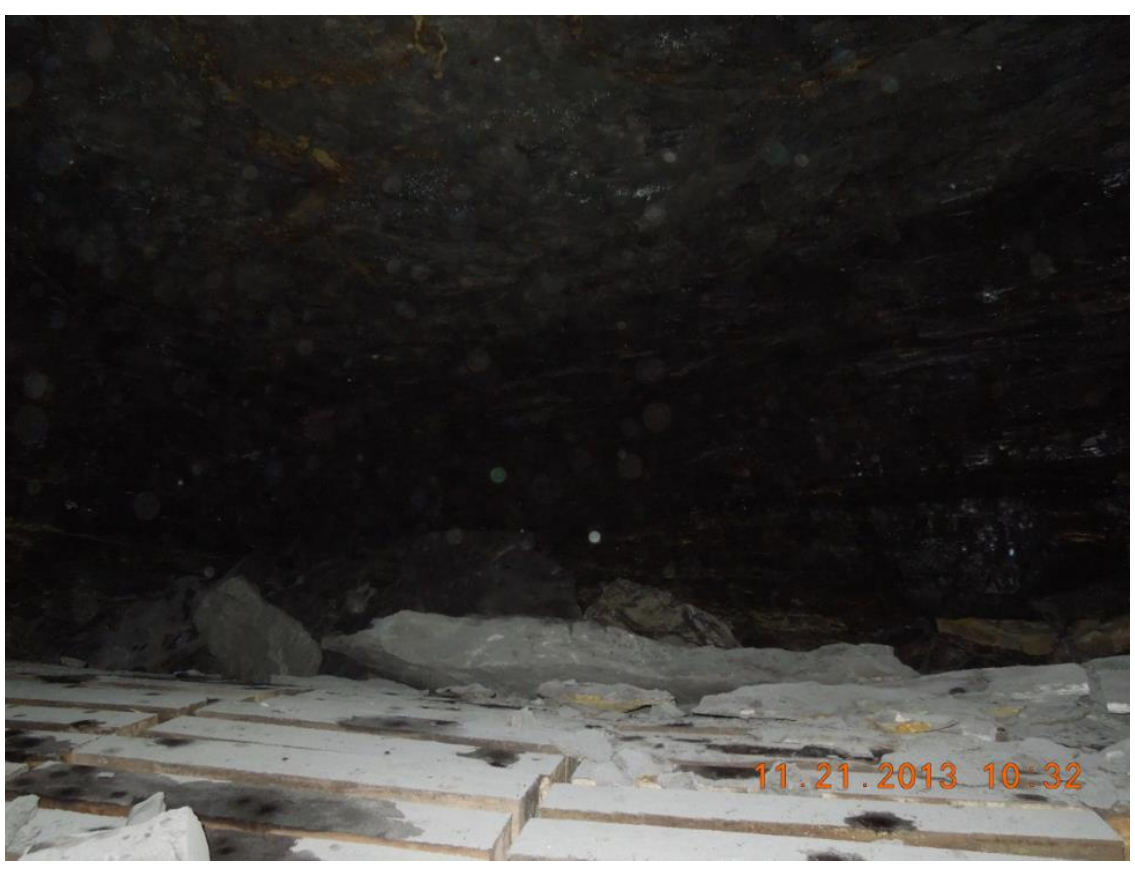

Figure 5.17 - Secondary roof fall 


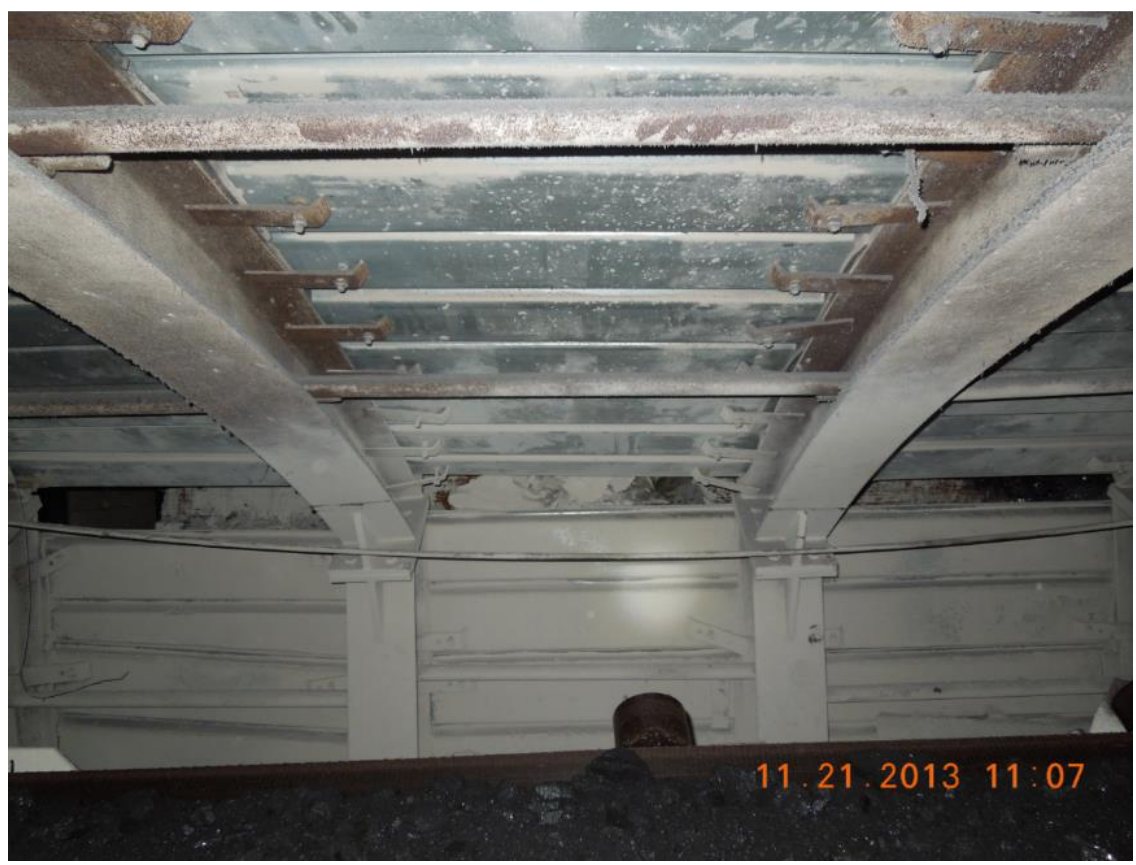

Figure 5.18 - Steel sets under the secondary roof fall area

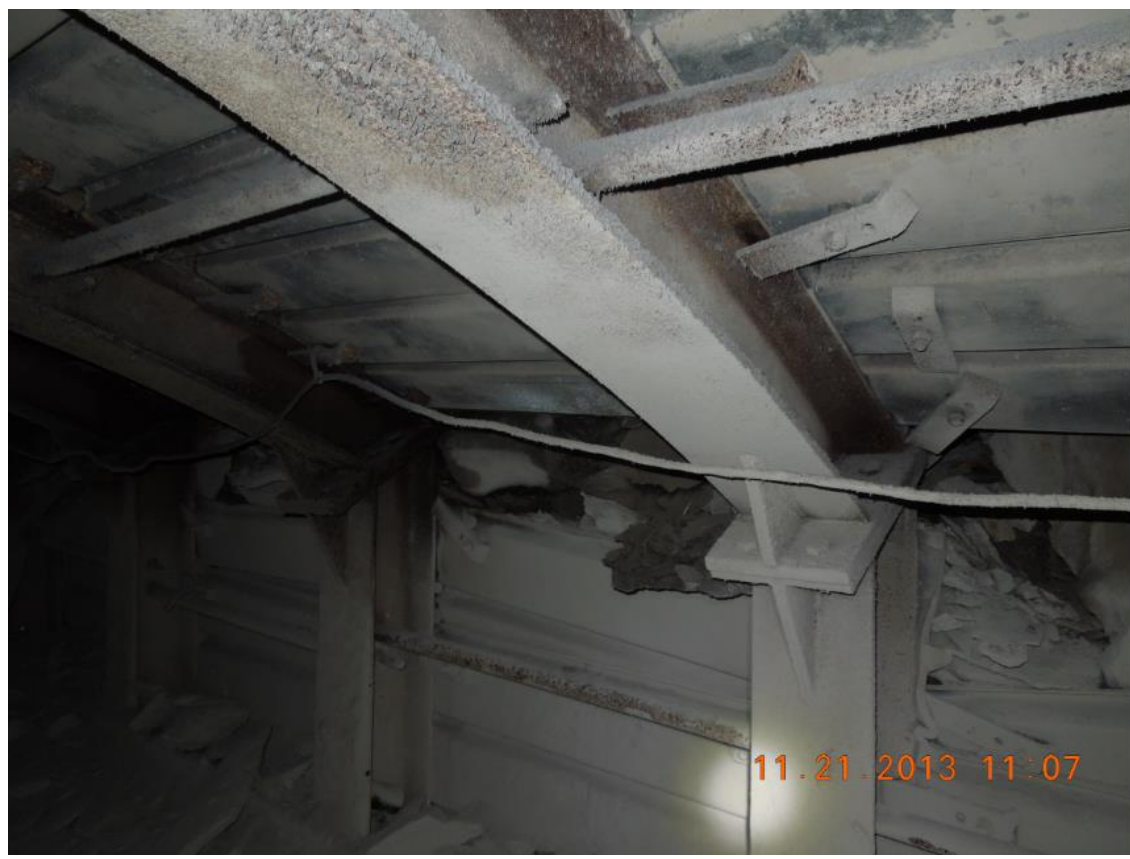

Figure 5.19 - Steel sets under the secondary roof fall area

However, some V-deck lagging panels at several impacted locations did deform with a mid-span deflection ranging from $0.25-8$ inches. Shown in Figures 5.20, 5.21, and 5.22 
are a few lagging panels with $0.25 \mathrm{in}, 3.5 \mathrm{in}$, and 8 in of permanent deflection at mid-span. At 3.5 in to 8 in deflection, the SLB fractures but the IR lagging still remains on the steel set still functioning. One of the IR lagging (Figure 5.23) panels was slightly knocked off the Wbeam on one end due to improper installation and/or untightened clips. The problem is considered insignificant since the SLB is still intact and the lagging assembly is supported by the tie rods and spacer tubes.

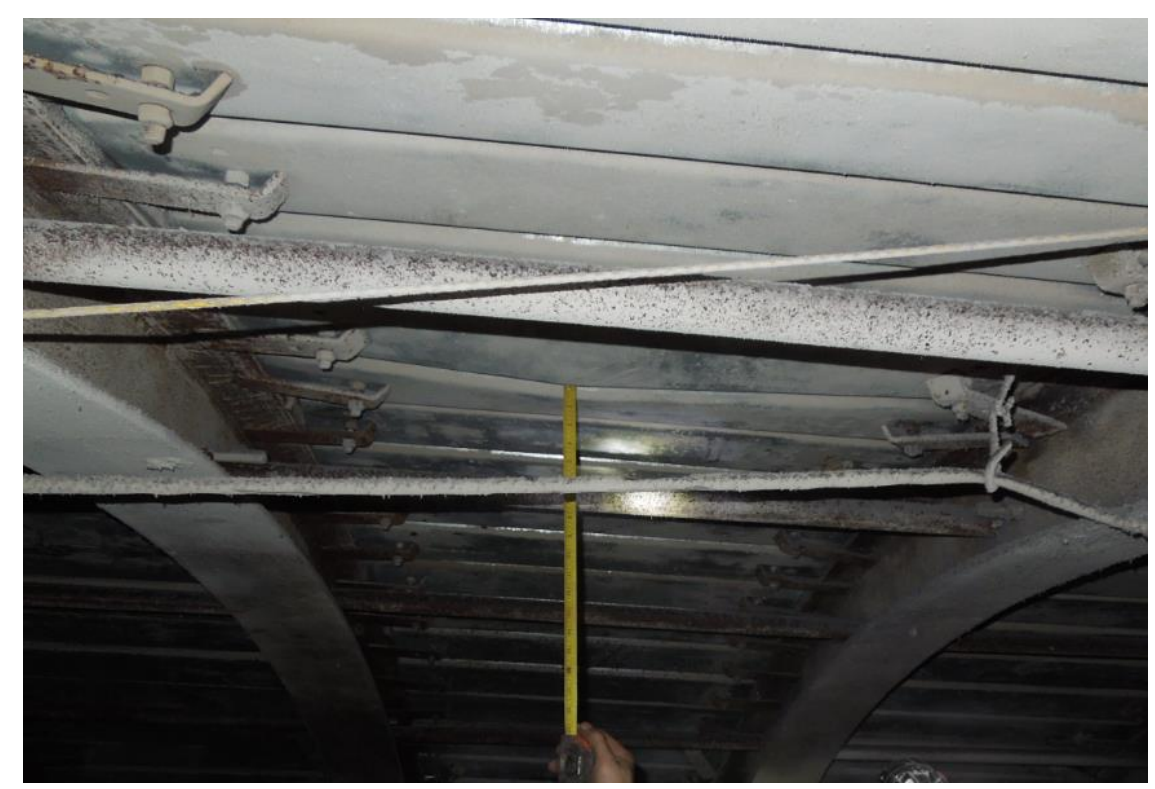

Figure 5.20 - Minor lagging deflection ( $0.25 ")$ due to rock impact 


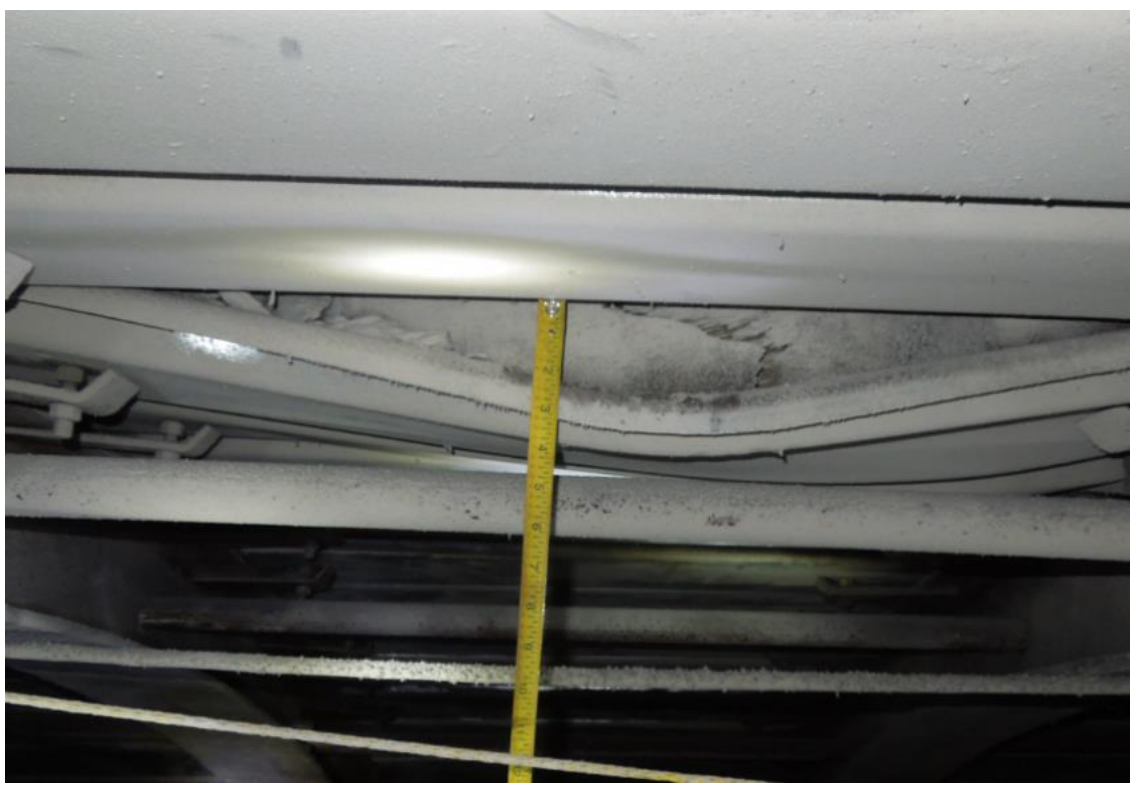

Figure 5.21 - Medium lagging deflection (3.5") due to rock impact

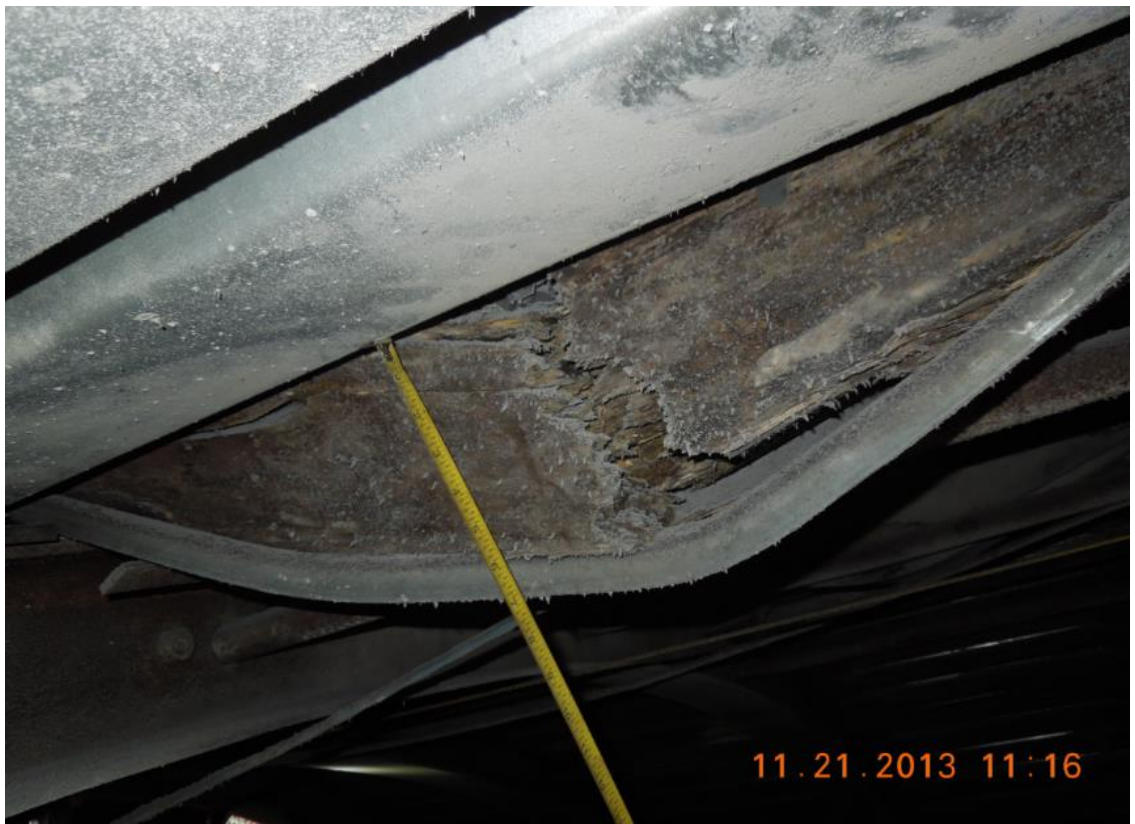

Figure 5.22 - Large lagging deflection (8") due to a pointed impact 


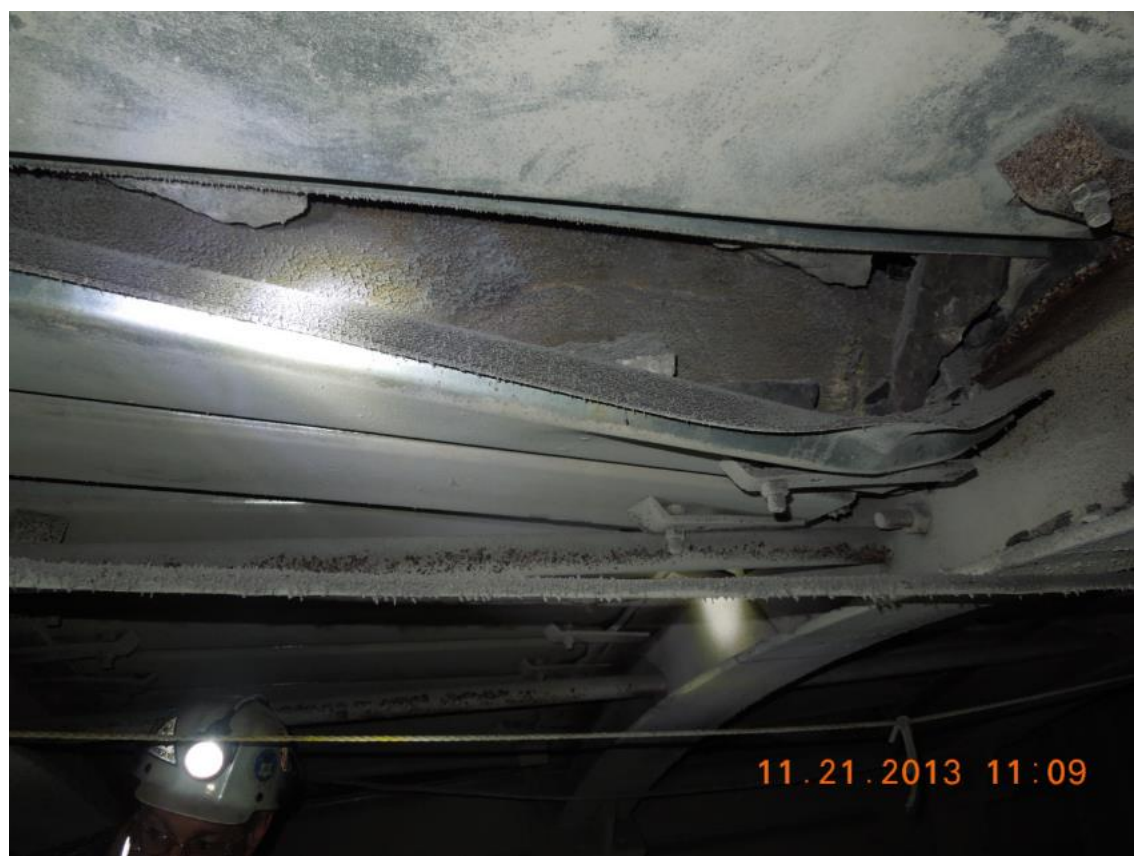

Figure 5.23 - Improperly installed lagging

\subsection{2 \#1 Entry:}

The roof fall Area 2 in \#1 Entry was also evaluated on the same date. A similar W8 $x 31$ long radius impact arch set was installed in this area in the same time frame. It appears that secondary small scale roof falls occurred during the same 56-month period. However, the area is in return air entry and no photos could be taken.

It was measured that the maximum roof fall height was approximately $11 \mathrm{ft}$ to the top of the canopy. The rock pieces that fell on this canopy were generally smaller than those in Area 1. However, there were two large sandy shale blocks ( $3.5 \mathrm{ft}$ wide $\times 7 \mathrm{ft}$ long $x 5 \mathrm{ft}$ thick) that fell off the roof/rib corner and onto the side corner of the steel set. Even so, under the impact areas, the steel sets were still intact and with no measureable deflection on the lagging panels. 


\subsection{Summary of Field Evaluations:}

Both KMS and MSHA personnel were impressed with the IR steel set performance.

It was mutually agreed that the IR steel set has a higher capacity than previously reported and the set should be applicable to any comparable roof fall areas in other coal mines. 


\section{CHAPTER 6: CASE APPLICATION TWO}

In this case, a longwall mine experienced a roof fall in July, 2010, at the bottom area of the slope. The roof fall occurred at an intersection where the slope entry splits into the sump, travel, and track entries. Due to blockage of the primary escape way, the mine lost safe access and underground operations were suspended. Mine management contacted Jennmar and KMS for a viable, safe, and quick roof fall rehabilitation plan. The roof fall area was examined on August, 2010.

\subsection{Geo-Technical Conditions:}

The mine is located in a mountainous region and extracts coal from the Powellton seam. Overburden thickness in this area ranges from 400-1000 ft (122 - $305 \mathrm{~m}$ ). Review of log data from two adjacent boreholes and other mapped information indicates that the coal seam thickness averages $37 \mathrm{in}(.94 \mathrm{~m})$ and is approximately level $(<1 \%$ grade). Figure 6.1 shows the mine layout map and location of the roof fall and the boreholes. The contours represent thickness of overburden.

The overburden consists of thinly laminated, weak stack rock, including black shale, coal streaks with boney layers, coal bands, dark gray fireclay, dark gray shale, and interbands. Field investigation indicated that the roof fall was the result of a gradual separation of the laminated dark gray shale from the overlaying gray massive sandstone due to the existence of weak coal bands. The roof fall height was approximately $40 \mathrm{ft}$ (12.2 m). Figure 6.2 depicts the large roof fall cavity. 


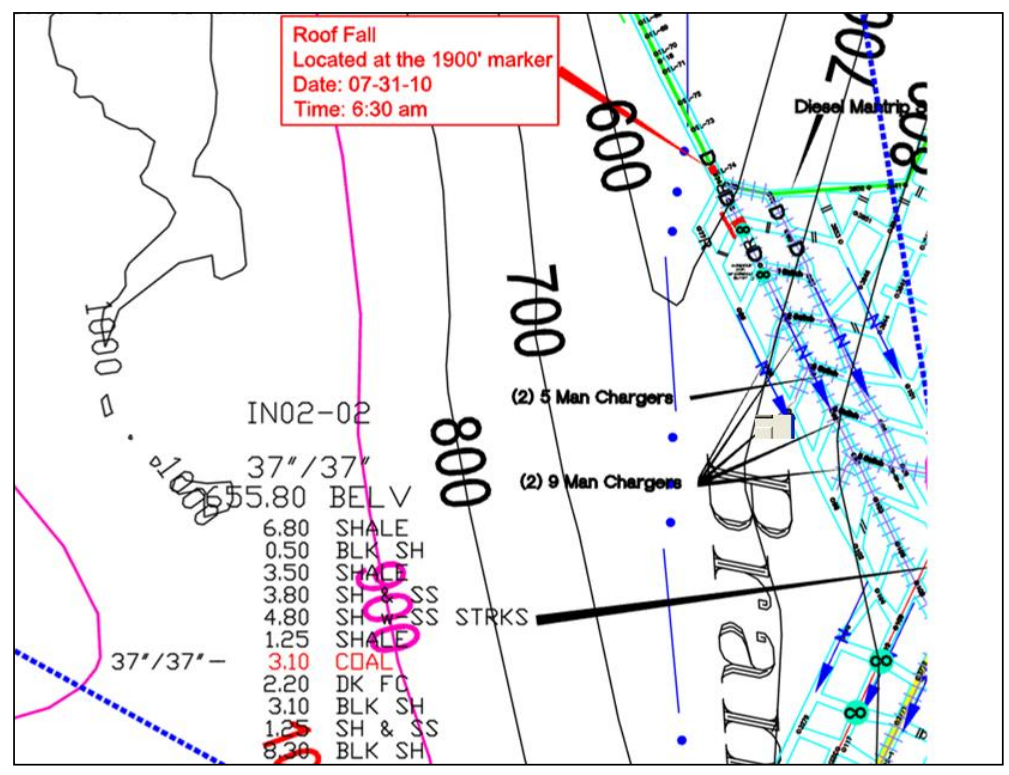

Figure 6.1. Roof fall location

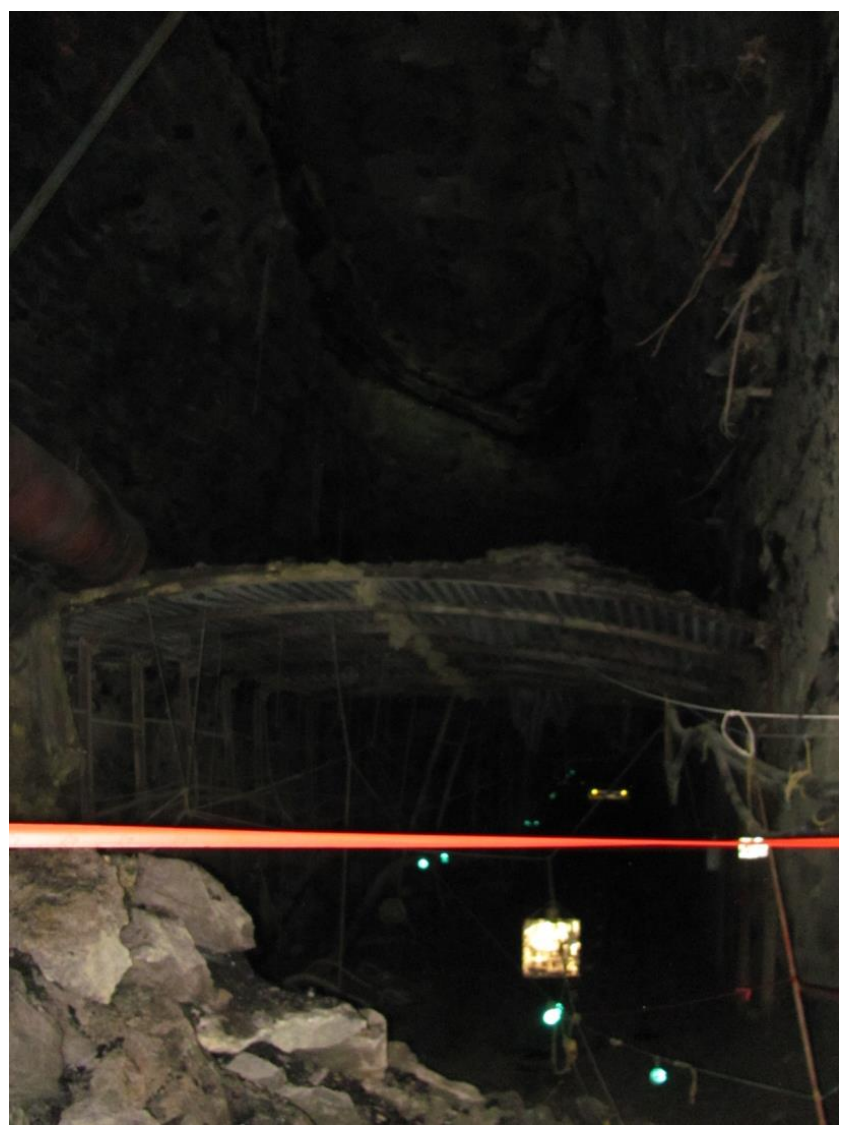

Figure 6.2. Large roof fall cavity 


\subsection{Rehabilitation Plan:}

It was decided that an impact-resistant steel canopy would be used to rehabilitate the roof fall area. The plan enabled the mine to establish a safe passage through the roof fall area and resume mining operations as soon as possible. The impact-resistant steel canopy was assembled in an adjacent safe area and then pushed into roof fall area while rock debris was removed. Once reaching the fall area, the steel canopy was positioned and bolted to the floor. The canopy was covered with impact-resistant lagging on the top and only V-deck panels on the sides. Once the mine gained safe access to the slope entry, steel-sets were installed in the adjacent slope section and affected entries. The steel-sets were covered with lagging panels on all sides. Foamed, light-weight, cementitious grout was pumped into the voids to stabilize the surrounding strata.

\subsection{Recommended Impact-Resistant Square Set:}

Based on the field evaluation and engineering requirements, the steel canopy must have an inside dimension of $15 \mathrm{ft}(4.6 \mathrm{~m})$ wide and $10 \mathrm{ft}(3 \mathrm{~m})$ high. The structure has to have enough clearance to enable a rubber tire mine trip car (119 in (3 m) wide $\times 335$ in (8.5 m) long) to pass through into the left travel entry. The structure must be capable of sustaining the impact generated by $1 \mathrm{ft} 3(.02 \mathrm{~m} 3)$ of rock falling from a height of $30 \mathrm{ft}(9.14$ $\mathrm{m})$. The structure must also be able to support more than $30 \mathrm{ft}(9.14 \mathrm{~m})$ of backfill grout. Structural analysis and steel structure design indicate that a steel canopy consisting of seven one-leg square sets (W16 x 50 (W410 x 74) cross-member and W8 x 31 (W200 x 46) leg) and a W12 $\times 72(\mathrm{~W} 12 \times 107)$ king beam set will satisfy these requirements. Figure 6.3 shows the two-dimensional engineering drawing showing the front view of the structure. Figure 6.4 shows the three-dimensional view of the entire canopy unit. 


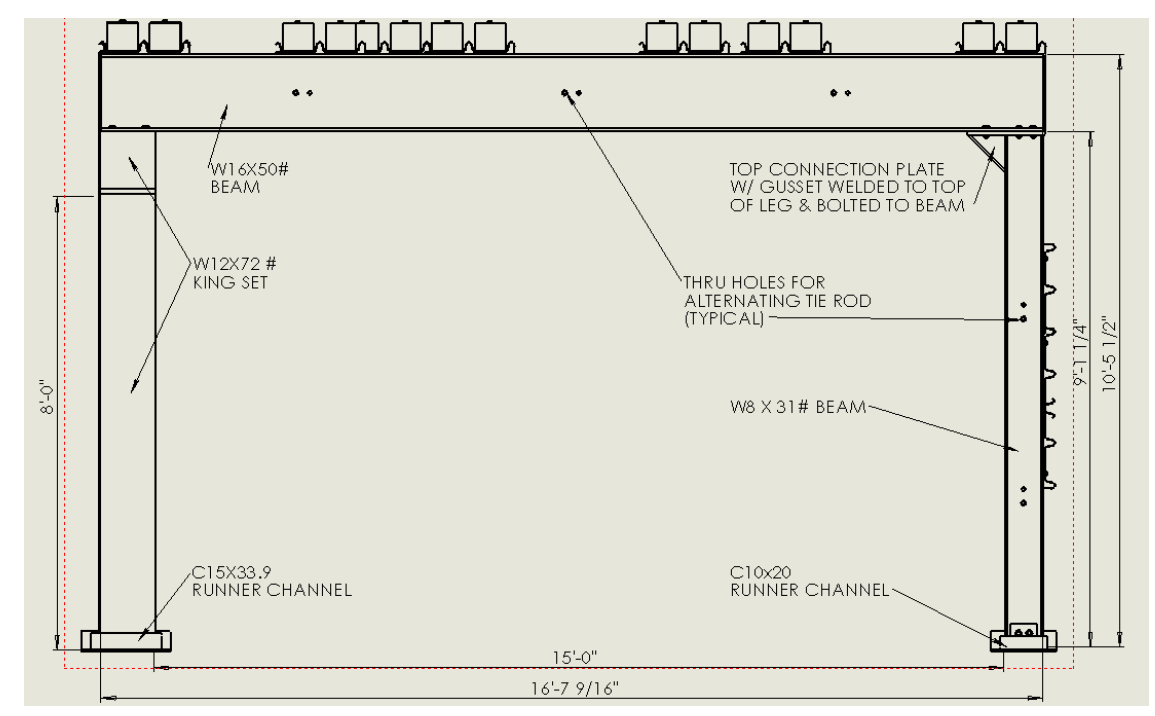

Figure 6.3. 2D engineering drawing - front view

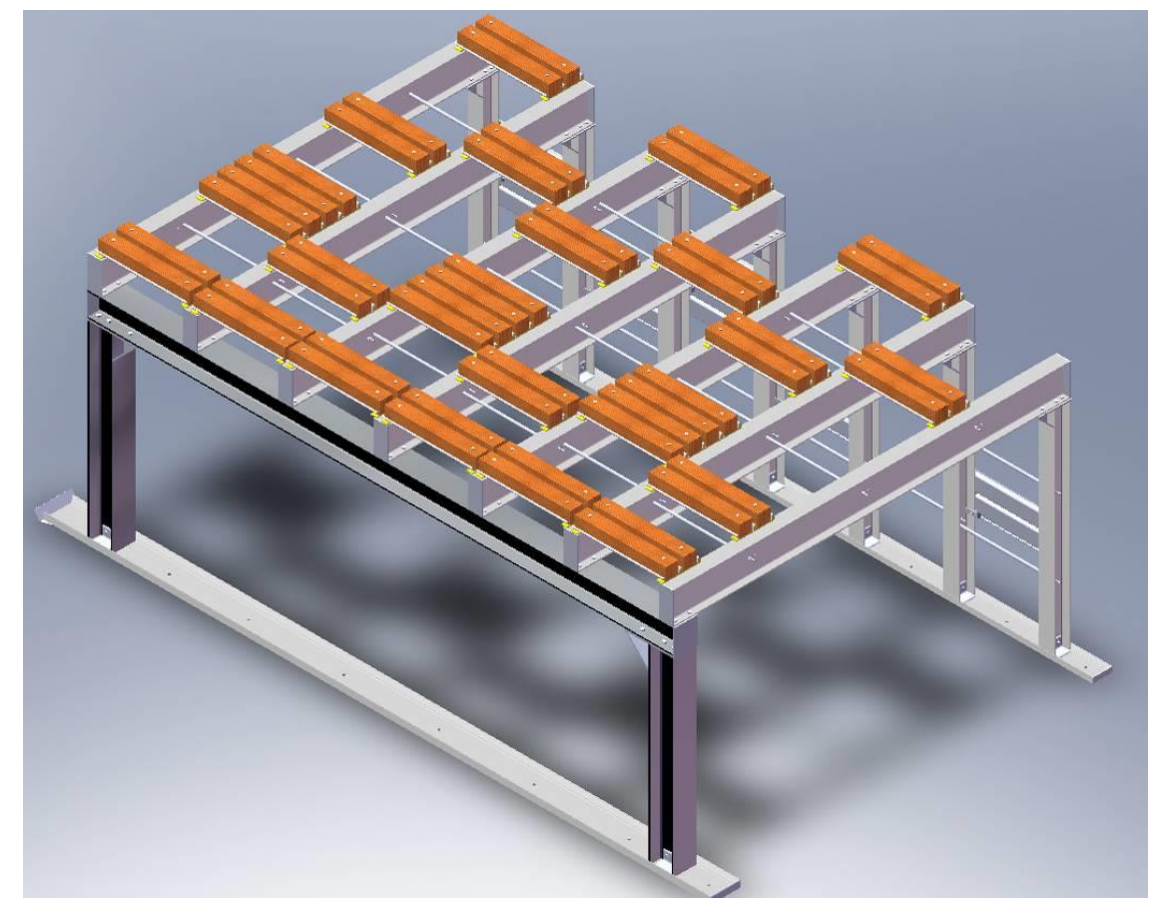

Figure 6.4. 3D view of the canopy set

\subsection{Structural Analyses - Static Uniform Load:}

The structural analysis indicated that assuming a $30 \mathrm{lb} / \mathrm{ft}^{3}\left(480 \mathrm{~kg} / \mathrm{m}^{3}\right)$ average backfill grout density, the proposed canopy set is capable of sustaining 209 tons (189 
tonne) of total load (or equivalently $33.2 \mathrm{ft}(10.1 \mathrm{~m})$ of grout backfill at $4 \mathrm{ft}(1.22 \mathrm{~m})$ set space).

\subsection{Structural Analyses - Dynamic Impact Load:}

Analysis was conducted assuming that the cross-member is subjected to a localized impact load from falling rock. Structural analysis indicated that the proposed steel canopy set is capable of sustaining a maximum of 30.8 tons (27.9 tonnes) dynamic impact load at mid-span. Figure 6.5 shows the external load diagram. Figures $6.6-6.8$ present the shear stress, torsional stress, and bending moment diagrams, respectively.

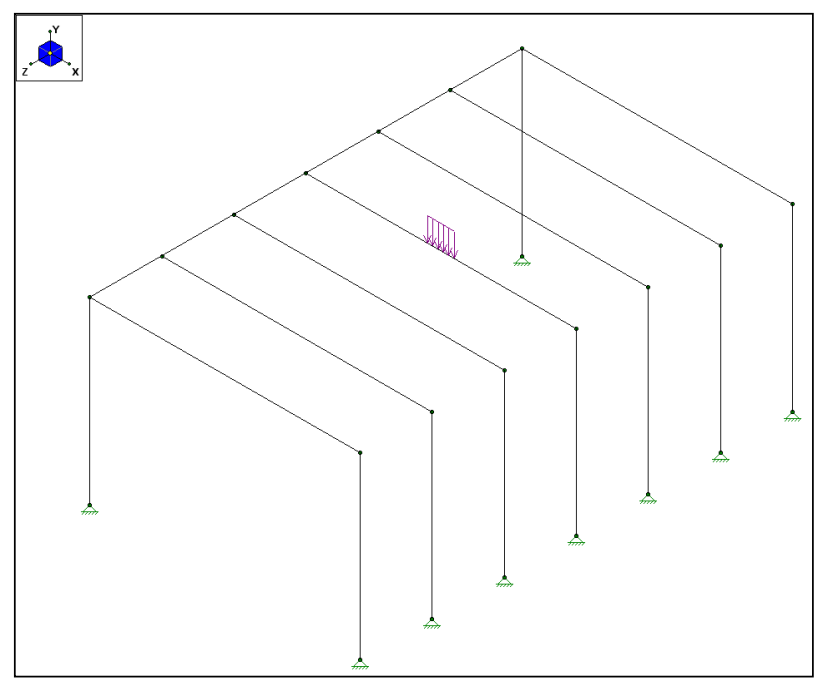

Figure 6.5. Load diagram

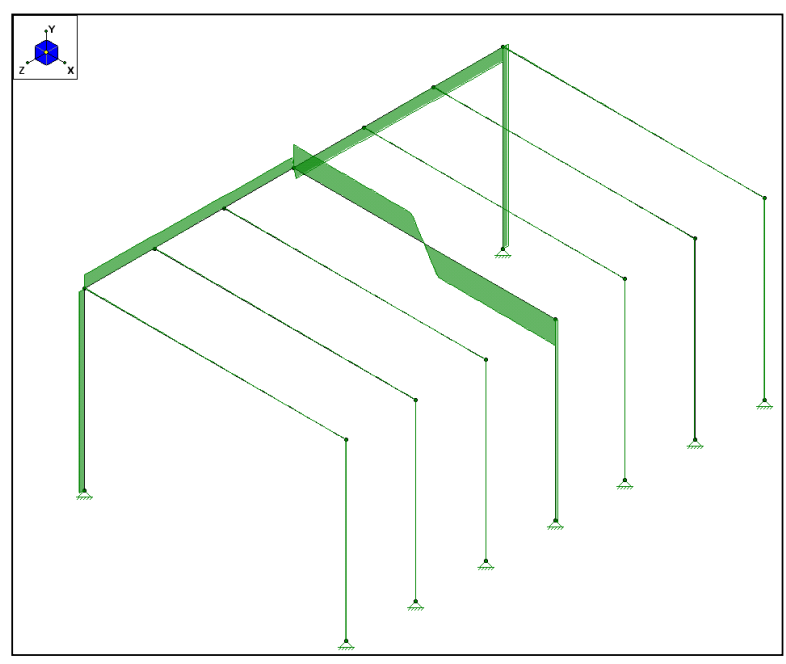

Figure 6.6. Shear stress diagram 


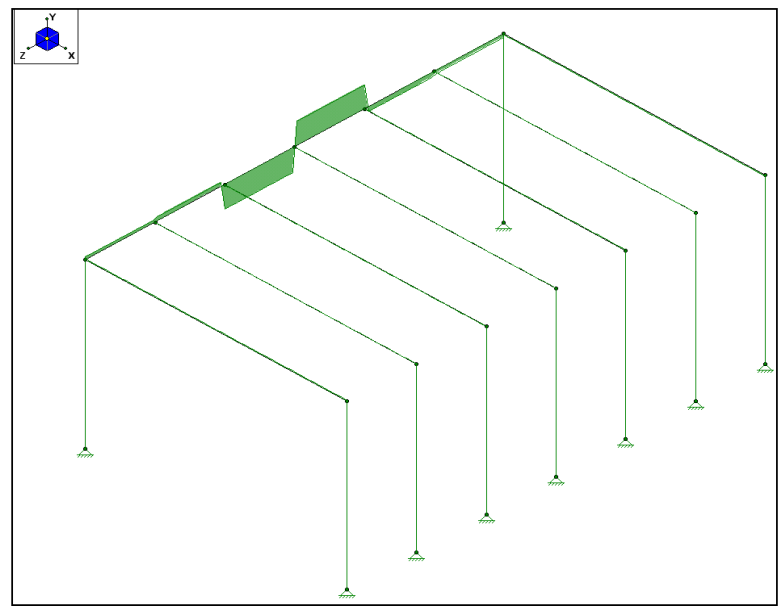

Figure 6.7. Torque diagram

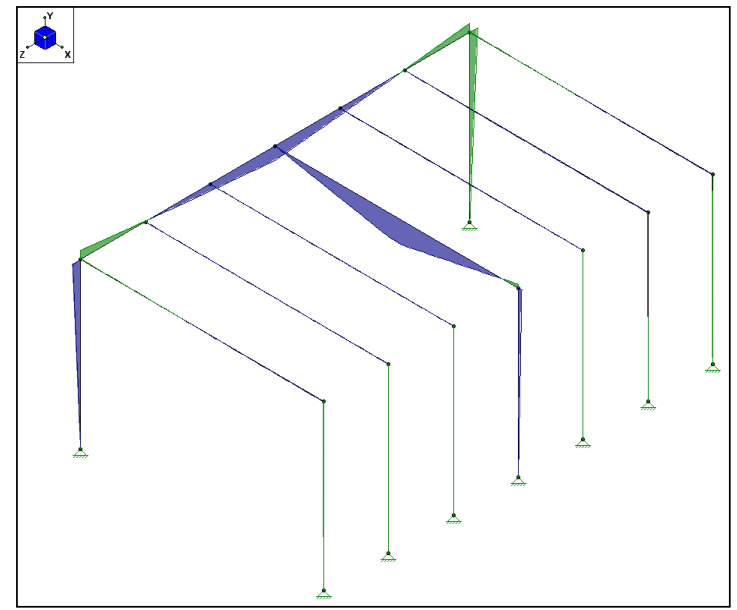

Figure 6.8. Bending moment diagram

\subsection{Numerical Validation:}

A 3D computer model was developed to evaluate the steel canopy set performance under maximum support capacity loading conditions. Figures 6.9 and 6.10 show the safety factor distribution when the structure is subjected to a static uniform load and dynamic localized impact load, respectively. The structure does not have any apparent major material yielding. Therefore, it is concluded that the steel-set and connections have the expected support capacity. 


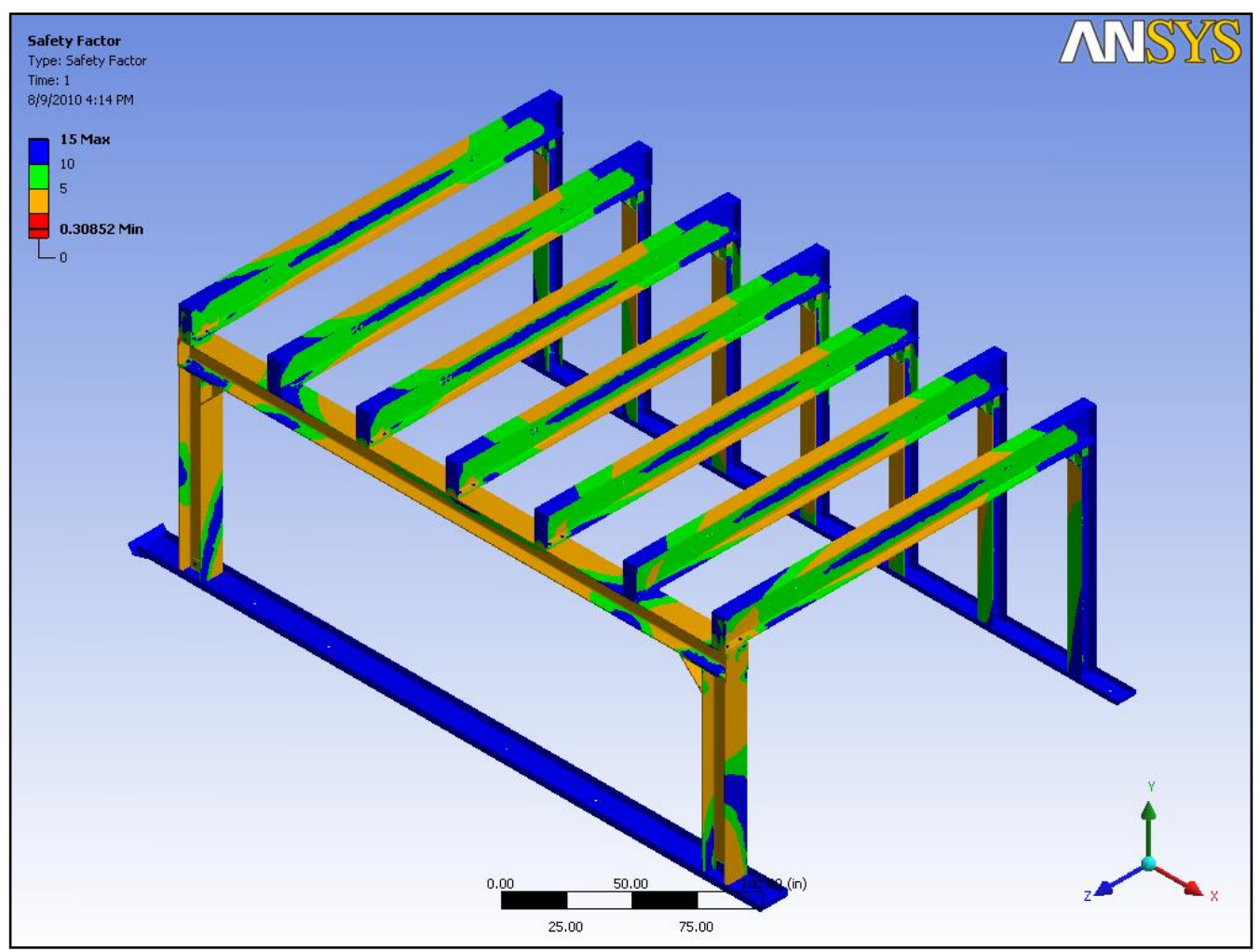

Figure 6.9. Safe factor (static uniform load)

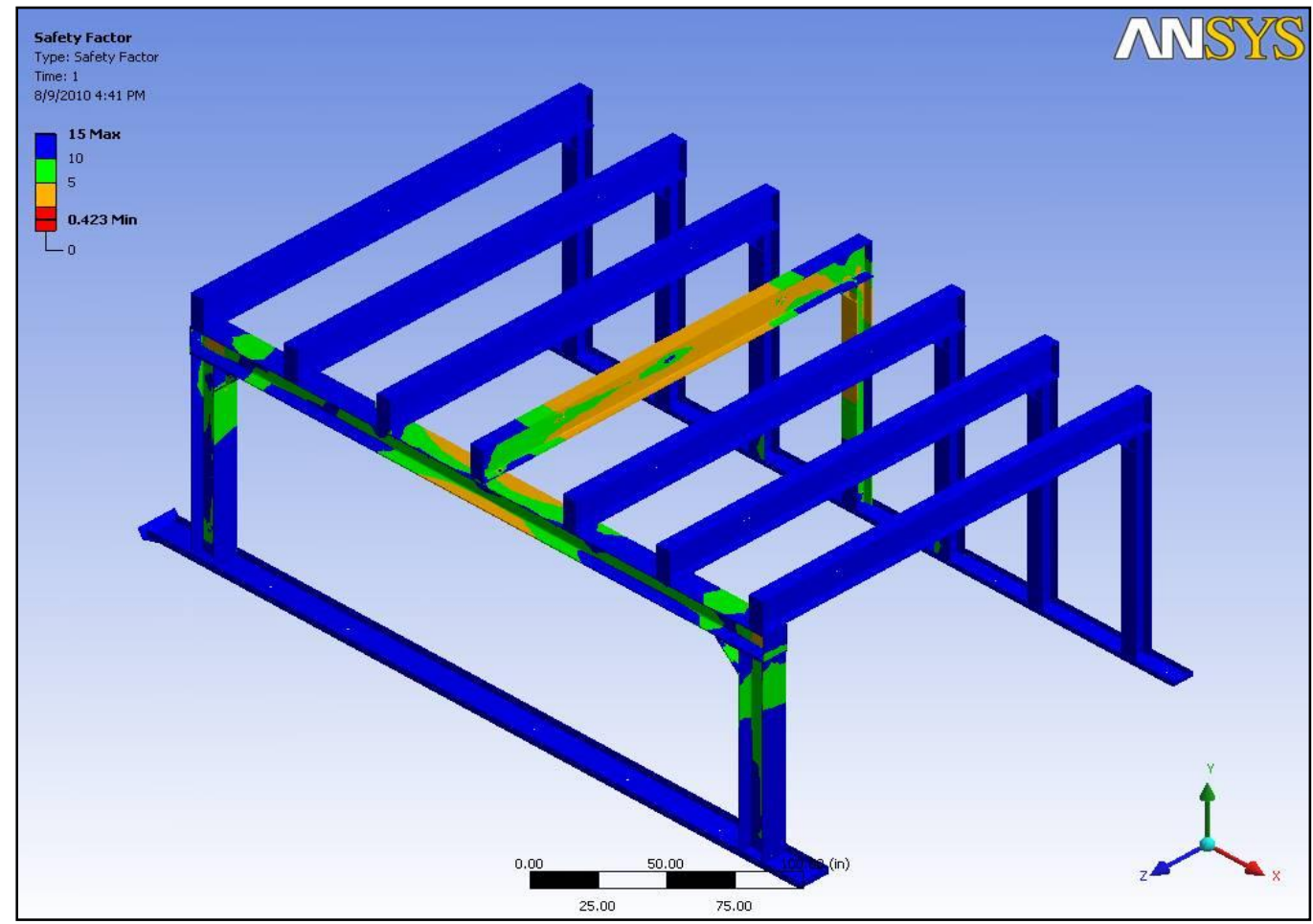

Figure 6.10. Safety factor (dynamic impact load) 


\subsection{Performance Evaluation:}

The roof fall rehabilitation plan developed by the mine was based on the designed impact-resistant square set and was reviewed and approved by the MSHA district office. The roof fall area was quickly rehabilitated in a safe manner with no personnel injuries or equipment damage during the process. Figure 6.11 shows the rehabilitated slope bottom. The mine operator commented that the impact-resistant steel-sets gave "peace of mind" to the miners and acted as an important protection canopy. The mine was able to resume operations within a few weeks after the roof fall with no reported problems to date.

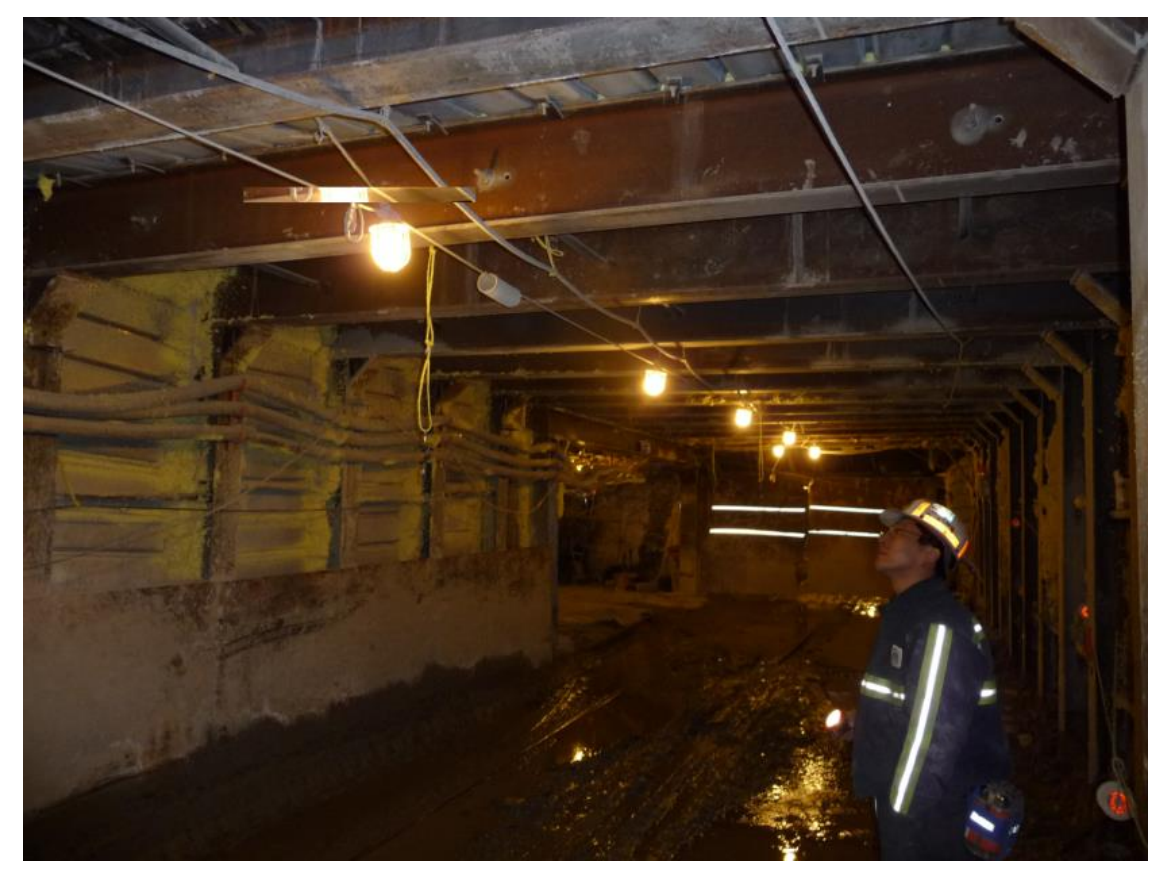

Figure 6.11. Rehabilitated slope bottom 


\section{CHAPTER 7: APPLICABILITY EVALUATION GUIDELINE OF AN IR STEEL SET}

\subsection{Applicability Evaluation Guideline}

Prior to the installation of the IR square set, mine engineers should carefully evaluate applicability of the design to a given roof fall condition. The following preliminary evaluation guidelines are offered for consideration:

- Evaluate overburden stability of affected mining zone by considering regional geological features, horizontal stress, orientation of affected entry, pillar size, adjacent mined out areas, possible nearby mining activities in the near future (longwall mining, pillar retreat mining, blasting), etc. If secondary roof falls triggered by nearby mining activities are of concern, applicability of the IR steel set will be limited. It is recommended that the voids above IR steel canopy should be backfilled with light weight foamed cementitious grout or similar material.

- Conduct field visits and collect relevant geotechnical information, including but not limited to: entry size, roof fall height, lithology of fallen rock, visual estimate of the size and thickness of fallen rock slab, shape of the roof fall opening, sign of any localized geological features (faults, folds, fractured zones, sandstone channel, slickensides, etc), accessibility and entry dimension of adjacent safe area, type and overall dimension of available equipment that may be used to clean out the rock debris, and so on.

- Based on the field data, engineers need to make a reasonable judgment regarding applicability of the IR steel set. For a given roof fall height, if the thickness of probable falling rock slab is less than the maximum allowable thickness (Table 5 or similar table if different IR steel set design), it may be considered that the IR steel set is applicable. Otherwise, either an alternate IR steel set should be designed, or a better cushioning effect should be created above the available IR steel set. 
- Evaluate accessibility and entry size of adjacent safe area. Make sure that the selected area is stable and there is sufficient space for the IR steel set to be assembled.

- Check overall dimensions of available mining equipment that may be used to rehabilitate the fall area. Make sure the IR steel canopy has sufficient room for the mining equipment to maneuver inside. 


\section{CONCLUSION}

This thesis presents a special impact-resistant lagging panel and a methodology of designing an impact-resistant steel-set with lagging as exterior protection using steel structural analysis, the AISC national standard, and numerical modeling techniques. To assist mining engineers justifying if an IR steel set design is applicable to a given roof fall condition, a preliminary applicability evaluation guideline of the IR steel set is outlined. Applications of impact-resistant steel-sets in various roof fall rehabilitation projects during the last few years have proven the design has acceptable impact resistant capacity for roof fall rehabilitation in the field.

With the laboratory tests, field case study, elasto-plastic structural analysis, and dynamic impact numerical modeling, the following conclusions can be made:

- A steel set protected with IR lagging panels offers a viable solution for mine operators to rehabilitate the roof fall area in a safe, quick, and economical manner;

- Updated drop tests confirmed that the IR lagging panel is capable of supporting an instantaneous impact that was generated by a $1,541.5 \mathrm{lb}$ metal block falling 63 " with an acceptable mid-span deflection of less than 6".

- Field investigation indicates that the installed impact resistant arch sets have a higher impact capacity than previously reported and have met the intended engineering purpose.

- Two case design projects are used to demonstrate the IR steel set design methodology. Major steps are summarized as following: 
- Static uniform load support capacity of an IR steel set can be determined through AISC-based structural analysis,

- An elasto-plastic analysis approach can be used to evaluate and determine the maximum impact support capacity of an IR square set for a given maximum allowable deflection at the cross beam mid-span.

- A full-scale dynamic impact numerical model can be used to validate performance of the developed IR steel set under the worst case impact loading condition.

- The Law of Conservation of Energy can be used to establish applicable roof fall scenarios.

- A preliminary guideline is offered for engineers to evaluate if an IR steel set design is applicable to a given roof fall condition.

If the rehabilitated entry will be in service for the entire mine life, backfilling the voids between the steel canopies and caved roof with light weight foamed cementitous grouts or similar material should be considered. In cases that the IR lagging panel experiences more than 6" mid-span deflection due to unexpectedly high impact load by secondary roof fall, necessary measures (sand bags or some backfill) should be taken to prevent further deflection in the future. Similarly, if the cross beam experiences more than expected deflection, supplemental standing support such as posts or props under the deflected beam should be considered. 


\section{REFERENCES}

Allwes R. A., Mangelsdorf C. P., Pappas D. M. (1987). "Arch canopy design procedure for rehabilitation of high-roof-fall areas." U.S. Bureau of Mines. RI 9075. 51 pp.

Allwes R. A., Mangelsdorf, C. P., (1992). "Evaluation of structures for roof-fall areas." U.S. Bureau of Mines. RI 9414. 31 pp.

Ma K. J., Stankus J., Mcginnis R., Faulkner D., Brandon D., Feyrer J. (2009). “Impact resistant lagging, method for designing impact resistant lagging, and apparatus for testing impact resistant lagging." U.S. Patent Application 20100266349. Filed February 27. EFS ID: 4876032.

Serway R. A., Jewett J. W. (2004). Physics for scientists and engineers. 6th ed. Belmont, CA: Thompson-Brooks/Cole.

Cutnell J. D., Johnson K. W. (1997). Physics. 4th ed. New York: John Wiley \& Sons, Inc.

MSHA. Part 50 data user's handbook. 2007 Retrieved from https://arlweb.msha.gov/STATS/PART50/P50Y2K/P50Y2KHB.PDF.

MSHA. Accident, illness and injury and employment self-extracting files (Part 50 data), 1999-2008. 2010 Retrieved from https://arlweb.msha.gov/ACCINJ/accinj.htm.

NIOSH. MSHA data file: NIOSH Office of Mine Safety and Health Research data file downloads. 2010 Retrieved from www.cdc.gov/niosh/mining/data/default.html.

Bajpayee T. S., Pappas D. M., and Ellenberger J. L.(2014) "Roof Instability-What Reportable Noninjury Roof Falls in Underground Coal Mines Can Tell Us" Professional Safety. 59 57-62

Mark C., Pappas D. M., Barczak T. M. (2010) "Current Trends in Reducing Ground Fall Accidents in US Coal Mines" Retrieved from https://www.cdc.gov/niosh/mining\%5C/UserFiles/works/pdfs/ctirgf.pdf 


\section{CURRICULUM VITAE}

Dakota D. Faulkner, PE

\section{Education:}

West Virginia University

Benjamin M. Statler College of Engineering and Mineral Resources

- Bachelor of Science in Mechanical Engineering, June 2008

- Master of Science in Mining Engineering, (Projected) May 2020

\section{Professional Engineer}

- Since December 2016

\section{Work Experience:}

Keystone Mining Services LLC (Affiliate of Jennmar Corporation): 2008 - Present Positions:

- Research \& Development Engineer, July 2008 - June 2015;

- Manager of Research \& Development, June 2015 - July 2017;

Duties:

- Vice President of Research \& Development, July 2017 - Present.

- Develops and recommends ground control solutions for mining, tunneling, \& civil applications.

- Provides technical expertise directly to management, sales, customers and government agencies both domestically and internationally.

- Instructs and educates personnel on the proper application of ground control products.

\section{Awards:}

2018 John T. Boyd Memorial Young Engineer Award, SME Pittsburgh Section 2019 J.W. Woomer Young Engineer Award, SME

\section{Patents:}

Over a dozen granted U.S. and International Patents related to ground control products for the mining, tunneling, and civil industries.

\section{Articles/Publications:}

-US and International publications/articles/technical papers. 
1. New Ground Support Technology

MSHA Roof Control Seminar, May 2010

2. JENNCHEM's Pumpable Crib Solves Difficult Longwall

World Coal, 2010

3. New Ground Support Technology

MSHA Roof Control Seminar, May 2011

4. Application of Stress, Geologic, and Support Design System (SGSSM) to Ground Control for Mine Slope Entries

ICGCM, July 2011

5. Development and Application of Impact-Resistant Lagging for Steel Sets Installed at Underground Roof Fall Areas

ICGCM, July 2011

6. New Ground Control Technology for Longwall Entry Support

Coal News, September 2011

7. Impact Resistant Lagging for Steel Sets

Coal News, October 2011

8. Application of Stress, Geologic, and Support Design System (SGSSM) to Ground Control for Mine Slope Entries

SME (Society for Mining, Metallurgy \& Exploration Annual Conference \& Expo), February 2012

9. Development and Application of Impact-Resistant Lagging for Steel Sets Installed at Underground Roof Fall Areas

SME, February 2012

10. New Standing Support Technology, MSHA Roof Control Seminar, May 2012

11. Standing Support Problems, World Coal 2012

12.J-CRETE: An Engineered Cementitious Composite Rock Coating ICGCM, August 2012

13. Development and Application of Polyurethane Injectable Cable Bolts ICGCM, August 2012

14. The Development and Application of Polyurethane Injectable Cable Bolts for Longwalls

World Coal, March 2012 
15. Application of Impact Resistant Steel Sets* for Underground Roof Fall Rehabilitation

MSHA Roof Control Seminar, May 2013

16. Update on New Ground Support Systems for Longwall Gate Roads Longwall USA, June 2013

17. A Comprehensive Analysis of Cable Bolt Anchorage Characteristics ICGCM, August 2013

18. A Comprehensive Analysis of Cable Bolt Anchorage Characteristics GIG (Główny Instytut Górnictwa) Central Mining Institute Poland, November 2013

19. Development and Application of Polyurethane Injectable Cable Bolts GIG, Central Mining Institute Poland, November 2013

20. A Comprehensive Analysis of Cable Bolt Anchorage Characteristics SME, February 2014

21. MSHA Roof Control Seminar May 2014

22. Update: Analysis and Case Study of Impact-Resistant Steel Sets for Underground Roof Fall Rehabilitation

ICGCM, July 2014

23. A Case Study of a Low Overburden Longwall Recovery with Pre- Developed Recovery Entries

ICGCM, July 2014

24. A Comprehensive Analysis of Cable Bolt Anchorage Characteristics IMI, September 2014

25. A Case Study of a Low Overburden Longwall Recovery with Pre- Developed Recovery Entries GIG, Central Mining Institute Poland, November 2014

26. Development and Evaluation of the Inflatable PythonM3 Bolt and Innovative PyFlexU2TM Coating against Highly-Corrosive Ground Conditions SME, February 2017

27. Multiple Point Anchor (MPA), Self-Drilling, Hollow Core Yielding Bolt with Injectable J-Lok P Resin System for High-Stress and Squeezing Ground Conditions

SME, February 2017 
28. Development and Evaluation of Expandable Python M3 and Its PyFlexU2 Coating against Highly-Corrosive Ground Conditions

ARMA, May 2017

29. Multiple Point Anchor (MPA), Self-Drilling, Hollow Core Yielding Bolt with Injectable J-Lok P Resin System for High-Stress and Squeezing Ground Conditions

ARMA, May 2017

30. Development and Evaluation of Corrosion Resistant Coating for Expandable Rock Bolt Against Highly-Corrosive Ground Conditions

ICGCM, July 2018

31. Single Pass Drill, Install and Inject Self-Drilling Resin Bolt Application in Poor Ground

AUSROCK, November 2018

32. Single Pass Drill, Install and Inject Self-Drilling Resin Bolt Application in Poor Ground

SME, February 2018

33. Polyester Resin Injection of Dynamic Resin and Cable Bolting Systems to Improve Development Efficiency, 9th International Symposium on Ground Support in Mining and Underground Construction, October 2019 